Portland State University

PDXScholar

Winter 4-2-2014

\title{
Reciprocal Effects of Student Engagement and Disaffection on Changes in Teacher Support Over the School Year
}

Cailin Tricia Currie

Portland State University

Follow this and additional works at: https://pdxscholar.library.pdx.edu/open_access_etds

Part of the Junior High, Intermediate, Middle School Education and Teaching Commons, and the Psychology Commons

Let us know how access to this document benefits you.

\section{Recommended Citation}

Currie, Cailin Tricia, "Reciprocal Effects of Student Engagement and Disaffection on Changes in Teacher Support Over the School Year" (2014). Dissertations and Theses. Paper 1646.

https://doi.org/10.15760/etd.1645

This Thesis is brought to you for free and open access. It has been accepted for inclusion in Dissertations and Theses by an authorized administrator of PDXScholar. Please contact us if we can make this document more accessible: pdxscholar@pdx.edu. 


\title{
Reciprocal Effects of Student Engagement and Disaffection on Changes in Teacher Support Over the School Year
}

by

\section{Cailin Tricia Currie}

A thesis submitted in partial fulfillment of the requirements for the degree of

\author{
Master of Science \\ in \\ Psychology
}

Thesis Committee:

Ellen Skinner, Chair Thomas Kindermann Andrew Mashburn

\author{
Portland State University \\ 2014
}




\begin{abstract}
Building upon previous research on the importance of students' motivation for their learning and academic success, this study sought to examine how students' motivation in the classroom may impact the way their teachers' treat them. Specifically, data from 423 middle school students and their 21 teachers were used to examine the extent to which student engagement and disaffection (individually and in combination) in the fall predicted changes in teachers' provision of motivational support from fall to spring of the same school year. The study also examined whether these relationships might differ by student grade or gender, and whether the effects of each component of motivation can be buffered or boosted by the level of the other component.

Overall, results provided partial support for study hypotheses. As expected, engagement and disaffection (as reported both by students and by teachers) individually predicted changes in teacher motivational support over the school year, such that engaged students were more likely to gain teacher support across the school year whereas disaffected students were more likely to lose teacher support. Assessing the unique effects of engagement and disaffection suggested partial support for their combined predictive utility, although less support was found for teacher-reports than studentreports. Across time, student-reported disaffection demonstrated unique effects on changes in teacher support but student-reported engagement did not. For teacher-reports of engagement and disaffection, neither component of motivation predicted changes in teacher support above and beyond the other component.
\end{abstract}

Across reporters, mean-level gender differences in the constructs of interest were 
consistent with expectations based on previous research suggesting that girls tend to be more motivated than boys in school; however, despite these significant differences in mean-levels, there were few gender differences in the strength of the reciprocal effects of student motivation on teacher support. Of the 12 tests for gender differences in the links between student motivation and teacher support, only two were found, and both cases demonstrated significant gender effects of the same form, such that engagement and disaffection demonstrated significant reciprocal effects for both genders; however, the effects were significantly stronger for boys. As expected, examination of mean-level differences in engagement and disaffection as a function of grade suggested that student motivation and teacher support decline as students progress through middle school. In general, significant reciprocal effects of student motivation on teacher support across time were found for students of all grades for both student- and teacher reports; however there were some grade-level differences in the strength of those associations. Results indicated that engagement and disaffection were more important predictors of changes in teacher support over the school year for older students ( $8^{\text {th }}$ graders) than for younger students $\left(6^{\text {th }}\right.$ or $7^{\text {th }}$ graders $)$.

Finally, the expected interaction between engagement and disaffection was only partially supported and only for teacher-reports. Specifically, as predicted, the relationship between teacher-reported engagement and teacher support was stronger for students who were low in disaffection, suggesting low disaffection boosted the positive effects of engagement. At the same time, and contrary to expectations, instead of the relationship between disaffection and teacher support being weaker for students 
perceived as highly engaged, these relations were actually stronger such that disaffection was a stronger predictor of losses in teacher support for highly engaged students than for their equally disaffected but less engaged peers. Implications for educational interventions and daily classroom practices are discussed. This study, by utilizing a two time-point design, a diverse at-risk student population, and measures from both student and teacher perspectives, attempted to make a contribution to the sparse but potentially important research literature on how student's motivation can shape their experiences with teachers in the classroom. 
Table of Contents

Chapter Chapter title/subtitle

Page

Abstract

i.

List of Tables

vi.

List of Figures

vii.

$1 \quad$ Problem Statement

1.

$2 \quad$ Literature Review

9.

Differential Teacher Behavior

9.

Studies Examining the Impact of Students' Motivation on

Teachers' Behaviors

13.

Experimental Studies Examining the Effects of

Child Characteristics on Adult Reactions

29.

3

The Current Study

37.

Profiles of Engagement and Disaffection

37.

Multiple Perspectives on Engagement and Disaffection

40.

Nature of reciprocal effects: Amplifying versus Compensatory

42.

Research Questions and Hypotheses

43.

4

Research Design and Methods

49.

Participants

49.

Design and Procedure

49.

Measures

50. 
V.

Chapter Chapter title/subtitle

5

Results

Initial Analysis

Descriptive Analysis

Research Questions

6

Discussion

Strengths and Limitations

Implications and Future Studies

Implications for Interventions and policy

Conclusion

References

Appendix A. Literature Review Tables

Appendix B. Measures
Page

53.

53.

54.

61. 
List of Tables

Table Title

Page

5.1. Summary of Descriptive Statistics for each Construct in Fall and Spring

5.2. Intercorrelations Among Study Constructs

in Fall and Spring

60.

5.3. Mean Level Differences by Gender (Student Engagement and Student Disaffection)

63.

5.4. Summary of Descriptive Statistics for each Construct

by Grade level in Fall and Spring

68.

5.5 Mean Level Differences by Gender (Student Engagement and Student Disaffection)

81.

5.6. Summary of Descriptive Statistics for each Construct

by Grade Level in Fall and Spring

87.

6.1 Summary of Results

111. 
List of Figures

Figure Title

Page

1.1 Motivational Model adapted from Self-Determination Theory 5 .

5.1. Relationship Between Student Engagement (SR) and

Teacher Support Over Time

61.

5.2. Relationship Between Student Disaffection (SR) and

Teacher Support Over Time

62.

5.3. Interaction Between Engagement and Gender

on Teacher Support in Fall

64.

5.4. Interaction Between Engagement and Gender

on Teacher Support in Spring

64.

5.5. Interaction Between Disaffection and Gender

on Teacher Support in Fall

65.

5.6. Interaction Between Disaffection and Gender

on Teacher Support in Spring

65.

5.7. Interaction Between Engagement and Gender

on Teacher Support Over Time

66.

5.8. Interaction Between Disaffection and Gender

on Teacher Support Over Time

67.

5.9. Gender Moderation of the Relationship between

Engagement (SR) and Changes in Teacher Support

67.

5.10. Interaction Between Engagement and Grade

on Teacher Support in Fall

69.

5.11. Interaction Between Engagement and Grade

on Teacher Support in Spring

70.

5.12. Interaction Between Disaffection and Grade

on Teacher Support in Fall

70.

5.13. Interaction Between Disaffection and Grade

on Teacher Support in Spring

71. 
5.14. Interaction Between Engagement and Grade on Changes in Teacher Support

5.15. Interaction Between Disaffection and Grade on Changes in Teacher Support

5.16. Relationship Between Engagement, Disaffection, and Teacher Support in Fall

5.17. Relationship Between Engagement, Disaffection, and Teacher Support in Spring

5.18. Relationship Between Engagement, Disaffection, and Changes in Teacher Support

5.19. Interaction Between Engagement and Disaffection on Teacher Support in Fall

5.20. Disaffection Moderating the Relationship between

5.21. Engagement Moderating the Relationship between

5.22. Interaction Between Engagement and Disaffection on Teacher Support in Spring

5.23. Interaction Between Engagement and Disaffection on Changes in Teacher Support from Fall to Spring

5.24. Relationship Between Student Engagement (TR) and Teacher Support (SR) Over Time

5.25. Relationship Between Student Disaffection (TR) and Teacher Support (SR) Over Time

5.26. Interaction Between Engagement (TR) and Gender on Teacher Support (SR) in Fall

5.27. Gender Moderation of the Relationship between Engagement (TR) and Teacher Support in the Fall 
5.28. Interaction Between Engagement (TR) and Gender on Teacher Support (SR) in Spring

5.29. Interaction Between Disaffection (TR) and Gender on Teacher Support (SR) in Fall

5.30. Interaction Between Disaffection (TR) and Gender on Teacher Support (SR) in Spring

5.31. Interaction Between Engagement and Gender on

Changes in Teacher Support

5.32. Interaction Between Disaffection and Gender on Changes in Teacher Support

5.33. Interaction Between Engagement (TR) and Grade on Teacher Support (SR) in Fall

5.34. Interaction Between Engagement (TR) and Grade on Teacher Support (SR) in Spring

5.35. Interaction Between Disaffection (TR) and Grade on Teacher Support (SR) in Fall

5.36. Interaction Between Disaffection (TR) and Grade on Teacher Support (SR) in Spring

5.37. Interaction Between Engagement (TR) and Grade on Teacher Support (SR) in Fall

5.38. Relationship Between Engagement (TR) and Teacher Support for $6^{\text {th }}$ and $7^{\text {th }}$ Graders in Fall

5.39. Relationship Between Engagement (TR) and Teacher Support for $6^{\text {th }}$ and $8^{\text {th }}$ Graders in Fall

5.40. Interaction Between Disaffection (TR) and Grade on Teacher Support (SR) in Fall

5.41. Relationship Between Disaffection (TR) and Teacher Support for $6^{\text {th }}$ and $8^{\text {th }}$ Graders in Fall 
5.42. Interaction Between Engagement (TR) and Grade on Changes in Teacher Support (SR)

5.43. Interaction Between Disaffection (TR) and Grade on Changes in Teacher Support (SR)

5.44. Interaction Between Engagement (TR) and Grade (compared to $6^{\text {th }}$ grade) on Changes in Teacher Support (SR) 95.

5.45. Relationship Between Engagement (TR) and Changes in Teacher Support (SR) for $6^{\text {th }}$ and $8^{\text {th }}$ graders

5.46. Interaction Between Engagement (TR) and Grade (compared to $7^{\text {th }}$ grade) on Changes in Teacher Support (SR) 96.

5.47. Relationship Between Engagement (TR) and Changes in Teacher Support (SR) for $7^{\text {th }}$ and $8^{\text {th }}$ graders

5.48. Interaction Between Disaffection (TR) and Grade (compared to $6^{\text {th }}$ grade) on Changes in Teacher Support (SR) 97.

5.49. Relationship Between Engagement (TR) and Changes in Teacher Support for $6^{\text {th }}$ and $8^{\text {th }}$ graders

5.50. Interaction Between Engagement (TR) and Grade (compared to $7^{\text {th }}$ grade) on Changes in Teacher Support (SR) 98.

5.51. Relationship Between Disaffection (TR) and Changes in Teacher Support (SR) for $6^{\text {th }}$ and $8^{\text {th }}$ graders

5.52. Relationship between Engagement, Disaffection, and Teacher Support in Fall

5.53. Relationship between Engagement, Disaffection, and Teacher Support in Spring

5.54. Relationship Between Engagement, Disaffection, and Teacher Support over time

5.55. Interaction Between Engagement (TR) and Disaffection (TR) on Teacher Support (SR) in Fall 
5.56. Interaction Between Engagement (TR) and Grade

(compared to $7^{\text {th }}$ grade) on Changes in Teacher Support (SR) 103.

5.57. Engagement Moderating the Relationship between Disaffection and Teacher Support in Fall

103.

5.58. Interaction Between Engagement and Disaffection on Changes in Teacher Support from Fall to Spring

105.

5.59. Relationship Between Engagement and Changes in Teacher Support from Fall to Spring

5.60. Relationship Between Disaffection and Changes in Teacher Support from Fall to Spring 


\section{Chapter 1}

\section{Problem Statement}

The constructs of academic engagement and disaffection have gained prominence in the motivational and educational research literatures because of their utility in predicting academic outcomes. Research indicates that engaged students learn more than disaffected students, have higher GPAs, and higher achievement test scores (Skinner, Wellborn \& Connell, 1990; Janosz, Archambault, Morizot, \& Pagani, 2008; Klem \& Connell, 2004). Highly engaged students are more likely to graduate high school and to do so in a timely manner (Ullah \& Wilson, 2007; Fredricks, Blumenfeld, \& Paris, 2004). Engagement also appears to be a protective factor against a host of risky adolescent behaviors (Morrison, Robertson, Laurie, \& Kelly, 2002; Finn, 1989). Conversely, high student disaffection is associated with negative scholastic and developmental outcomes such that highly disaffected students learn less in school, are more likely to drop out of school, and are more likely to engage in risky adolescent behaviors such as drug and alcohol abuse, delinquency, and risky sexual behavior (Janosz, Archambault, Morizot, \& Pagani, 2008; Finn, 1989, Gottfried, Fleming, \& Gottfried, 2001).

Highly engaged students, although clearly more successful in school, become increasingly harder to find as they progress through their academic careers. Student motivation for school peaks the day before Kindergarten starts and suffers continuous declines until students graduate from (or drop out of) high school, with severe losses at the transitions to middle school and high school (Wigfield, Eccles, Schiefele \& Roeser 2006; Gottfried, Fleming, \& Gottfried, 2001; Anderman \& Maehr, 1994 Janosz, Archambault, Morizot, \& Pagani, 2008). These losses are even more pronounced for 
students who are at-risk for underachievement and drop out due to their membership in low socioeconomic status (SES), English as a second language, and racial/ethnic minority groups (Greenwood, 1999; Finn 1993). However, unlike other strong predictors of scholastic success (such as SES, ethnicity, and gender), engagement is a plastic process and thus has the potential to be enhanced through improvements in the learning environment, the structure of curriculum, and the quality of relationships between students and their teachers (Fredricks, Blumenfeld, \& Paris, 2004; Guthrie \& Davis, 2003; Furrer, Skinner, \& Pitzer, 2012).

\section{Conceptualization of Engagement and Disaffection}

Conceptualized as the strength and emotional quality of children's initiation and participation in learning activities, engagement refers to participation on academic tasks that is active, goal-oriented, constructive, persistent, focused, and emotionally positive (Furrer, Skinner, \& Pitzer, 2012; Jimerson, Campos, \& Greif, 2003). Engaged students are intrinsically motivated, enthusiastic learners. Engagement includes both behavioral (effort) and emotional (interest) components (Skinner, Kindermann, Connell, \& Wellborn, 2009; Skinner, Kindermann, \& Furrer 2009; Fredricks, Blumenfeld, \& Paris, 2004).

The other side of engagement is disaffection, which not only represents a lack of engagement, but also describes a state resulting from low student motivation. Disaffection encompasses both behavioral (giving up) and emotional (apathy) components. Disaffection can manifest as withdrawal from learning activities or passively 'going through the motions', indicating student boredom or anxiety. Disaffection also encompasses disruptive off-task behavior such as refusing to participate 
or attempting to undermine other students' learning experiences, which reflect negative emotional states such as frustration or anger (Jimerson, Campos, \& Greif, 2003; Skinner and Belmont, 1993; Skinner, Kindermann, Connell \& Wellborn, 2009; Skinner, Furrer, Marchand, \& Kindermann, 2008).

While clearly related, structural analyses of engagement and disaffection suggest that these constructs are not the mirror images of each other. Engagement and disaffection seem to be structurally distinguishable constructs, not the opposite ends of a single continuum. Structural analyses of items tapping both engagement and disaffection indicate that a four-factor model, which separates both engagement and disaffection into their emotional and behavioral components, best reflects the structure of engagement in elementary and middle school (Skinner, Furrer, \& Kindermann, 2003).

\section{Teacher Motivational Support}

Research suggests that teacher motivational support is a powerful predictor of student engagement and academic achievement (Wigfield, Eccles, Roeser, \& Schiefele, 2006; Martin \& Dowson, 2009; Anderman \& Maehr, 1994; Ullah \& Wilson, 2007). Selfdetermination theory (SDT) posits one conceptualization that specifies how teachers can support the development of student motivation through the fulfillment of students' basic psychological needs (Deci \& Ryan, 1985, 2000). SDT provides a framework for conceptualizing how different social environments can promote or hinder volitional, high quality motivation and engagement based on the environment's ability to fulfill three basic psychological needs, namely, relatedness, competence, and autonomy $(1985,2000)$. Relatedness refers to the desire to feel a connection to others and that one belongs; while the need for competence concerns the need to experience oneself as effective in 
producing desired outcomes and experiencing mastery. The need for autonomy is the need to feel that one's actions emanate from one's self, the sense that one is steering the course of one's own life.

Teachers can help fulfill these three basic psychological needs by providing students with involvement, structure, and autonomy support (versus neglect, chaos, and coercion). Teachers help support students' need for relatedness when they provide students with high quality involvement, by expressing caring, being emotionally available, and spending time with students. In order to fulfill students' need for competence, teachers can supply their students with structure by clearly communicating expectations, giving consistent and predictable responses, and adjusting their teaching to the level of the student. Finally, autonomy supportive teachers make lessons relevant to their students' lives, give their students choices, and allow their students to work at their own pace and in their own way (Reeve et al. 2004; Skinner \& Belmont, 1993; Connell \& Wellborn, 1990; Reeve, 2012).

These three facets of teacher motivational support are positively correlated with components of engagement such as higher classroom participation and on-task behaviors. Teacher support is negatively correlated with components of disaffection such as disruptive behavior and the probability of dropping out of school (Fredricks, Blumenfeld, \& Paris, 2004; Martin \& Dowson, 2009; Furrer, Skinner, \& Kindermann, 2009; Ullah \& Wilson, 2007). When teachers create supportive classroom environments, emphasize the value and relevance of learning, and support their students' sense of autonomy, students report experiencing higher engagement in schoolwork and more positive affect towards learning (Fredricks, Blumenfeld, \& Paris 2004; Guthrie \& Davis, 2003; Marks, 2000; 
Wigfield, Eccles, Roeser, \& Schiefele, 2006). See Figure 1 for Motivational Model.

While it is vital that we continue learning about how the quality of teacher support can promote or hinder children's engagement in the classroom, it may be equally important to view these powerful classroom interactions from the opposite direction. Most studies investigating the effects of teacher support on student engagement and disaffection examine correlations at a single time point. This research design makes it impossible to draw any conclusions about the potential direction of effects. In fact, these correlational findings could be interpreted from the opposite perspective, and could potentially reflect the reciprocal effect, namely, that students' levels of engagement and disaffection could shape the way their teachers treat them.

Figure 1.1 Motivational Model adapted from Self-Determination Theory

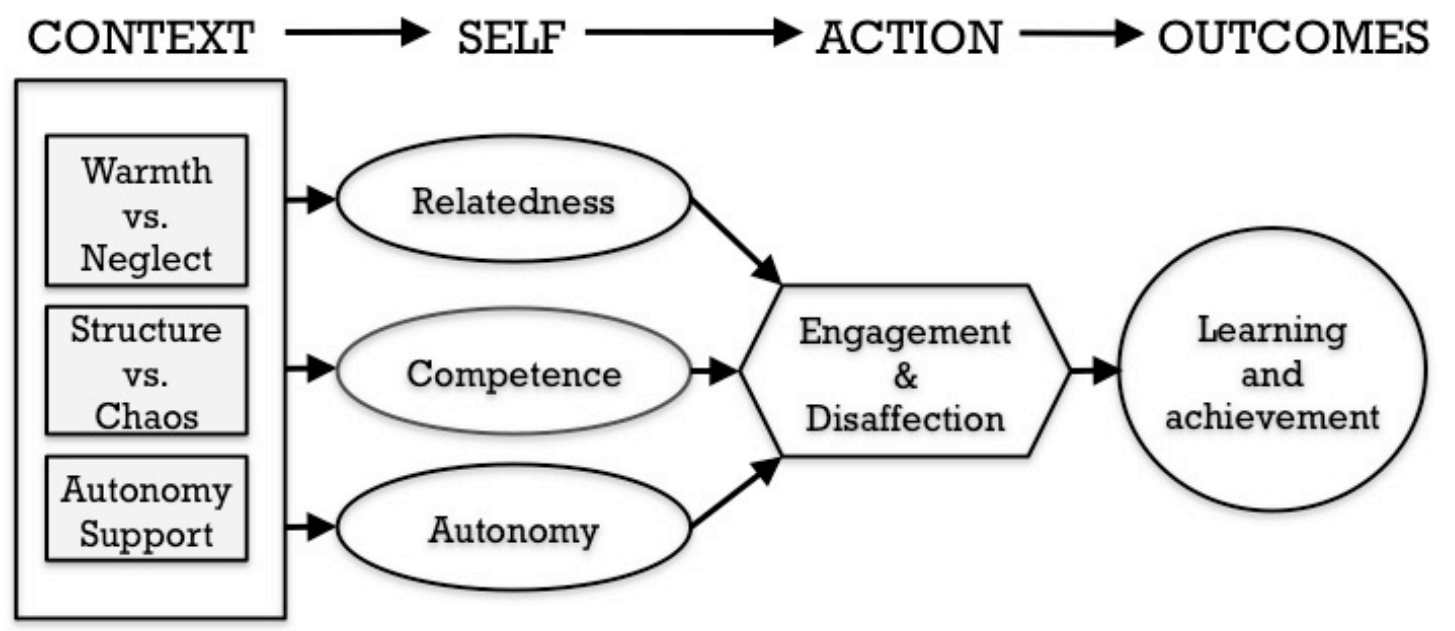

\section{Reciprocal Effects}

Engagement is a valuable resource to students, not only because it contributes to their learning and school success, but also because it shapes their daily experiences in school. Students who are engaged have access to more engaged peers (Kindermann, 1993). Perhaps even more importantly, highly engaged students, compared to their more 
disaffected classmates, may be treated differently by their teachers. Because of their enthusiasm and effort in the classroom, highly engaged students may be liked better by their teachers and consequently may receive more positive, emotional support from their teachers. Conversely, unmotivated students are among the top stressors reported by teachers, making it probable that highly disaffected students are not as well liked or as well treated by their teachers (Chang, 2009). For teachers, student engagement and disaffection are salient, observable behavioral states and may have the potential to influence how teachers respond to students. Teachers are active interaction partners for students and thus should be constantly reacting and responding to input from students. It follows that teachers' behaviors could be affected by how engaged or disaffected their students are in the classroom.

This hypothesis is strengthened by a small number of studies examining the effects of student behavior on teachers. Skinner and Belmont were the first to examine student engagement and disaffection as a predictor of changes in teacher support across the school year (1993). Their findings suggest that teachers taught more directly to engaged students, were more involved in their lives, showed them more warmth, and allowed them more freedom to work at their own pace and in their own way (Skinner \& Belmont, 1993; Furrer, Skinner, \& Kindermann, 2003). Unfortunately, teachers appeared to show disaffected students less involvement and warmth and were more likely to be coercive in their interactions with disaffected students (Skinner \& Belmont, 1993; Furrer, Skinner, \& Kindermann, 2003). Research suggests students who like school tend to receive fewer negative comments from their teachers, have better relationships with their teachers, receive more teacher support, and perceive their classrooms as more positive 
and caring than students who do not like school (Baker, 1999). Kindergarteners who exhibit antisocial behavioral styles in the classroom have lower quality relationships with their teachers and experience higher levels of teacher-child conflict (Ladd, Birch, \& Buhs, 1999). Observational data of middle school students suggests that higher participation in the classroom is associated with greater teacher responsiveness (Altermatt, Jovanovic, \& Perry, 1996). These studies align with findings in the parenting literature that emphasize the ways in which children's actions impact the quality of support they receive from the adults in their lives (Bell, 1968; Jelsma,1982; Anderson, Lytton, \& Romney, 1986; Brunk \& Henggeler, 1984).

In sum, this study sought to examine the individual and combined utility of engagement and disaffection as predictors of changes in teacher support across the school year. The following chapter, Chapter 2, summarizes the literature on the differential ways that teachers support students based on student characteristics in order to validate the idea that student engagement and disaffection may impact teachers' provision of support over time. Chapter 2 also explores research in the parenting and education literature that examines the impact of student motivation on teachers' behaviors. Finally, Chapter 2 ends with a review of the literature on how experimentally manipulated child behaviors impact the quantity and quality of adult support. Chapter 3 discusses the purpose of the current study and presents the research questions and hypotheses. The current study also examined potential grade-level differences, gender differences, and differences in results due to student-reports versus teacher-reports of engagement and disaffection. Chapter 4 outlines information about the participants, study design, and measures. Chapter 5 contains details about the analysis plan and results. Finally, strengths, limitations, and 
directions for future research are discussed in Chapter 6. The unique contributions of this study stemmed from the utilization of a two time-point design which allowed for causal interpretations, a racially diverse, low SES sample of students which extends generalizability to at-risk student populations, and student- and teacher-reports of engagement and disaffection which yielded additional information about the relationship between the target constructs due to the presence of multiple perspectives. 
Chapter 2

\section{Literature Review}

Although little research has investigated whether teachers treat students differently based on students' academic motivation, there is an extensive history of research on teachers' differential treatment of students based on other student characteristics. Student race and gender, as well as teacher expectancies for student achievement and students' past achievement have all been shown to result in teachers' differential treatment of students (for reviews, see Sadker, Sadker \& Klein 1991; Babad 1993). Research also suggests that there are interactions between these student characteristics, creating even more nuanced patterns concerning teachers' unequal allocation of support to individual students (Irvine, 1985). It is important to note that in this context, differential teacher treatment does not refer to differential instruction provided to students with different learning styles, but instead refers to providing differing levels of emotional and motivational support to students based on their individual characteristics. While teachers are trained to provide individualized instruction based on students' current ability levels, it is assumed teachers are not taught to provide students with differing levels of the type of warmth, caring, and emotional support that underlies teacher motivational support.

\section{Differential Teacher Behavior}

In order to lay the groundwork for the argument that students' motivation may shape how teachers support to them in the classroom, a brief overview of the educational literature on teacher differential behaviors is provided. The next section presents a summary of the research on how teachers treat students differently based on individual 
characteristics. This research supports the major assumption of the current study by suggesting that students' characteristics shape the type of relationships they have with their teachers.

Gender. Teacher differential treatment of boys and girls appears to begin at the pre-elementary school level and continue through postsecondary education. A comprehensive review by Sadker, Sadker, and Klein (1991) of over 30 large-scale studies suggests that effects begin as early as preschool where boys receive more instruction time, over 1.5 times more attention, more nurturant instructional attention, double the likelihood of engaging in extended conversations with teachers, and more hugs from their teachers than girls. In elementary school, researchers found a higher number of teachermale interactions occurring across all subjects than teacher-female interactions. Middle school teachers directed more complex and abstract question to boys, initiated conversation more often with boys, and had higher numbers of academic contacts with boys than girls, with whom teachers were more likely to be restrictive. A study by Irvine found that female students received less total communication, less praise, less negative feedback, less neutral procedural feedback, and even less nonacademic feedback (1985). Even more concerning, research suggests that as they progress through school, girls initiate interactions with their teachers less and less often. By the time students reach college, men are twice as likely to dominate classroom interactions, and undergraduates perceived men as being called-on more, praised more, and encouraged more than female students (Sadker, Sadker \& Klein 1991).

However, the direction of these gender differences is not unanimously agreed upon in the research literature. There is also empirical support for the idea that female 
teachers are more likely to discipline and warn male students and report having less close relationships with male students compared to female students (Jones \& Wheatley, 2006; Split, Koomen, \& Jak, 2012). Additionally, boys received more negative oral feedback from their teachers than did girls (Chen, Thompson, Kromrey \& Chnag, 2001). There is also research suggesting that both male and female teachers reported having more conflictual relationships with boys than with girls (Split, Koomen, \& Jak, 2012). Clearly, more research is needed to better understand how student gender in the classroom impacts teachers' relationships with their students. Regardless of whether it is boys or girls that are receiving more support, teacher's provision of support should not be confused with student motivation or achievement. Boys are generally less engaged and receive lower grades in school compared to girls. Perhaps some teachers compensate for boys' low motivation and achievement by giving them more support while other teachers react by increasing discipline and withdrawing the emotional support necessary to create close relationships with these boys.

Race. Race has also immerged as a student characteristic that appears to shape how teachers support their students. Observational research across grade levels suggests that, compared to Caucasian students, teachers treat African American students less favorably, have less positive interactions with African American students, and have lower academic expectations of African American students (Tucker, Zayco, Herman, Reinke, Trujillo, Carraway, \& Ivery 2002; Castell, 1998). African American students also receive more negative behavioral feedback and more overall (positive and negative) feedback than Caucasian students (Irvine, 1985). Race seems to be particularly intertwined with gender such that trends suggest Caucasian males receive the most teacher support, 
African American males receive the most teacher criticism, and Caucasian females receive less total communication than the other three race/gender groups (Irvine, 1985; Simpson \& Erikson 1983). Race and teacher expectations of student success also appear to be interconnected for certain minority groups such that teachers have significantly different educational expectations for Asian compared to Caucasian students (Wong, 1980).

Expectations. Perhaps the most extensive literature on teacher differential support comes from research on the behavioral-mediation of teachers' differential expectations for high and low achieving students. Babad's 1993 review complied results from multiple meta-analyses to create a list of the ways teachers treat students differently based on teachers' expectations of students' academic achievement (1993). Differential behaviors including teachers' affective behavior (i.e., warmth, supportiveness, negative affect), physical distance, amount and level of teaching, duration of interaction, accepting students' ideas, and provision of praise favor students for whom teachers have high expectations. Even when teachers' verbal behavior with students was somewhat equitable, a study of teachers' nonverbal communication found that teachers' facial expressions and body movements were rated as expressing more positive affect when talking to and about high expectancy students. The reverse was true for low expectancy students, with raters judging teacher body language to indicate more negative affect (Babad, 1993).

Achievement. Finally, because research suggests that teacher expectations are mostly informed by students' past performance, it is no surprise that students' previous achievement shapes differential teacher behaviors. In a study comparing teacher behavior 
with students in different ability groups in both low and high SES classrooms, findings indicated that teachers spent more time, engaged in more personal interchanges, and directed less criticism towards high achieving reading groups across classrooms. High achievement groups were characterized by a warmer emotional climate and more personal social relationships (Grant \& Rothenberg, 1986). Additionally, student and teacher expectations appear to intertwine such that teachers' expectations of students are biased towards high performing students. Research suggests that teachers overestimate high ability students' cognitive and noncognitive skills (i.e. self-concept and attributional beliefs) compared to middle or low ability students (Carr \& Kurtz-Costes, 1994).

Taken together, the literature on teacher differential behavior dispels the myth that teachers treat all of their students equally. Teachers respond differently to different student characteristics, supporting the idea that students have the ability to affect their teachers' behavior. Considering that student motivation can be viewed as a student characteristic that is both visible and salient to teachers, it is not unreasonable, given the research on teacher differential behavior, to assume that student motivation could shape how teachers interact with their students.

\section{Studies Examining the Impact of Students' Motivation on Teachers' Behaviors}

The following section reviews the research literature on the impacts of student motivation on teacher behavior and student-teacher relationships. While only two of the eleven studies reviewed specifically measured engagement and disaffection, the constructs these studies explored directly map onto emotional and behavioral components of engagement and disaffection in the classroom. By reviewing studies assessing student characteristics such as student satisfaction versus dissatisfaction with school, 
difficult/challenging versus easy student behaviors, student personality, prosocial versus antisocial student behavioral styles, as well as teacher characteristics that tap teacher support including quality of teacher-student interactions, teacher effort expenditure per student, teacher interaction-approach orientation towards students, and teacher-student relationship quality and closeness, this chapter hopes to coalesce key findings of related research to compensate for the dearth of research directly assessing the reciprocal effects of engagement and disaffection on changes in teacher support. See Appendix A for tables of literature review studies.

\section{Skinner and Belmont (1993)}

Skinner and Belmont (1993) conducted one of the only studies that directly examined the reciprocal effects of student engagement on changes in teachers' provision of motivational support over time. In accordance with a self-system model of motivational development, which assumes an individual's motivational outcomes are optimized when her interactions with her social contexts fulfill the three universal psychological needs for relatedness, competence and autonomy outlined by Deci and Ryan's (1985) self-determination theory, this study tested a model specifying the feedforward and feedback relationships between student motivation and teacher support. More specifically, the full model explored the typical feedforward effect, examining whether teachers' provision of motivational support could predict changes in students' perceptions of that support, which could in turn predict changes in students' emotional and behavioral engagement. The feedback or reciprocal effects, on which this review will more closely focus, were also investigated. The study examined whether teachers' perceptions of students' emotional and behavioral engagement predicted changes in 
teachers' reports of the motivational support they subsequently provided to students.

Student motivation was assessed by measures of (1) emotional engagement, which tapped students' emotional reactions in the classroom and (2) behavioral engagement, which tapped students' effort, attention, and persistence in learning activities. Teacher motivational support was measured by assessing the extent to which teachers provided their students with involvement, structure, and autonomy support. Students and teachers completed questionnaires at two time-points, fall and spring, (October \& April) assessing student engagement [61 item student-report; 33 item teacherreport] and teacher support [65 item student-report; 62 item teacher-report]. By utilizing two time points, this study was able to assess how levels of teacher support changed across the school year. By collecting ratings from student and teacher reporters for both of the constructs of interest, (though only teacher reports of student engagement were used in the examination of reciprocal effects), this study has the added benefit of utilizing multiple perspectives through which to view the association between student motivation and teacher support over time.

In a sample of $3^{\text {rd }}$ through $5^{\text {th }}$ grade students, the authors conducted a time-lagged path analysis such that the dependent variable was the target construct measured in spring and the predictor variables were all the constructs measured in fall that preceded the target construct in the model. Though each link in the path analysis was examined, of specific relevance to this review are the findings from regression analyses examining the effects of teachers' perceptions of students' engagement in the fall on changes in teacher and student reports of the three sub-dimensions of teacher support from fall to spring. In spite of the high stabilities (cross-year correlations) of teacher support, findings 
demonstrated that student behavioral engagement uniquely predicted changes in teacher support from fall to spring. For both student and teacher reports, findings suggest that students who were perceived by their teachers as being highly behaviorally engaged in fall received more of all three teacher support behaviors in spring than students who were perceived as less engaged. Unfortunately, students who were perceived as more behaviorally disaffected in fall were more neglected, more coerced, and treated with less consistency and contingency by their teachers in spring. However, teachers' perceptions of students' emotional disaffection in fall were positively related to teachers' provision of autonomy support, suggesting that teachers attempt to compensate for students' negative emotions in the classroom by providing students with more teacher support in the form of more choices and more opportunities for self-direction.

\section{Furrer, Skinner, and Kindermann (2003)}

Further evidence for the reciprocal effects of student motivation on changes in teacher support was found by Furrer, Skinner, and Kindermann (2003). In order to establish the direction of effects, the authors utilized a similar two time-point design in which students and teachers completed surveys assessing student motivation and teacher support in fall and spring of the same school year. Both student and teacher surveys measured four indicators of student motivation (behavioral engagement, emotional engagement, behavioral disaffection, and emotional disaffection) as well as six-sub dimensions of teacher motivational support (involvement vs. neglect, structure vs. chaos and autonomy support vs. coercion). Unlike Skinner and Belmont (1993) who relied on reverse coding engagement items, the authors made a distinction between engagement and disaffection in order to better capture the full scope of the construct of disaffection. 
The researchers also investigated the possibility of gender and grade level differences in their sample of $8054^{\text {th }}-7^{\text {th }}$ grade students. Findings that mean levels differed significantly as a function of gender differences were consistent with previous research suggesting that girls are generally more engaged than boys. Initial analyses also found that, compared to their male peers, girls perceived their teachers as more supportive. Grade level differences were also found in the expected direction; namely, elementary school students were more engaged and less disaffected than middle school students. Thus, gender and grade level were controlled for in the final series of regression analyses predicting teacher support in the spring from student engagement and disaffection in the fall.

Consistent with Skinner and Belmont's findings, this study found that engaged students gained teacher support while disaffected students lost teacher support from fall to spring. Across reporters, students who were more disaffected in the fall experienced greater declines in teacher support over the school year, with the most consistent predictor across reporters being behavioral disaffection. The findings concerning emotional disaffection were somewhat more contradictory as students who reported experiencing higher anxiety rated their teachers as withdrawing support whereas teachers reported that they increased their involvement with students who displayed such aspects of emotional disaffection. The effects of engagement were not as pronounced as those for disaffection. For teacher reports, both emotional and behavioral engagement predicted modest increases in teacher support from fall to spring. However, for student reports, the authors found no significant association between engagement and teacher support. Finally, the authors confirmed their hypothesis that teacher perceptions of students' 
engagement mediated the association between students' reports of their engagement and teachers' provision of motivational support.

Taken together, Skinner and Belmont (1993) and Furrer, Skinner, and Kindermann (2003) suggest that teacher support and student motivation not only feed forward, as previously established, but may also feed backwards, suggesting the possibility of a self-perpetuating cycle. While engaged students are receiving more motivational fuel from their teachers, disaffected students, who would seem to need teacher support the most, are receiving less of it, thereby setting the stage for further erosion of their academic motivation.

\section{Pelletier, Seguin-Levesque and Legaul (2002)}

Although there appear to be no other studies that look explicitly at the constructs of engagement and disaffection, there are several studies that examine how similar student behaviors and attitudes affect teachers' subsequent behavior. Pelletier, SequinLevesque and Legaul also utilized a self-determination theory (SDT) framework to examine how students' motivation in the classroom can impact the quality of teachers' autonomy support. As previously discussed, the model of teacher support outlined by SDT is comprised of three components, warmth/involvement, structure, and autonomy support. Pelletier, Sequin-Levesque and Legaul, who were particularly interested in exploring the possible determinants of teachers' autonomy supportive behaviors in the classroom, examined how teachers' perceptions of student motivation can impact teachers' motivation towards their work and teachers' consequent provision of autonomy support. Findings suggested that the more teachers perceived their students to be extrinsically motivated, the more they themselves indicated being extrinsically motivated 
towards teaching, and the less likely they were to be autonomy supportive in their interactions with their students.

Participants were 254 Canadian $1^{\text {st }}$ and $2^{\text {nd }}$ grade teachers who completed a questionnaire package at home measuring their perceptions of strain, student motivation, their own motivation towards teaching, and their provision of autonomy support. Student motivation and teacher motivation were measured by four subscales, designed to assess the motivational constructs identified by SDT, tapping intrinsic motivation, extrinsic motivation by identified regulation, extrinsic motivation by introjected regulation, and extrinsic motivation by external regulation. In order to create a composite score of how self-determined students and teachers were overall, intrinsic motivation and extrinsic motivation by identified regulation items were assigned weights of 2 and 1, and extrinsic motivation introjected and external regulations were assigned weights of -1 and -2 , respectively. While the current study focuses solely on the impact of student motivation, Pelletier, Seguin-Levesque and Legaul also considered the impact of professional strain as measured by scales tapping pressure from colleagues, school administration, and performance standards/curriculum, to gain a more holistic view of the stressors teachers face every day. Teacher's autonomy support versus control orientation was measured by teachers' responses to eight vignettes describing typical problems that occur in the classroom. Teachers' ways of dealing with the problems presented were coded as either highly autonomy supportive, moderately autonomy supportive, moderately controlling, or highly controlling.

Using structural equation modeling, the authors found support for their proposed four factor mediated model. Results indicated that the mediated model was the model of 
best fit: Teachers' motivation towards work mediated the relationship between teachers' perceptions of student motivation and teacher provision of autonomy support versus coercion, such that teachers' motivation explained $13 \%$ of the variance of teachers' autonomy support. It appears that the more teachers believed their students were being self-determined (intrinsically motivated), the more self-determined teachers were towards their own work. In turn, the more self-determined teachers were towards their work, the more autonomy supportive their behavior were towards students. While the study's design, in which all measures were collected as at single time point, prevents this study from establishing directional causality, this study highlights the burgeoning work exploring how students motivation in the classroom is linked to teachers' provision of autonomy support.

\section{Houts, Caspi, Pianta, Arseneault, \& Moffitt (2010)}

Utilizing data from a nationally representative birth cohort assessed in the British E-Risk Longitudinal Twin Study, Houts et al. (2010) expanded on the work investigating reciprocal effects by examining how student personal characteristics in childhood affected the amount of teacher effort required to instruct students at age 12. At age five, children's challenging behavior was assessed by mother and teacher reports of 18 symptoms of hyperactivity-impulsivity and inattention as well as observer ratings of children's irritability/negative affect and impulsivity/distractibility during a home visit. The authors used a composite score of mother, teacher, and observer reports in their analyses. IQ scores for children at age five were also obtained. When the children were 12 years old, their teachers completed survey reports of the amount of effort that was required to teach these children. Teachers were asked about their effort expenditures for 
individual students (Ex. "How frequently must you give this child extra encouragement to get him/her to take part?" "How frequently must you act to curb disruptive behavior by this child?").

The authors found that students' challenging behavior (i.e., irritable, impulsive, hyperactive, and inattentive behavior) at age 5 was positively correlated with the effort required of teachers at age $12(r=.33)$, demonstrating that early student characteristics can predict teachers' later responses. Also, children's IQ scores at age five were negatively correlated with the effort required by teachers at age $12(r=-.20)$. Students with lower IQ scores who displayed challenging behavior at school entry elicited greater teacher effort later than students who did not exhibit challenging behavior. Interestingly, whereas the findings of this study suggested that teachers react to challenging student characteristics by increasing their responsiveness in an attempt to compensate for student difficulties, other studies have documented the reverse reaction, namely that teachers withdraw their effort and attention from challenging students (Skinner and Belmont, 1993). Such conflicting results highlight the need for more research on reciprocal effects in order to better understand how the classroom context and individual teacher characteristics may influence teachers' differential reactions to students exhibiting challenging behavior. In sum, this study suggests that individual student characteristics may have a long-term impact on the quantity and quality of support they receive from their teachers.

\section{Baker (1999)}

A study by Baker (1999) investigated whether student satisfaction or dissatisfaction with school was related to the quality of student-teacher relationships and 
the extent to which students felt that their teachers and classrooms were supportive and positive. Presumably, students who like school would be more highly engaged while students who dislike school would be more likely to be disaffected. The authors used a multi-methods approach utilizing observations, qualitative interviews, and surveys to assess the differential association between teacher-student interactions and relationship quality for students who are satisfied with school compared to students who are dissatisfied with school. Participants were 61 African American $3^{\text {rd }}-5^{\text {th }}$ grade students selected from a pool of 126 students based on their scores on the Multidimensional Student Life Satisfaction Scale. Students who scored in the upper quartile were placed in the "satisfied with school" group while students who scored in the lower quartile made up the "dissatisfied with school" group. While this extreme group design excluded students with ambivalent or neutral attitudes towards school, it served the important function of creating groups that were more likely to reflect meaningfully different motivational states.

The authors found that students who liked school received more teacher support, had better relationships with their teachers, and overall had different patterns of behavioral interactions with theirs teacher than did children who did not like school. Baker found that dissatisfied students received almost twice as many behavioral reprimands and 5.5 times more negative comments from their teachers than did their satisfied peers. Student interviews revealed that students who were dissatisfied with school, in comparison to satisfied students, were more likely to report getting in trouble at school, more likely to report they had problems getting along with their teachers, less likely to report their teacher cared about them, and less likely to cite their relationship 
with their teacher as what made their classroom a nice place to be. Finally, students who were highly satisfied with school reported that they received more social support from teachers and reported experiencing "a significantly more positive and caring classroom social environment than did their dissatisfied peers" (p 64).

These findings support the idea that students who like school and students who don't like school may have different experiences at school because of the differential ways their teachers interact with and relate to them. This study suggests that, like student engagement and disaffection, student school satisfaction and dissatisfaction can manifest as salient, observable constructs that influence teacher support and the overall studentteacher relationship. However, considering the measures were concurrent, it is not possible to determine whether these are feedforward or feedback effects. Though the researchers' interpretation of this study suggests that students who are highly satisfied with school forge better relationships with their teachers, these findings could also be interpreted such that students who have high quality relationships with their teachers are more likely to report high overall satisfaction with school. The indefinite nature of these interpretations emphasizes the need for longitudinal studies that directly assess the causal impacts of student motivational states.

\section{Newberry and Davis (2008)}

A qualitative study by Newberry and Davis (2008) furthers the investigation of how student characteristics similar to engagement and disaffection are linked to the quality of teacher's responses to their students. Through structured interviews with teachers, the authors examined the student factors that influence how teachers understand their feelings of closeness to students in their classes, and how feelings of closeness, in 
turn, affect teachers' interactions and relationships with their students. The researchers conducted interviews with three Caucasian elementary school teachers guided by the overall question of 'How do these teachers understand their feelings of closeness and connection to their students'? Interviews were transcribed and coded in three separate passes. The first pass focused on what the teacher was saying about her teaching self; a second pass focused on how the teacher understands her connection to her students; and the final pass focused on how the teacher managed her relationship with her students, such as what tools and strategies she utilized. This organizational method allowed the researchers to code $75 \%$ of the interview data. Inter-coder agreement was established by sorting coded cards containing portions of interviews separately and then comparing categorization. Finally, combining the interview data with teachers' closeness rating for each of their students, each individual student-teacher relationship was classified in terms of the dominant interaction-approach orientation the teacher used with that particular student.

Systematic analyses of qualitative interview data allowed the researchers to formulate a grounded model of teachers' conceptions of the three factors that shape their experience of closeness to their students and how their experiences of closeness relate to five different teacher interaction-approach orientations. The first two student factors that impact teacher closeness, the match or mismatch of a students' personality with their teacher's personality and the way challenges, such as students' problem behavior, create emotionally charged or draining interactions with teachers, were both influenced by the third factor, students' press for a relationship with their teacher, such that when teachers felt students pressed them to develop a closer relationship, teachers found it easier to 
respond to students regardless of student personality or presence of challenges. These three student factors in turn appeared to influence whether teachers responded to students with feeling of affinity, by being reflective, by implementing strategies, by treating students casually, or by acting professional.

Findings suggested that student personality, challenges, and press for relationships each led to different teacher reactions such that students with easy personalities, low levels of challenges, and an average press for academic and emotional teacher support were treated in a more emotionally open and supportive way by their teachers whereas students with difficult personalities, high levels of challenges, and very low or very high levels of push received less emotionally open and more distant treatment from their teachers. Specifically, teachers reported 'feeling affinity' towards students who were friendly, polite, bright and capable. Conversely, teachers were more likely to use an 'acting professional' (unemotional, detached) interaction approach to students who they perceived as aggressive, competitive, manipulative, or odd and were more likely to 'act casually' (polite but reserved) with students they perceived as quiet, timid, or shy. In terms of challenges posed by students, those that were familiar to teachers were related to an 'implementing strategies' approach while unfamiliar challenges tended to lead to 'treating casually' or 'acting professional' approach orientations.

Students' press for relationship appeared to be the most important student factor that influenced the type and quality of teacher's emotional support, not only because of its impact on teacher's evaluation of the other two student factors, but because student press for relationship determined the amount of academic and emotional labor teachers dedicated to a given student. Relational press describes the demands placed on the 
teacher to meet students' academic and emotional needs. Findings suggest that teachers reacted favorably to students press for academic needs, most likely because this makes the teacher feel needed. While students who exerted average levels of press for relationship tended to require less effort to reciprocate, students who exerted high levels of need for relationship were viewed as emotionally draining and treated with more distant approach orientations by teachers. Similarly, students who did not press for a relationship were view by their teachers as "not needing my help" and were consequently treated with distant approach orientations.

In sum, while the student factors of personality, presence of challenges, and press for teacher academic and emotional support are not identical to the target constructs of the current study, Newberry and Davis's study supports the idea that how students behave in the classroom impacts the quantity of support they receive and the overall quality of their relationships with their teachers. Students who are friendly and bright, pose few challenges, and actively seek a close relationship with their teachers' have higher quality relationships with their teachers and received more emotionally supportive interactionapproaches from their teachers. Conversely, students who are more difficult to get along with, pose many challenges to teachers, and are either uninterested in having a close relationship or require a great amount of teacher effort to interact with, appear to make teachers feel vulnerable and as a result are more likely to be marginalized by their teachers. This exploratory study provides new insight into how the interaction between student characteristics and teachers' perceptions of students affects whether teachers move towards, away, or against developing relationships with their students. 
Ladd, Birch, and Buhs (1999)

Ladd, Birch, and Buhs were also interested in examining the potential impact of student characteristics and interaction styles on the quality of teacher-student relationships. The aims of their study were similar to those of the current study as they both focus on how the individual characteristics that students carry with them into their interactions with teachers affects the subsequent ways their teachers interact with them. Specifically, Ladd, Birch, and Buhs observed students with prosocial and antisocial behavioral styles to better understand how these types of student interaction styles relate to teacher-student closeness, conflict, and relationship quality. Findings suggest that kindergarteners exhibiting antisocial behavioral styles have lower quality relationships with their teachers characterized by less closeness and more conflict.

In study 1 of this two-part, short term longitudinal research project, observations of 200 kindergarteners and their 16 teachers were conducted over the course of 14 weeks beginning at kindergarten entry. Children's behavioral style was assessed during the first 10 weeks by trained observers who used a combination of time-point and scan sampling techniques to observe kindergarteners during free play periods, and coded children's behavior into one of six codes with an interrater agreement reliability of $77-90 \%$. Composite scores for prosocial behavioral styles were created by summing kindergarteners scores on social conversation, cooperative play, and friendly touch whereas the composite scores for antisocial behavioral styles consisted of ratings of aggression, object possessiveness, and arguing. Student-teacher relationship quality was assessed by observer reports of the emotional tone of teacher-child interactions as rated on a 5-point Likert type scale ranging from very negative (mutually argumentative or 
negative toned talk or actions) to very positive (warm, nurturant, containing positive verbal and physical expressions). Study 2 used the same measures and procedures with a second sample of kindergarteners $(\mathrm{N}=199)$ and their teachers $(\mathrm{N}=17)$ to increase generalizability by replication. However, instead of utilizing an overall emotional tone measured of relationship quality, Study 2 used an observational measure of teacher-child closeness and teacher-child conflict.

Results of lagged regression analysis revealed that kindergarteners' behavioral styles in the classroom predicted the types of teacher relationships they formed above and beyond the contributions of gender, cognitive maturity, and preschool experience in both Study 1 and Study 2. Specifically, student antisocial behavioral styles were negatively related to teacher-child relationship quality in Study 1. Similarly, in Study 2, student antisocial behavioral styles were negatively related to teacher-child closeness, and significantly predicted teacher-child conflict. Student prosocial behavioral styles were not significantly related to measures of teacher-student relationship quality. However, they were significantly positively associated with peer relationship quality measures such as peer acceptance and number of mutual best friends. These findings support the overarching hypothesis of the present study, namely, that how students interact with their teachers in the classroom impacts how supportive and close their teachers are to them.

Taken together, while the studies summarized in this portion of the literature review do not all directly target engagement and disaffection per se, they do provide vital information about how students' emotions and actions impact the ways their teachers treat them. Whether comparing intrinsic versus extrinsic motivation, satisfaction versus dissatisfaction, prosocial versus antisocial behavioral style, high participation versus low 
participation, these studies encompass aspects of emotional and behavioral participation in the classroom as well as teacher support.

\section{Experimental Studies Examining the Effects of Child Characteristics on Adult}

\section{Reactions}

The following studies do not assess students and teachers but rather utilize experimental approaches to evaluating the impacts of child characteristics on adults. Beginning in the late 1960s, a movement towards considering children as active interaction partners capable of shaping the behavior of the adults in their lives spawned experimental research systematically assessing parents' reactions to children (Bell, 1968; Bell, 1977). While studies of children and parents may lack generalizability to studentteacher relationships, these studies can provide strong causal support for the Bell's model of parent-child bidirectionality and the idea that children are not simply sponges to absorb adult input but are also members of a dyadic system that helps produce their social contexts.

\section{Brunk \& Henggeler (1984)}

Brunk and Henggeler examined whether different experimentally manipulated child characteristics elicited differential provision of parental support. By using child confederates trained to display either anxious-withdrawan or conduct-disordered behavior, the authors were able to reliably assess how mothers differentially responded to the different child characteristics. The two confederates were 10-year-old boys of above average intelligence with similar physical appearances. The confederates were trained to act in a conduct-disorder role (aggressively noncompliant, rejects help) and an anxiouswithdrawn role (passively noncompliant, quiet, avoids interacting with adult) The 
children engaged in a training session that included memorizing written descriptions, viewing videotapes of both roles, and engaging in role-play exercises with each other and the experimenters. The participants were 32 mothers aged $25-48$ who were recruited from an undergraduate psychological class and a local women's center.

After being told which role to play, the confederate joined the participants who had been told that they needed to complete a game of checkers with the child. As the mothers and confederates interacted, researchers coded the mothers' responses in order to determine whether different child behaviors elicited differential use of 7 main parent behaviors: Discipline, Command, Ignore, Indirect Command, Reward, Helping, Question.

MANOVA's were performed on the frequency of mother's response behaviors as well as on each group of child-mother sequential behaviors, producing information about differences in overall behavior patterns as a function of condition as well as differences in parent reactions in response to specific child behaviors. Mothers in the conductdisordered condition had higher overall rates of ignoring, commands, and discipline than mothers in the anxious-withdrawn condition. Similarly, mothers interacting with an anxious-withdrawn child had higher overall rates of verbal helping and rewards compared to mothers interacting with the conduct-disordered child. Specifically, in the conduct disorder condition, adults responded to the confederate most often with discipline (17.4\%), commands (9.7\%), and ignoring (3.3\%) though they almost never responded to anxious-withdrawn confederates responses in any of these negative ways. In order to assess mother's responses to specific child behaviors, child responses were coded into Response, No Response, Negative Response, Compliance, and 
Noncompliance. No response from the child garnered more discipline from the conductdisorder condition (13\%) than the anxious condition (3\%). For the anxious group, No response was most often met with helping (24\%) compared to the conduct-disorder condition (6\%). A negative response was much more likely to evoke parental commands $(23 \%)$ and ignoring $(10 \%)$ in the conduct-disorder condition than in the anxiouswithdrawn condition. Child compliance was met with more rewards in the anxiouswithdrawn condition but more discipline in the conduct-disorder condition. As demonstrated by this study, controlling child behavior experimentally may help researchers gain a better understanding of reciprocal effects by examining how specific child behaviors evoke differential parental support.

\section{Jelsma (1982)}

Similar to Brunk and Henggeler, Jelsma utilized child confederates in order to systematically assess mothers' reactions to "easy" and "difficult" child behavior conditions. Forty four Mothers between the ages of 30-and 45-years-old were brought into a lab setting and asked to spend 10 minutes teaching anagrams to elementary school students. The child confederates were trained to show either less active and more responsive behaviors (attentive/easy) or highly active and less responsive behaviors (inattentive/difficult). The frequency and quality of mother's responses were coded into three categories, Controlling statements, Informational statements, and Positive feedback. Mothers' affect was also assessed by verbal and non-verbal language.

Results indicated that children's attentiveness affected mothers' verbal behavior, the quality of mother-child interactions, and mothers' provision of autonomy support. The mothers were more controlling, less supportive, and enjoyed interacting less with 
children in the highly active/less responsive condition. These findings bolster the hypothesis that child characteristics are powerful enough to shape parental reactions and potentially impact child-parent relationships.

\section{Anderson, Lytton, and Romney (1986)}

Another group of researchers interested in addressing how children elicit differential reactions from adult interaction partners studied mother's reactions to boys with and without conduct-disorders. The authors found that conduct-disordered boys were treated more negatively by a group of mothers regardless of whether the mothers had conduct-disordered sons or 'normal' sons.

In order to assess whether maladaptive interactions between mothers and conductdisordered boys were determined mainly by the mother or the son, the authors brought 32 mother-child dyads (16 with conduct-disorder, 16 without diagnosed behavior problems) into the lab to observe the quality of mother's interactions with both groups of children. Boys in the conduct-disorder group were 6-11-years-old and had been referred to mental health facilities and formally diagnosed. Boys without conduct disorders were matched for age and mother's education in order to minimize the effects of possible third variables. Mothers were observed for 15 minute sessions with their own child; a child of the opposite classification (CD vs. normal) of their own; and a child of the same classification of their own. During each session, mothers were instructed to spend 5 minutes on free play, to clean up after free play, and to spend 5 minutes on math problems with the child. Mother's responses were coded into three categories: Positive (acceptance/ approval), Negative (dislike/disapproval), and Requests (asking child to complete a task), although for the analyses of variance, Negative and Requests were 
combined. Volunteer nurses from the inpatient mental health unit coded the data. Nurses spent 4-5 hour being trained in person and with practice tapes until an interrater reliability of .80 was achieved on two checks.

The authors conducted a $2 \mathrm{X} 2$ repeated measures MANOVA to examine differences in mother's behavior towards conduct-disorder and 'normal' boys. The between-group factor was type of mother (i.e., mother of conduct-disorder child or mother of 'normal' child) and the within-subjects factor was conduct-disordered vs. 'normal' boys. The authors found that, while mothers of conduct-disordered boys and mothers of 'normal' boys did not differ significantly in the three response behaviors, mothers of both groups made significantly more negative responses to and asked significantly more requests of the conduct-disorered boys than the 'normal' boys, suggesting that it is the behavior of the child that elicits differential responses from the mothers. The authors also conducted an ANOVA on child compliance rates which revealed that the conduct-disordered boys complied less than normal boys regardless of type of mother, or the relationship of mother. This suggests that the conduct-disordered boys' behavior was not a manifestation of relational dynamics unique to a mother and her child but instead were consistent across adult interaction partners. This research suggests that regardless of whether mothers were interacting with their own child or another child, and regardless of whether the mothers had conduct-disordered sons themselves, boys displaying problem behaviors that negatively impacted mothers' reactions to them.

\section{Pelletier and Vallerand 1996}

Finally, an experimental study by Pelletier and Vallerand illustrates the impact of perceptions of subordinates' motivational orientation on supervisor's provision of 
autonomy support. Although this study utilizes graduate and high school students acting as supervisors and subordinates instead of students and teachers, it suggests that motivation orientation is so salient that just labeling people as intrinsically versus extrinsically motivated can affect how others treat them.

Participants were 30 male graduate supervisors in an MBA program and 30 male high school students. In the lab, graduate participants were told that they would serve as a supervisor and that they would be teaching a subordinate in how to solve a spatial relations puzzle for a period of 20 minutes. Supervisors were also given a packet of information purportedly filled out by the subordinate. In the intrinsic motivation condition, the information stated that "the answers to the questionnaire indicate that the participant (subordinate) enjoyed working on that type of task, he likes to do this type of experiment, he finds these puzzles interesting and challenging." In the extrinsic motivation condition, the supervisor was told that "the answers to the questionnaire indicate that the participant was not interested by that type of task, he thought the task was boring, and the only reason he was participating in the experiment was because $\$ 10$. 00 were given to all subjects." Supervisors in the control condition did not receive any information about the subordinate's motional orientation.

After the teaching exercise, the researchers collected ratings of the autonomy supportiveness of the supervisor's behavior from both the subordinates and the supervisors (survey measures) as well as from judges (blind to condition) who had observed the interaction from behind a one-way mirror. The authors conducted one-way ANOVAs with three conditions (intrinsic, extrinsic, control) to assess whether the mere suggestion of an individual's motivational orientation could affect the amount of 
autonomy support subordinates received. Supervisors who had been led to believe that they were interacting with an intrinsically motivated subordinate perceived themselves, and were perceived by the subordinates and the unbiased observers, as supporting autonomy much more than the supervisors who had been led to believe that they were interacting with an extrinsically motivated subordinate. These results carry important implications for how teachers may be affected by children's motivation in the classroom. If even unfounded suggestions relating to a "student's" motivation towards a teaching task can have a significant impact on the "teacher's" subsequent provision of autonomy support, then it seems reasonable that teachers' perceptions of students' motivation as well as students' actual motivation might be able to exert an impact on teachers' responses.

In sum, this literature review attempts to compensate for the lack of research on the reciprocal effects of student engagement and disaffection on changes in teacher support by delving into the educational and parenting literature to examine support for the underlying assumption that child characteristics have the power to impact the quantity and quality of support they receive from the adults close to them. Teachers treat their students differently based on a host of child characteristics and thus could potentially treat students differently based on students' motivation towards school. This study aims to build on Skinner and Belmont's findings that highly engaged students receive more support than their highly disaffected peers (1993), by expanding the research base directly examining whether student academic motivation shapes changes in teacher support over time. Support for the existence of reciprocal effects of students on teachers can be found from studies examining similar constructs. By reviewing research on 
constructs that align with engagement such as satisfaction with school and being intrinsically motivated, and constructs that align with disaffection such as exhibiting challenging behavior, being "difficult to get along with", having antisocial behavioral styles, or having conduct-disorders, we can generate hypotheses about how teachers might provide differing levels of support to students exhibiting differing patterns of engagement and disaffection in the classroom. 


\section{Chapter 3}

\section{Purpose of the Current Study}

The purpose of the present study was to examine the reciprocal effects of student engagement and disaffection on changes in teacher support from fall to spring. This study was designed to circumvent two of the major limitations in the field, namely, the inconclusiveness of findings drawn from one-time point correlational studies and the lack of generalizability that results from relying solely on Caucasian, middle-class participants. The current study assessed a diverse urban population at two time points, one in fall and one in spring of the same school year, and thus was capable of investigating whether a student's level of engagement and disaffection at the beginning of the year predicted increases or decreases in teachers' provision of motivational support across the school year. By conducting this study in a middle school that serves a large proportion of low SES, racial/ethnic minority students, we gained information about the population most susceptible to states of low engagement and underachievement as well as expanded the generalizability of reciprocal effects findings. This study utilized these design improvements in order to better understand how student engagement and disaffection affected the quality and amount of support students received from their teachers across the school year.

\section{Profiles of Engagement and Disaffection}

The literature has established two general profiles to categorize a student's level of academic motivation. An 'engaged student' is a student who scores high on measures of engagement and low on scales of disaffection. These students should be more likely to gain teacher support over the course of the school year. 'Disaffected students' are 
students who score high in disaffection and low in engagement. These students should be more likely to lose teacher support from fall to spring (Skinner \& Belmont, 1993; Furrer, Skinner, \& Kindermann, 2009). While engagement and disaffection are negatively correlated, they are structurally distinguishable and thus it should be possible to conceptualize student engagement and disaffection profiles or combinations that deviate from this traditional recipe (Skinner, Kinderman, \& Furrer, 2009).

During pilot observations for the present study, coding of engagement data revealed that some students who displayed very high levels of engagement also showed high levels of disaffection. This type of student was engaged in learning activities but also highly engaged with their peers; they were reprimanded often for off-task, disruptive behavior but were also able to reengage easily to have high overall participation during the lesson. These students' attention appeared to be almost simultaneously divided between listening to the teacher's lesson, covertly interacting with their friends (e.g., talking, kicking each other under the table) and other activities (e.g., swinging around in a chair, drawing on oneself). This type of student could be conceptualized as the "charming trouble-maker". These students appeared to garner more support from their teachers than traditionally defined disaffected students who displayed high disaffection but low engagement.

Another subset of students was identified that did not fit either the traditional definition of an engaged student or that of a disaffected student. These students were both low in engagement and low in disaffection. They were not following along with the lesson (e.g., not looking at the teacher, not following directions) but neither were they talking to their friends. They followed classroom etiquette enough not to attract teachers' 
negative attention but they did not participate enough to attract teachers' positive attention. These unfortunately named "invisible students" are likely to experience little change in teacher support, as they appear to attract little individualized attention of any sort from teachers in the first place.

The idea that a student can be high or low on both engagement and disaffection is a recent but interesting direction for motivational research to investigate. Although researchers have examined engagement and disaffection as a bipolar variable in the past, advances in our knowledge of these constructs suggest that the components of motivation can also be viewed as distinct variables (Skinner, Kindermann, \& Furer, 2009), Continuing to score ratings of engagement and disaffection as bipolar (by reverse coding disaffection items and combining them with engagement items) may obscure our understanding of students who fall in the middle of this continuum. If the constructs are viewed as bipolar, a score composed of extremes would be masking as a median score as large scores of opposite signs effectively cancel each other out. The same situation would occur if a student scored low on both engagement and disaffection as that student's overall score would fall in the middle of the engagement/disaffection continuum. These two hypothetical students (high on both components versus low on both components) would not be experiencing the same motivational state; however, their combined engagement and disaffection scores would suggest that they were indistinguishable from one another.

By viewing engagement and disaffection as bipolar, researchers may lose vital information about how the constructs function and reflect children's differential experiences in the classroom. Perhaps there are even more nuanced associations such that 
students high in both engagement and disaffection may be more likely to be disruptive, resistant, and feel frustrated as opposed to students who are low in both engagement and disaffection might be passive and apathetic. Engagement and disaffection, as behavioral states that are shaped by hundreds of interactions between the developing child and her social context, are captured and lost from moment to moment. A student high on both engagement and disaffection may be capturing and losing engagement all day long while students low in both constructs may never capture or loose engagement. Thus, in order to tease apart how students who have similar average bipolar scores but different individual scores may have differing experiences of motivation in the classroom, this study viewed engagement and disaffection separately. Additionally, because engagement and disaffection are not stable personality traits but fluctuating states, reports of engagement and disaffection that reflect these intricate patterns would be more likely to be multidimensional than unidimensional.

\section{Multiple Perspectives on Engagement and Disaffection}

The current study, which utilized both student- and teacher-reports of engagement and disaffection, enabled a consideration of student motivation from multiple perspectives. The use of multiple reporters permitted this study to provide additional insight into how perceptions of motivation may differ depending on whether the reporter is experiencing or simply observing student engagement and disaffection. For example, a study by Skinner, Kindermann, and Furer (2009), focusing on the psychometric properties of measures of engagement and disaffection, revealed that students and their teachers show a modest degree of convergence (average $r=.30$ ) in their ratings of student engagement and disaffection. The fact that these ratings were not more strongly 
correlated across reporters highlights the power of perspective in influencing subjective experience and subsequent responses to questionnaire items. Many factors may influence differences between teachers and students as reporters: Teachers are older, more experienced in viewing (and potentially norming) student engagement, may be influenced by levels of student performance and other student characteristics, and have access only to observable student behavior, whereas students are younger, more focused on their own individual experience, likely to be influenced by how hard they are trying to remain engaged (whether they succeed or not), and have access to their own emotional engagement and disaffection.

In fact, previous research suggests that there may be systematic differences between student and teacher reports. Skinner, Kindermann, and Furrer (2009), upon separating engagement into behavioral and emotional components, found that students believed they were more behaviorally engaged than their teachers observed them to be, perhaps reflecting a positive self bias. Similarly, students reported being more emotionally disaffected than their teachers believed them to be which suggests that students may be masking their disaffection possibly to avoid negative attention from their teachers.

Consequently, the research questions in this study were tested using first studentand then teacher-reports of engagement and disaffection in order to explore any differences due to reporter. Findings replicated using teacher-reports of student engagement and disaffection will serve as an important replication of the effects of student motivation on changes in teacher behavior. 


\section{Nature of Reciprocal Effects: Amplifying versus Compensatory}

Unlike the vast majority of research investigating engagement, disaffection, and teacher support, which examined teachers' impacts on students, this study explored the possible reciprocal or feedback effects of students' motivation on teachers' provision of support. Because of the dearth of research investigating these reciprocal effects, it is important to consider the possible nature of these feedback effects from students to teachers. Prior research suggests that the relationship between teachers' provision of motivational support and student engagement is a positive, amplifying relationship such that more teacher support leads to more student engagement and less teacher support leads to disaffection (Skinner \& Belmont, 1993). The reciprocal effects found in the current study may follow this self-perpetuating pattern such that highly engaged students may garner more teacher motivational support, which will in turn increase their engagement. Unfortunately for highly disaffected students, if this positive relationship holds true, then students who are disaffected will loose teacher support and consequently become more disaffected over time. Findings from the current study may suggest that the nature of the reciprocal effects of student motivation on teacher's provision of support will not be amplifying but rather compensatory. Perhaps, upon seeing student disaffection in the classroom, teachers may respond by providing students with increasing amounts of motivational support thereby compensating for low student motivation. As previous research suggests that teacher motivational support can increase student motivation, reciprocal effects that are compensatory in nature would be more likely to result in improvements in student motivation for the children who need it most. Unfortunately, as stated earlier, the one published study on reciprocal effects suggests that they are 
positive, with the motivationally rich getting richer and the poor getting poorer (Skinner $\&$ Belmont, 1993). However, in that study, engagement and disaffection were treated as a bipolar construct, while in the current study, the constructs were considered independently.

\section{Research Questions and Hypotheses}

These observational inquiries, as well as a desire to build upon the findings of Skinner and Belmont (1993), guided the research questions of the present study. By utilizing a two time-point research design with participants representing a diverse, urban at-risk population, the present study attempted to further our understanding of reciprocal effects. The current study addressed the following research questions, which were divided into five sets. The first set focused on assessing the main effects of engagement and disaffection on changes in teacher motivational support. The second set of questions examined whether there were any grade or gender differences in these relationships within each time point (fall and spring) as well as across time. The third set assessed the unique effects of engagement and disaffection on teacher support within each time point and on changes in teacher support across time. The fourth set of questions explored whether there was a significant interaction between engagement and disaffection as predictors of teacher support with time and changes in teacher support across time. The final research question attempted to replicate the preceding research questions using teacher-reports of student engagement and disaffection as opposed to students' self-report measures.

Research Question 1. Do student engagement and disaffection predict changes in teacher support from fall to spring, controlling for teacher support in the fall? 
H1a) Student engagement will predict increases in teacher support from fall to spring.

H1b) Student disaffection will predict decreases in teacher support from fall to spring.

Research Question 2a1. Are there gender differences in the relationships between student engagement and disaffection and teacher support within each time point? Research Question 2a2. Are there gender differences in the relationships between student engagement and disaffection and changes in teacher support from fall to spring? Research Question 2b1: Are there grade differences in the relationships between student engagement and disaffection and teacher support within each time point?

Research Question 2b2: Are there grade differences in the relationships between student engagement and disaffection and changes in teacher support from fall to spring?

Research Question 3a. Does each component of motivation (engagement and disaffection) have an effect on teacher support above and beyond the effect of the other component?

H3a1) Student engagement will predict teacher support, over and above disaffection within each time point (fall and spring). H3a2) Student disaffection will predict teacher support, over and above engagement, within each time point (fall and spring).

Research Question 3b. Does each component of motivation (engagement and disaffection) have an effect on changes in teacher support from fall to spring above and beyond the effect of the other component?

H3b1) Student engagement in fall will predict changes in teacher support from 
fall to spring, over and above disaffection.

H3b2) Student disaffection in fall will predict changes in teacher support from fall to spring, over and above engagement.

Research Question 4a. Do the effects of one component of motivation on teacher support depend on the level of the other component within each time point (fall and spring)?

H4a1) The relationship between engagement and teacher support will be stronger for students who are low in disaffection, suggesting low disaffection boosts the positive effects of engagement.

H4a2) The relationship between disaffection and teacher support in fall and in spring will be weaker for students who are high in engagement, suggesting high engagement buffers the negative effects of disaffection.

Research Question 4b. Do the effects of one component of motivation on changes in teacher support from fall to spring depend on the level of the other component?

H4b1) The relationship between engagement and changes in teacher support will be stronger for students who are low in disaffection, suggesting low disaffection boosts the positive effects of engagement.

H4b2) The relationship between disaffection and changes in teacher support will be weaker for students who are high in engagement, suggesting high engagement buffers the negative effects of disaffection.

Research Question 5. Do these connections hold for student engagement and disaffection as reported by teachers?

Research Question 5a. Do student engagement and disaffection (as reported by teachers) predict changes in teacher support (as reported by students) from fall to spring, 
controlling for teacher support in the fall?

H5a) Student engagement (TR) will predict increases in teacher support (SR) from fall to spring.

H5b) Student disaffection (TR) will predict decreases in teacher support (SR) from fall to spring.

Research Question 5b1a. Are there gender differences in the relationships between student engagement and disaffection (TR) and teacher support (SR) within each time point?

Research Question $\mathbf{5 b 1 b}$. Are there gender differences in the relationships between student engagement and disaffection (TR) and changes in teacher support (SR) from fall to spring?

Research Question $\mathbf{5 b 2 a}$. Are there grade differences in the relationship between student engagement and disaffection (TR) and teacher support (SR) within each time point? Research Question $\mathbf{5 b} \mathbf{2 b}$. Are there grade differences in the relationships between student engagement and disaffection (TR) and changes in teacher support (SR) from fall to spring?

Research Question 5c1. Does each component of motivation (engagement and disaffection) as reported by teachers, have an effect on teacher support (SR) above and beyond the effect of the other component?

H5c1a) Student engagement (TR) will predict teacher support (SR), over and above disaffection within each time point (fall and spring).

H5c1b) Student disaffection (TR) will predict teacher support (SR), over and 
above engagement within each time point (fall and spring).

Research Question 5c2. Does each component of motivation (engagement and disaffection) as reported by teachers, have an effect on changes in teacher support (SR) above and beyond the effect of the other component?

H5c2a) Student engagement (TR) in fall will predict changes in teacher support (SR) from fall to spring, over and above disaffection.

H5c2b) Student disaffection (TR) in fall will predict changes in teacher support (SR) from fall to spring, over and above engagement.

Research Question 5d1. Do the effects of one component of motivation (TR) on teacher support (SR) depend on the level of the other component within each time point (fall and spring)?

H5d1a) The relationship between engagement (TR) and teacher support (SR) (in fall and in spring) will be stronger for students who are low in disaffection, suggesting low disaffection boost the positive effects of engagement.

H5d1b) The relationship between disaffection (TR) and teacher support (SR) (in fall and in spring) will be weaker for students who are high in engagement, suggesting high engagement buffers the negative effects of disaffection.

Research Question 5d2. Do the effects of one component of motivation (TR) on changes in teacher support (SR) from fall to spring depend on the level of the other component? H5d2a) The relationship between engagement (TR) and changes in teacher support (SR) will be stronger for students who are low in disaffection, suggesting low disaffection boost the positive effects of engagement.

H5d2b) The relationship between disaffection (TR) and changes in teacher 
support (SR) will be weaker for students who are high in engagement, suggesting high engagement buffers the negative effects of disaffection. 


\section{Chapter 4}

\section{Research Design and Methods}

Data for the current study were gathered as part of a larger five-year longitudinal study of middle school students in an urban area of the Pacific Northwest. Students were asked to complete surveys about their attitudes towards school, learning, their teachers, and their peers. The data were collected in-person by trained research assistants twice a year in Fall (October) and in Spring (May) for five consecutive years from 2007-2012. The current study utilized data from the two measurement points collected in year two (measurement points 3 and 4).

\section{Participants}

Participants for this study were a sample of 372 middle school students $\left(6^{\text {th }}-8^{\text {th }}\right.$ graders) ranging in age from 11-14 years old. The students were approximately evenly divided by gender (male $n=199$; female $n=224$ ). The middle school served a racially and ethnically diverse urban population, with 18\% Asian, 24\% Hispanic, 9\% African American, and $42 \%$ Caucasian students (with a large population of Russian immigrants). Over $20 \%$ of the students were English Language Learners and approximately $85 \%$ of the students qualified for free or reduced-price breakfast and lunch (www.pps.k12.or.us). Twenty-one teachers also participated in the study by completing questionnaires about each of the students' attitudes and efforts towards learning activities in the classroom.

\section{Design and Procedure}

Due to the sample population's status as minors, informed consent was obtained via permission slips passed out to all students to take home to their parents. The 
permission slips requested students' voluntary participation in completing two surveys. Active consent procedures were employed, such that parents who wanted their children to participate needed to return the consent form indicating their choice. The students were also reminded during the administration of the surveys that their participation was voluntary, they did not have to answer any questions that made them uncomfortable, and their responses were anonymous and had no bearing on their grades or school records.

Trained graduate student interviewers proctored the surveys in students' homeroom and science classrooms at the beginning and end of each school year. The interviewers introduced the survey, read the instructions out loud, and completed selected examples with the class before distributing the surveys to individual students.

Interviewers spent the rest of the 50-minute session answering students' questions and supporting students' progress through the survey. Students without parental consent to participate were assigned a different activity to complete during the class period. At the end of the survey session, students were reminded again of the anonymity of their responses and the importance of their voluntary contribution to "help us learn about your experiences in school so we can make it better". Teacher questionnaires assessing student engagement and disaffection were administered to each student's science teacher at the beginning of every datum collection. Teachers were compensated $\$ 1.00$ (in the form of gift cards) per student survey they completed.

\section{Measures}

From the expansive survey of the larger study, the current study utilized items tapping student- and teacher-reports of student engagement and disaffection as well as student-reports of teacher motivational support. All survey items were presented in a 5 
point Likert-scale format such that after each statement, the student/teacher was asked to choose whether she felt the statement was 'not at all true', 'a little bit true', 'somewhat true', 'fairly true', or 'totally true'. All individual items within a construct were averaged in order to obtain composite scores for each construct. Negatively worded items were reverse-coded, and the scores were averaged such that each composite scale score could range from 1 to 5, with higher scores indicating more of that construct. All items are included in Appendix B.

\section{Student Report of Engagement and Disaffection}

Engagement (student report). Engagement was measured with 5 items tapping student effort, enjoyment, and resilience in the face of challenges. Example items include "I enjoy learning new things in school" and "I try hard to do well in school". $(\alpha=.71)$.

Disaffection (student report). Disaffection was assessed with 7 items examining students' lack of motivation, negative emotions towards schooling, and low estimations of the value of and subsequent withdrawal from learning activities. Example items include "I can't stand schoolwork" and "In school, I don't work very hard". $(\alpha=.73)$. Teacher Report of Student Engagement and Disaffection

Student engagement (teacher report). Teachers completed a 7-item scale tapping student engagement in the classroom. Example items include "In my class, this student actively participates" and "In general, this student likes school". $(\alpha=.93)$.

Student disaffection (teacher report). Student disaffection was assessed with an 5item teacher-report scale. Example items include, "In my class, this student can be disruptive" and "In general, this student acts like school doesn't matter". $(\alpha=.76)$. $\underline{\text { Student Report of Teacher Support }}$ 
Teacher support (student report). The construct of teacher support was composed of 7-items assessing the amount of structure, involvement, and autonomy support teachers provided their students. Example items include "My teacher explains why the things I learn in school are important" and "My teacher doesn't understand me" (reverse coded). $(\alpha=.70)$.

Power analysis. A priori power analysis was conducted in order to ensure the sample size for the present study would be capable of detecting the proposed unique and interaction effects. A power of .80 and a moderate effect size, .03 , were used. The resulting sample size needed to detect an effect was $\mathrm{N}=320$, which was well below the current study $\mathrm{N}=423$. 


\section{Chapter 5}

\section{Results}

The goal of this study was to examine whether student motivation (i.e., engagement and disaffection) predicted changes in teachers' provision of motivational support over time. An initial discussion of missing data estimation, preliminary data cleaning, and examination of measurement properties is followed by analyses addressing each of the research questions.

\section{Initial Analyses}

Missingness report. Missing data were examined using SPSS version 21.

Missing values were evaluated using both variable-wise and case-wise analyses to determine whether the data fulfilled requirements to be considered missing at random (MAR), missing completely at random (MCAR), or not missing at random (NMAR). For this study, at each time point, each of the student participants in this study had the opportunity to respond to 19 items and teachers completed 12 items about each student. The items were a subset of the total items available from the larger LEAG study. A casewise analysis demonstrated that almost 94\% of individual participants (395 out of 423) had at least one missing value on a variable. A variable-wise analysis showed that 61 out of the 62 analysis variables had at least one missing value on a case. Seventy-seven students had data only at one time point, either student-reported or teacher-reported. Three hundred and ninety-five students had at least some data for the fall measurement point, and three hundred and seventy-two students had at least some data for the spring measurement point.

Further analysis of the missing values did not reveal any distinct patterns, and 
thus it was determined that the data were missing at least at random. The data were imputed five times using multiple imputation. All grades and time points were imputed together. The imputations were completed using the Missing Values module for SPSS 21. All further analyses were completed using the imputed dataset.

\section{Descriptive Analyses}

Initial descriptive statistics were evaluated for each variable included in the study. The means, standard deviations, and internal consistencies for each scale at each time point are presented in Table 5.1.

Examination of these values revealed that all scales demonstrated adequate internal consistency (i.e., $\alpha>.70$ ), which was assessed by Cronbach's alpha. It is unsurprising that teacher support displayed the lowest internal consistency $(\alpha=.70)$, as this scale measures three distinguishable subcomponents of motivational support, namely, warmth, structure, and autonomy support. Deleting items would not increase any of the scales' reliabilities.

The mean levels of student engagement, disaffection, and teacher support were examined to better understand the overall functioning of the sample. Mean levels of student engagement were high in fall and spring for both student-reports $(\mathrm{Ms}=3.7$ and 3.6, in fall and spring respectively) and teacher-reports $(\mathrm{Ms}=3.8$ and 3.7, in fall and spring respectively) and appear very similar across reporters. As expected given previous findings, both sources reported losses in engagement over the school year. Students and teachers reported relatively low disaffection at both time points $(\mathrm{Ms}=1.93$ and 2.05 for student-reports; Ms=1.65 and 2.07 for teacher-reports). Both reporters perceived an increase in disaffection from fall to spring, with teachers reporting a steeper increase than 


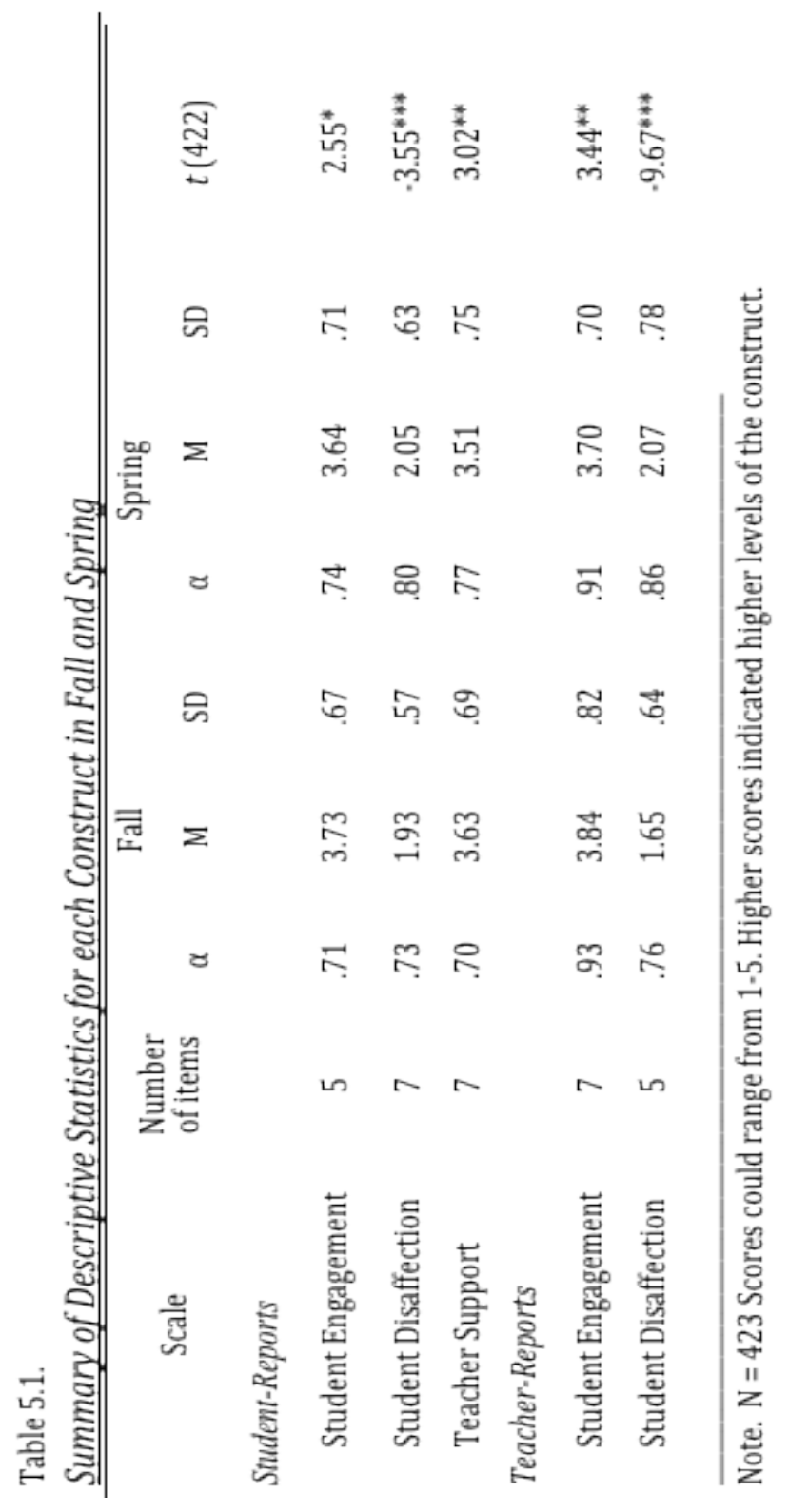


students. In comparing students' and teachers' reports of disaffection, it appears that teachers perhaps underestimated students' disaffection in fall when compared to students' reports, however by spring, teachers' ratings of disaffection were almost identical to students' ratings. Examination of the range statistics for each scale revealed that one scale had a restricted range, as no student endorsed the highest response option (5.0) for the disaffection scale in fall. All scales had moderate standard deviations, ranging from .57 .82 , which suggests somewhat limited variability in responses between subjects, potentially limiting the power to detect significant effects. However, no floor or ceiling effects were detected, as would be indicated by the minimum or maximum scale scores falling within one standard deviation of the scale mean.

Univariate outliers and non-normality. The data were also examined for outliers, non-normality, and nonlinear relationships among the study variables. In order to assess potential distributional non-normality, Skewness and Kurtosis statistics were assessed for each variable, and corresponding $p$ values were calculated. The distributions of 11 study variables significantly departed from normality $p>.05$. The disaffection scales for both time points reported by both students and teachers were significantly positively skewed, suggesting an encouraging finding that students appeared to be less likely to be highly disaffected. Disaffection in the fall and spring for student- and teacherreports, as well as teachers' reports of engagement in the spring were significantly platykurtic, suggesting a flatter distribution for these variables. Finally, teacher support in the fall and spring displayed significant negative kurtosis, though not skew, suggesting that students' ratings of their teachers' provision of support tended to fall near the median, with fewer values at either extreme. 
Construct correlations within reporter and time. Correlations among all

student engagement and disaffection subscales, teacher support subscales, and their crosstime stabilities are presented in Table 5.2. Correlations between the two components of motivation within time for student-reports were strong $(r=-.61$ and $r=-.64$, respectively in fall and spring) and negatively correlated as was expected. Student-reports of engagement correlated strongly with student-reports of teacher support within both time points averaging $r=.52$. Similarly, student-reports of disaffection and student-reports of teacher support correlated comparably in magnitude (though opposite in sign) at both time points averaging $r=-.55$. The correlation between engagement and disaffection for teacher-reports was stronger than that found for student-reports with correlations for fall $r$ $=-.76$ and spring $\mathrm{r}=-.80$. Because correlations between engagement and disaffection were high within reporters at both time points, the impact of multi-collinearity must be considered when interpreting the results.

Construct correlations across time. The cross-time stabilities for each construct were moderately high, ranging from $.26-.48$. The highest cross-time stability was found for students' reports of their engagement and the lowest stability was for found teachers' reports of student disaffection. This makes sense when considering the smallest change in mean levels over time was found for student-reports of engagement and the largest change in mean levels over time was found for teachers-reports of student disaffection.

Construct correlations across reporter. Correlations between student- and teacher-reported engagement were moderate, averaging .23. Student- and teacher- ratings of student disaffection were also moderately correlated, averaging .22. This was expected and aligns with previous findings that highlight the power of perspective in influencing 
the ratings of these motivational states. Across reporters and constructs, the correlations between motivational constructs were unsurprisingly less strong, ranging from -.12 to 32. Consistent with a positive within reporter bias, teacher support, which was a studentreport measure, more strongly correlated with student-reports of engagement and disaffection (ranging .51 - .58) than to teachers-reports (ranging .18 - .24).

Table 5.2.

Intercorrelations Among Study Constructs in Fall and Spring

\begin{tabular}{|c|c|c|c|c|c|}
\hline & $\begin{array}{c}\text { Student } \\
\text { Engagement } \\
(\mathrm{SR})\end{array}$ & $\begin{array}{c}\text { Student } \\
\text { Disaffection } \\
(\mathrm{SR})\end{array}$ & $\begin{array}{c}\text { Teacher } \\
\text { Support } \\
(\mathrm{SR})\end{array}$ & $\begin{array}{c}\text { Student } \\
\text { Engagement } \\
(\mathrm{TR})\end{array}$ & $\begin{array}{c}\text { Student } \\
\text { Disaffection } \\
(\mathrm{TR})\end{array}$ \\
\hline \multicolumn{6}{|l|}{ Student-Report (SR) } \\
\hline $\begin{array}{l}\text { Student } \\
\text { Engagement (SR) }\end{array}$ & $.44 * *$ & $-.61 * *$ & $.53 * *$ & $.23 * *$ & $-.12 *$ \\
\hline $\begin{array}{l}\text { Student } \\
\text { Disaffection (SR) }\end{array}$ & $-.64 * *$ & $.39 * *$ & $-.50 * *$ & $-.29 * *$ & $.18 * *$ \\
\hline $\begin{array}{l}\text { Teacher Support } \\
\text { (SR) }\end{array}$ & $.51 * *$ & $-.59 * *$ & $.39 * *$ & $.22 * *$ & $-.19 * *$ \\
\hline \multicolumn{6}{|l|}{ Teacher-Report (TR) } \\
\hline $\begin{array}{l}\text { Student } \\
\text { Engagement (TR) }\end{array}$ & $.23 * *$ & $-.32 * *$ & $.24 * *$ & $.40 \% *$ & $-.76 * *$ \\
\hline $\begin{array}{l}\text { Student } \\
\text { Disaffection (TR) }\end{array}$ & $-.17 * *$ & $.26 * *$ & $-.18 * *$ & $-.80 * *$ & $.22 * *$ \\
\hline
\end{tabular}

$\mathrm{N}=423$. Correlations for fall are above the diagonal. Correlations for spring are below the diagonal. Crosstime stabilities are reported in bold on the diagonal. $\mathrm{TR}=$ Teacher-report. $\mathrm{SR}=$ Student-report.

$* p<.05 * * p<.01 * * * p<.001$ 


\section{Research Questions}

Research Question 1. Do student engagement and disaffection predict changes in teacher support from fall to spring, controlling for teacher support in the fall?

H1a) Student engagement will predict increases in teacher support from fall to spring.

The first research question examined whether students' motivation in the classroom had an impact on the way their teachers treated them over the school year. Hypothesis la was tested using linear multiple regression analyses. Specifically, teacher support in spring was regressed on student engagement in the fall, controlling for teacher support in the fall. As can be seen in Figure 5.1, this relationship was positive and significant $(ß=.14, \mathrm{t}(420)=2.71, p<.01)$, with engagement in fall accounting for $16 \%$ of the variance in the change in teacher support from fall to spring.

Figure 5.1. Relationship Between Student Engagement (SR) and Teacher Support Over Time.

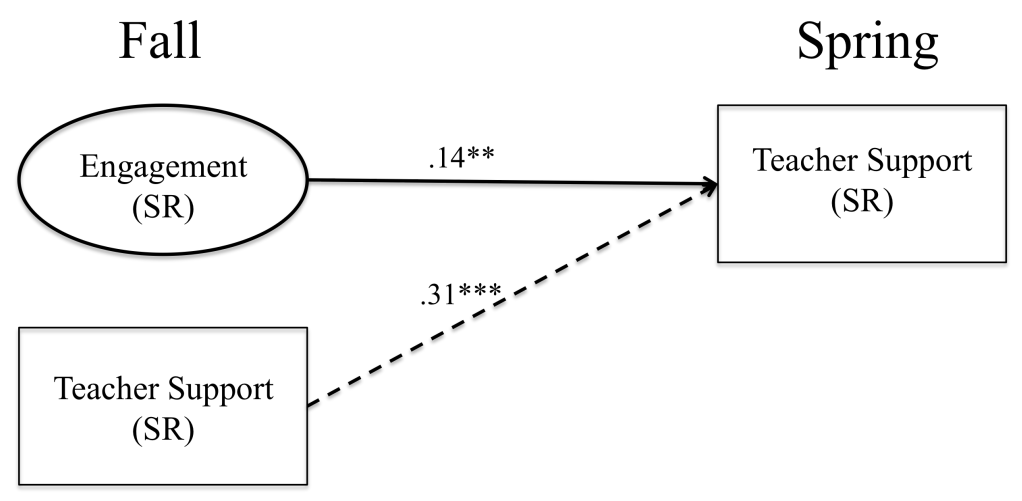

Note. ${ }^{*} p<.05 . * * p<.01 . * * * p<.001$

H1b) Student disaffection will predict decreases in teacher support from fall to spring. 
Teacher support in spring was regressed on student disaffection in the fall, controlling for teacher support in the fall. This relationship was negative and significant $(ß=-.21, \mathrm{t}(420)=-4.19, p<.001)$, with disaffection in fall accounting for $18 \%$ of the variance in the change in teacher support from fall to spring (see Figure 5.2).

Figure 5.2. Relationship Between Student Disaffection (SR) and Teacher Support Over Time.



Note. ${ }^{*} p<.05 . * * p<.01 . * * * p<.001$

Research Question 2a1. Are there gender differences in the relationships between student engagement and disaffection and teacher support within each time point?

Gender. The sample used in this study was approximately equally divided among male $(n=199)$ and female participants $(n=224)$. Independent-measures t-tests were used to examine whether levels of student engagement and disaffection (SR) and teacher support (SR) differed significantly for boys and girls. The results can be found in Table 5.3 . 
Table 5.3

Mean Level Differences by Gender (Student Engagement and Student Disaffection)

\begin{tabular}{|c|c|c|c|c|c|c|}
\hline & \multicolumn{2}{|c|}{ Fall } & \multirow[b]{2}{*}{$t$} & \multicolumn{2}{|c|}{ Spring } & \multirow[b]{2}{*}{$t$} \\
\hline & $\begin{array}{c}\text { Girls } \\
M \\
(S D) \\
\end{array}$ & $\begin{array}{c}\text { Boys } \\
M \\
(S D) \\
\end{array}$ & & $\begin{array}{c}\text { Girls } \\
M \\
(S D) \\
\end{array}$ & $\begin{array}{c}\text { Boys } \\
M \\
\text { (SD) }\end{array}$ & \\
\hline Student Engagement (Student-Report) & $\begin{array}{l}3.82 \\
(.65)\end{array}$ & $\begin{array}{l}3.63 \\
(.69)\end{array}$ & $-2.92 * *$ & $\begin{array}{l}3.69 \\
(.70)\end{array}$ & $\begin{array}{l}3.59 \\
(.72)\end{array}$ & $-1.48^{\mathrm{ns}}$ \\
\hline Student Disaffection (Student-Report) & $\begin{array}{l}1.85 \\
(.53)\end{array}$ & $\begin{array}{l}2.02 \\
(.59)\end{array}$ & $3.06^{* *}$ & $\begin{array}{l}1.95 \\
(.56)\end{array}$ & $\begin{array}{l}2.16 \\
(.68)\end{array}$ & $\begin{array}{c}3.57 * * \\
*\end{array}$ \\
\hline Teacher Support (Student-Report) & $\begin{array}{l}3.70 \\
(.65)\end{array}$ & $\begin{array}{l}3.55 \\
(.71)\end{array}$ & $-2.32 *$ & $\begin{array}{l}3.55 \\
(.73)\end{array}$ & $\begin{array}{l}3.46 \\
(.76)\end{array}$ & $-1.23^{\mathrm{ns}}$ \\
\hline
\end{tabular}

Note. $N=423 .{ }^{*} p<.05 .{ }^{* *} p<.01 .{ }^{* * *} p<.001$.

These results were consistent with previous research that suggests girls tend to be more motivated than boys in school (Furrer, Skinner, \& Kindermann, 2008). Girls reported significantly more engagement in the fall than boys, although the gender difference was not significant in the spring. Boys reported significantly more disaffection at both time points than girls. Finally, girls reported that they received significantly more motivational support from their teachers than did boys in fall but not in spring.

Additional, linear multiple regression analyses were conducted to test whether engagement and disaffection were more important predictors of teacher support for boys than for girls at each time point (fall and spring). Engagement, disaffection, and gender were grand mean centered. For each time point, teacher support (SR) was regressed on student engagement (SR), gender, and the interaction between student engagement and gender (created by calculating the cross-product of engagement and gender). Similarly, for each time point, teacher support was regressed on student disaffection (SR), gender, and the interaction between student disaffection and gender (created by calculating the cross-product of engagement and gender). Predictions for research question $2 \mathrm{a}$ were not supported; no significant interaction effects were found at either time point for 
engagement or disaffection (see Figures 5.3-5.6). The association between each component of student motivation and teacher support did not depend on students' gender within time.

Figure 5.3. Interaction Between Engagement and Gender on Teacher Support in Fall.

Fall

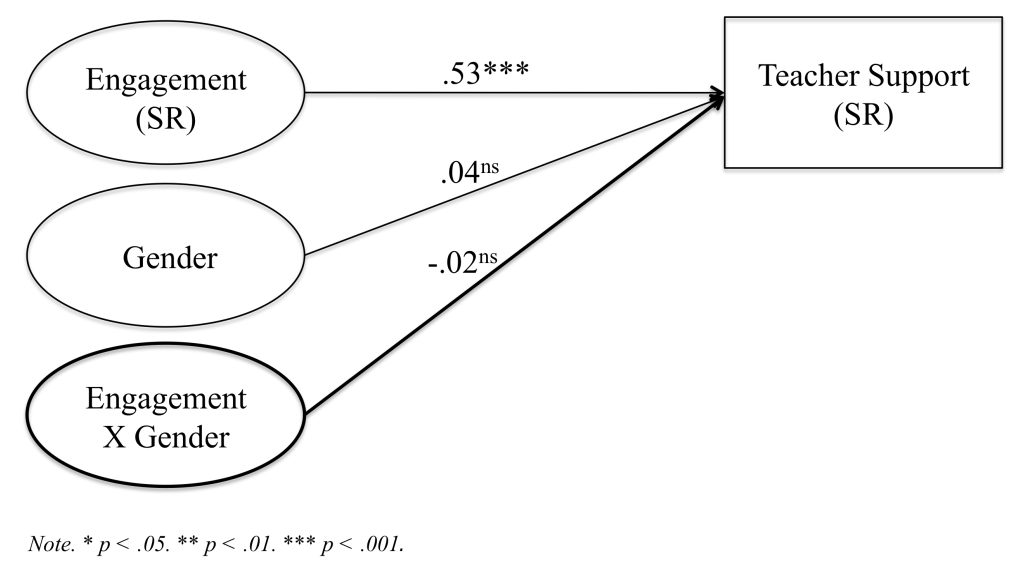

Figure 5.4. Interaction Between Engagement and Gender on Teacher Support in Spring. Spring Spring




Figure 5.5. Interaction Between Disaffection and Gender on Teacher Support in Fall.



Figure 5.6. Interaction Between Disaffection and Gender on Teacher Support in Spring. Spring Spring

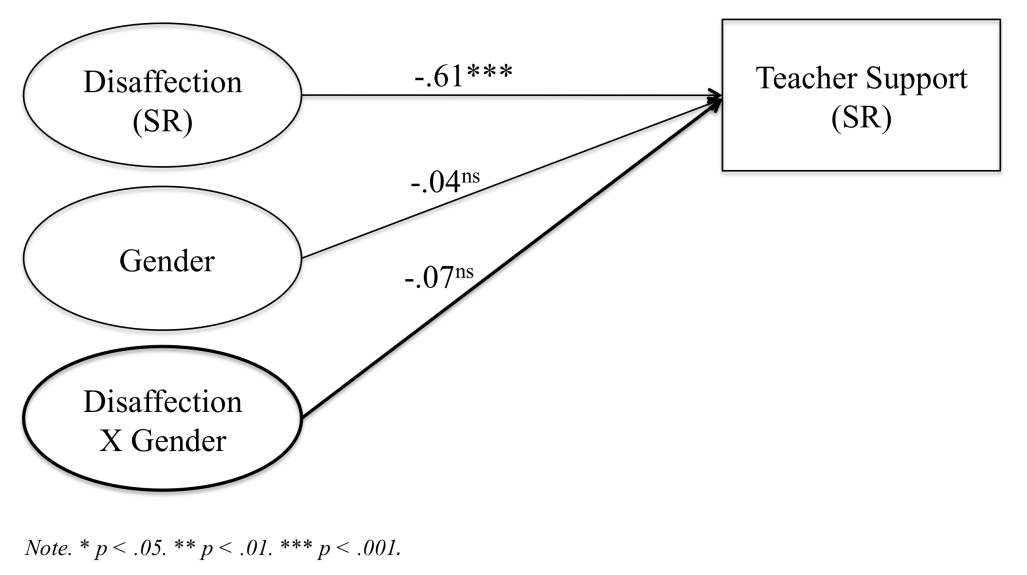

Research Question 2a2. Are there gender differences in the relationships between student engagement and disaffection and changes in teacher support from fall to spring? Although there were no significant gender interactions for engagement or disaffection within each time point, linear multiple regression analyses were conducted to test whether engagement and disaffection were more important predictors of teacher support for boys than for girls across time. Teacher support (SR) in spring was regressed on student engagement (SR) in fall, gender, and the interaction between student 
engagement in fall and gender (created by calculating the cross-product of engagement and gender), controlling for teacher support in the fall. Additionally, teacher support in spring was regressed on student disaffection (SR) in fall, gender, and the interaction between student disaffection in fall and gender (created by calculating the cross-product of engagement and gender), controlling for teacher support in the fall. Results suggested that the association between engagement and changes in teacher support from fall to spring did not depend on gender. However, there was a significant interaction effect between disaffection and gender such that the negative relationship between disaffection and changes in teacher support was stronger for boys $(r=-.47, \mathrm{p}<.001)$, than for girls $(r$ $=-.23, \mathrm{p}<.01)($ see Figures 5.7 and 5.8). This suggests that disaffected boys lost more teacher support over time than did disaffected girls (see Figure 5.9).

Figure 5.7. Interaction Between Engagement and Gender on Teacher Support Over Time.

\section{Fall}

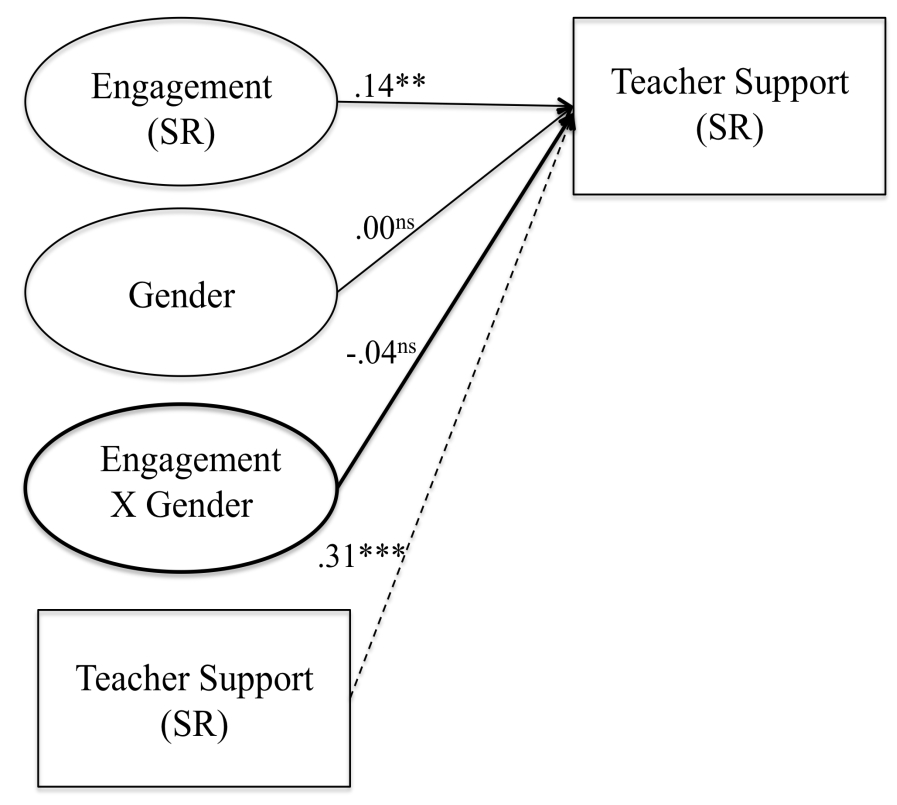


Figure 5.8. Interaction Between Disaffection and Gender on Teacher Support Over Time.

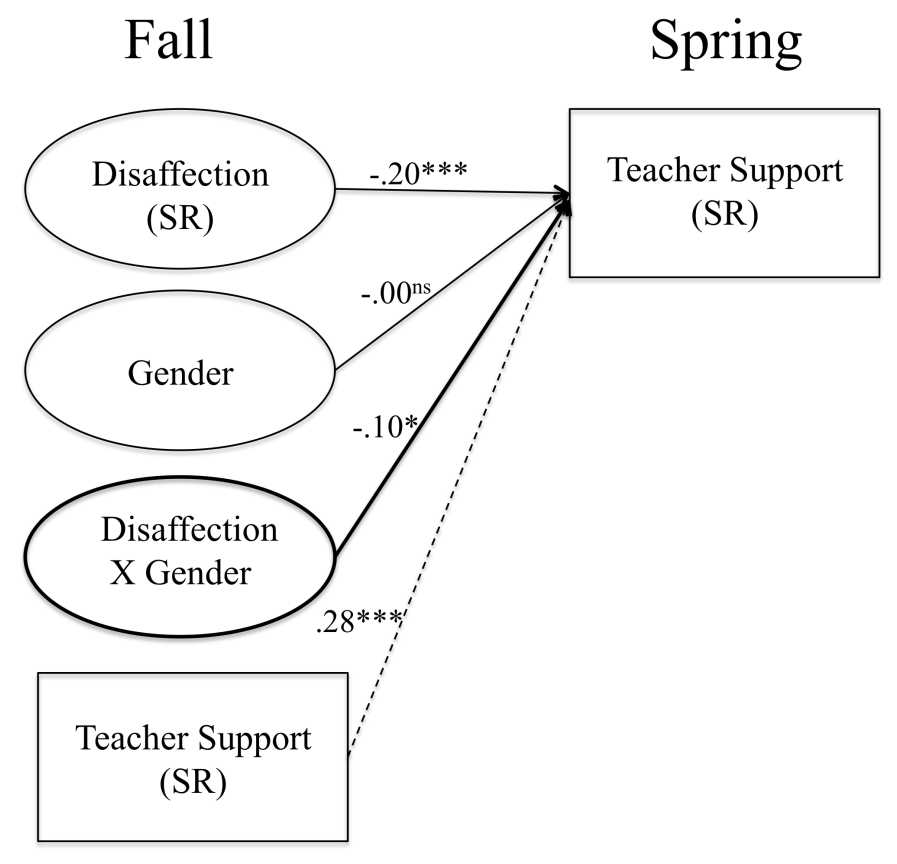

Figure 5.9. Gender Moderation of the Relationship between Engagement (SR) and Changes in Teacher Support.

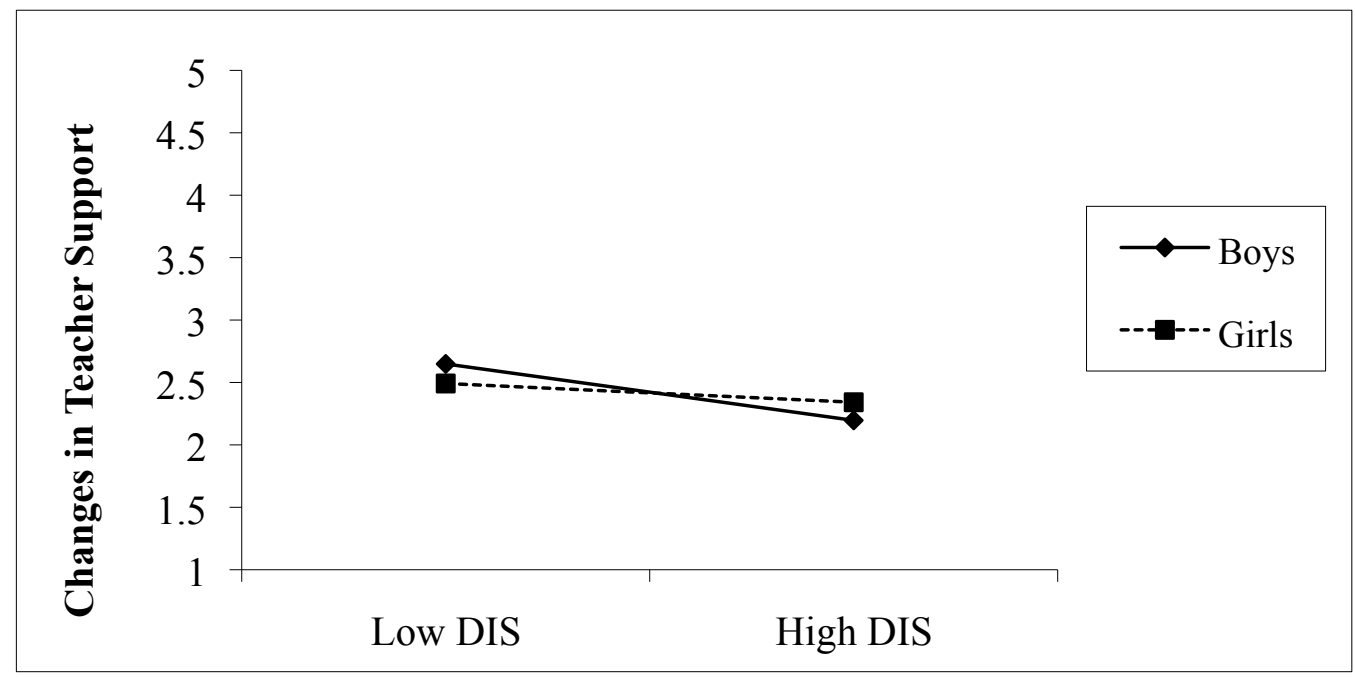


Research Question 2b1: Are there grade differences in the relationships between student engagement and disaffection and teacher support within each time point?

Grade Level. Considering that the sample included students in $6^{\text {th }}, 7^{\text {th }}$, and $8^{\text {th }}$ grade, mean level differences, as a function of grade, were examined using analysis of variance (ANOVA). Results can be found in Table 5.4. As all overall ANOVA's were significant, post hoc Tukey follow-up tests were conducted to determine more precisely how the three grade levels differed from one another. Engagement was significantly higher for $6^{\text {th }}$ than for $7^{\text {th }}$ or for $8^{\text {th }}$ graders in fall and spring; in addition, disaffection was significantly lower for $6^{\text {th }}$ than for $7^{\text {th }}$ or for $8^{\text {th }}$ graders in the spring. Teacher support was significantly higher for $6^{\text {th }}$ then $8^{\text {th }}$ graders in fall and spring. Teacher support was also significantly higher for $7^{\text {th }}$ then $8^{\text {th }}$ graders in spring.

Table 5.4

Summary of Descriptive Statistics for each Construct by Grade Level in Fall and Spring

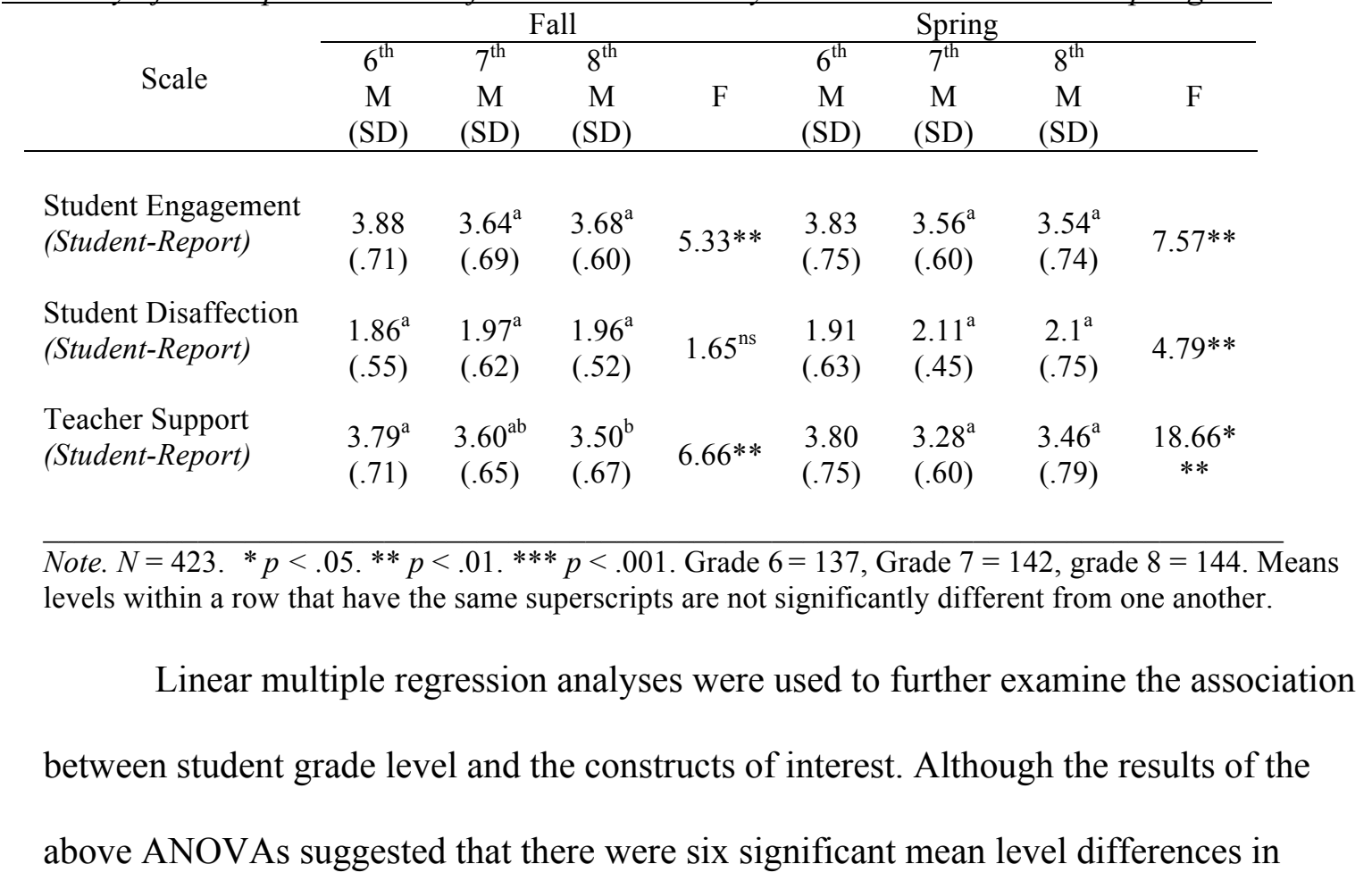


engagement and disaffection for students of different grades favoring younger students, linear multiple regression analyses were also conducted to determine whether student engagement and disaffection were more important predictors of teacher support for younger students than for older students.

For each time point, teacher support was regressed on student engagement (grand mean centered), grade level (grand mean centered), and the interaction between student engagement and grade level (created by calculating the cross-product of centered engagement and centered grade level). The process was repeated with student disaffection.

The interactions between grade and engagement were not significant at either time point (fall and spring), nor were the interactions between grade and disaffection (see Figures 5.10-5.13). It appears that although there are significant mean differences in motivation by grade level, engagement and disaffection were not better predictors of teachers' provision of motivational support for younger students than for older students.

Figure 5.10. Interaction Between Engagement and Grade on Teacher Support in Fall.

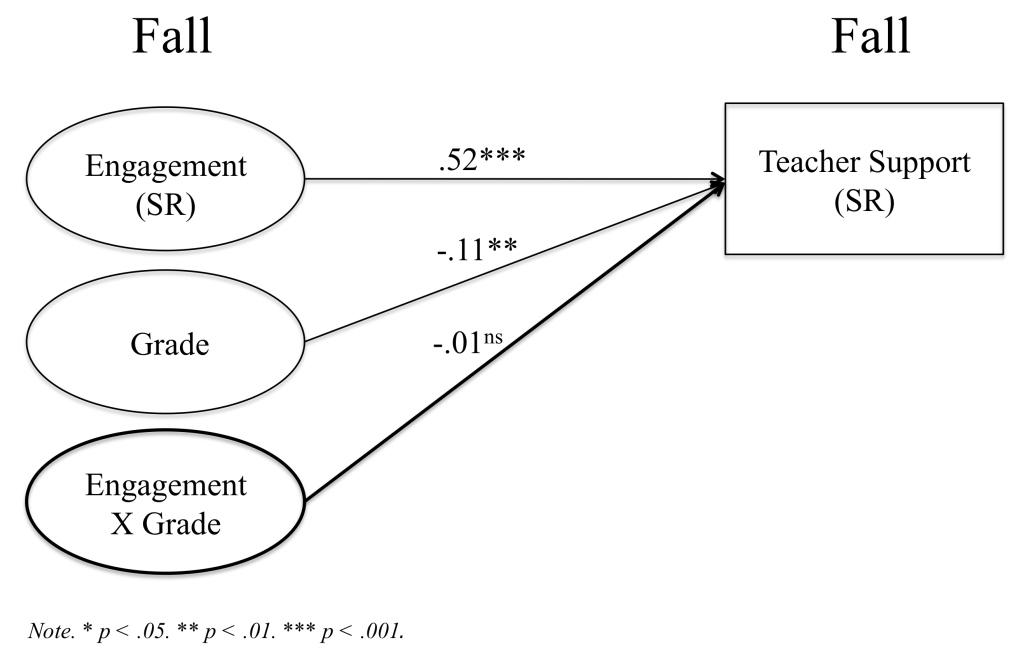


Figure 5.11. Interaction Between Engagement and Grade on Teacher Support in Spring.

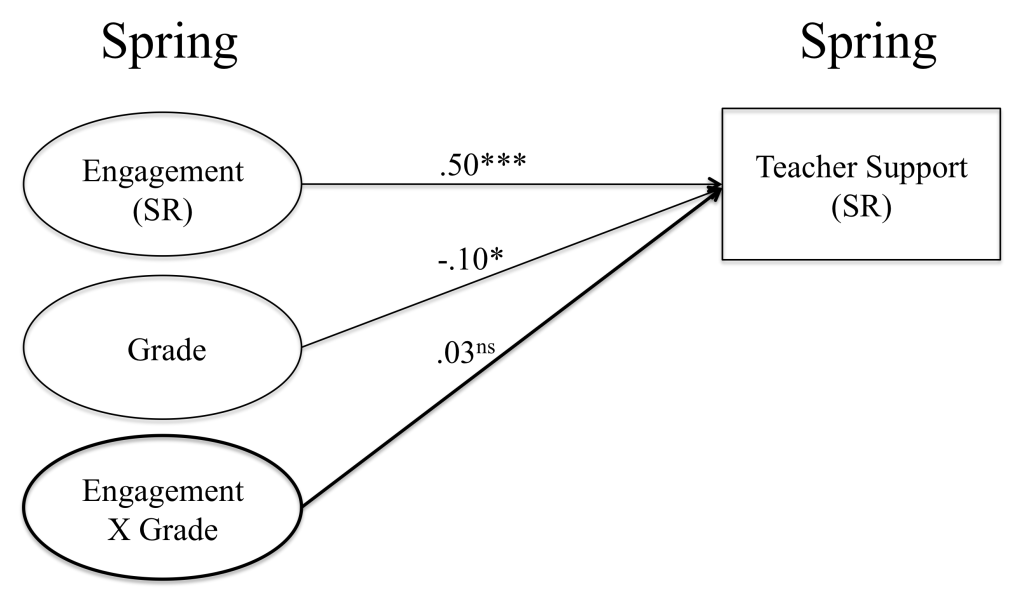

Note. $* p<.05 . * * p<.01 . * * * p<.001$.

Figure 5.12. Interaction Between Disaffection and Grade on Teacher Support in Fall.

Fall

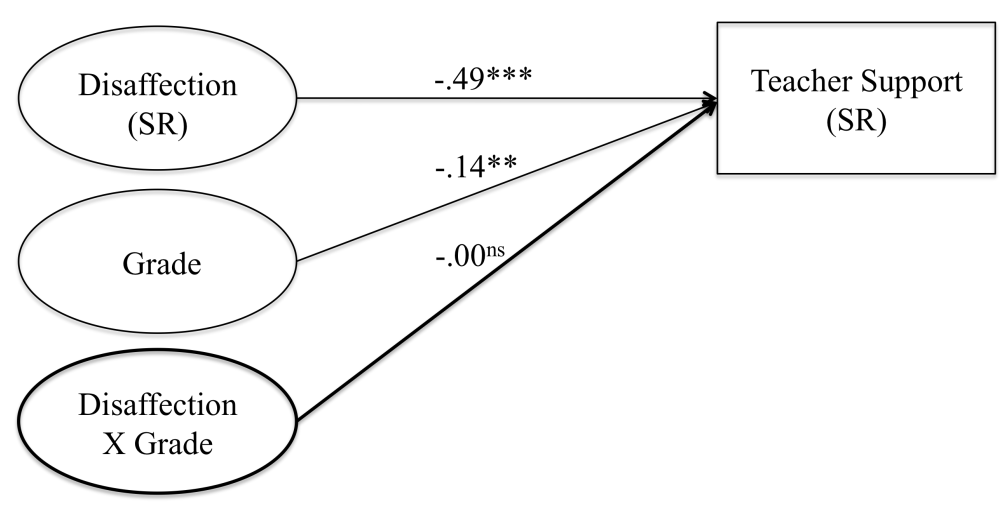

Note. $* p<.05 . * * p<.01 . * * * p<.001$. 
Figure 5.13. Interaction Between Disaffection and Grade on Teacher Support in Spring. Spring Spring

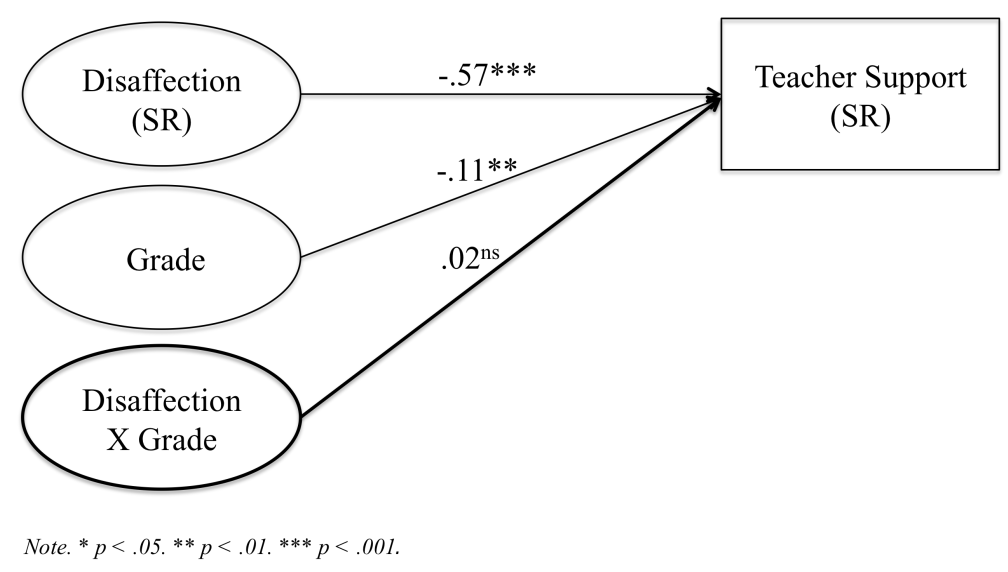

Research Question 2b2: Are there grade differences in the relationships between student engagement and disaffection and changes in teacher support from fall to spring?

Although there were no significant grade interactions for engagement or disaffection within each time point, additional linear multiple regression analyses were conducted to test whether engagement and disaffection were more important predictors of changes in teacher support over time for younger than for older students. No significant grade interaction effects were found for engagement or disaffection across time (see Figures 5.14 and 5.15). 
Figure 5.14. Interaction Between Engagement and Grade on Changes in Teacher Support.

Fall



Figure 5.15. Interaction Between Disaffection and Grade on Changes in Teacher Support.

Fall

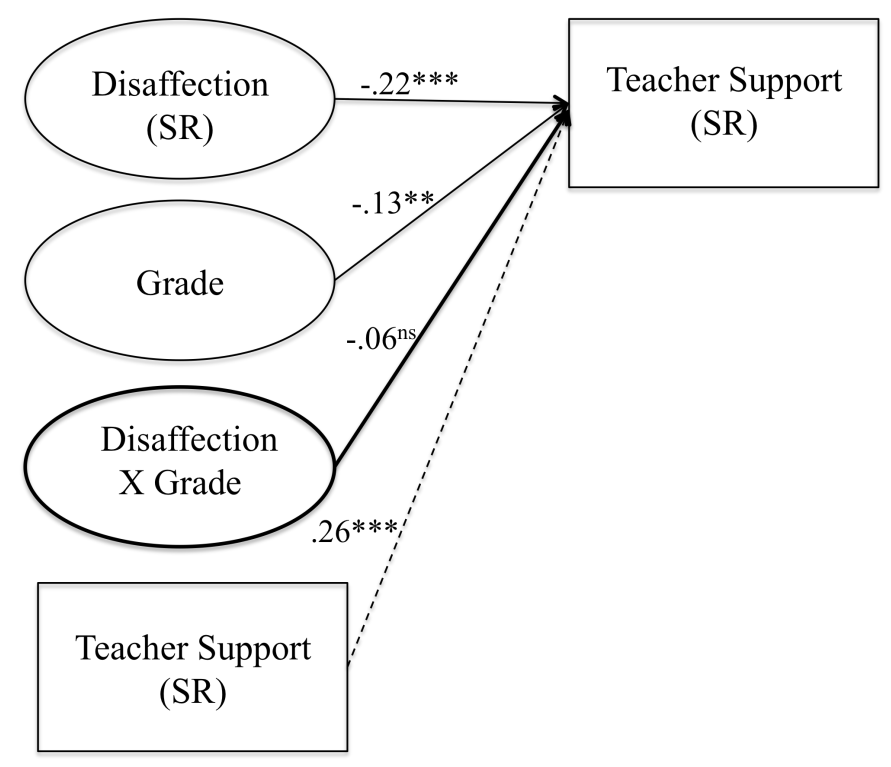

Spring 
Research Question 3a. Does each component of motivation (engagement and disaffection) have an effect on teacher support above and beyond the effect of the other component?

H3a1) Student engagement will predict teacher support, over and above disaffection within each time point (fall and spring).

H3a2) Student disaffection will predict teacher support, over and above engagement, within each time point (fall and spring).

Linear multiple regression analyses were used to examine whether student engagement and student disaffection jointly and uniquely predicted teacher support in fall and in spring. Teacher support in fall was regressed on engagement in fall and disaffection in fall. Next, teacher support in spring was regressed on engagement in spring and disaffection in spring. Hypothesis $3 \mathrm{a} 1$ and $3 \mathrm{a} 2$ were supported. In fall, student engagement significantly predicted teacher support over and above disaffection and vice versa. Similarly, in spring, student engagement predicted teacher support above and beyond student disaffection and vice versa. These results suggest that, in fall and in spring, each component of motivation demonstrated unique effects on teacher motivational support (see Figure 3.16 and 3.17). 
Figure 5.16. Relationship Between Engagement, Disaffection, and Teacher Support in Fall.

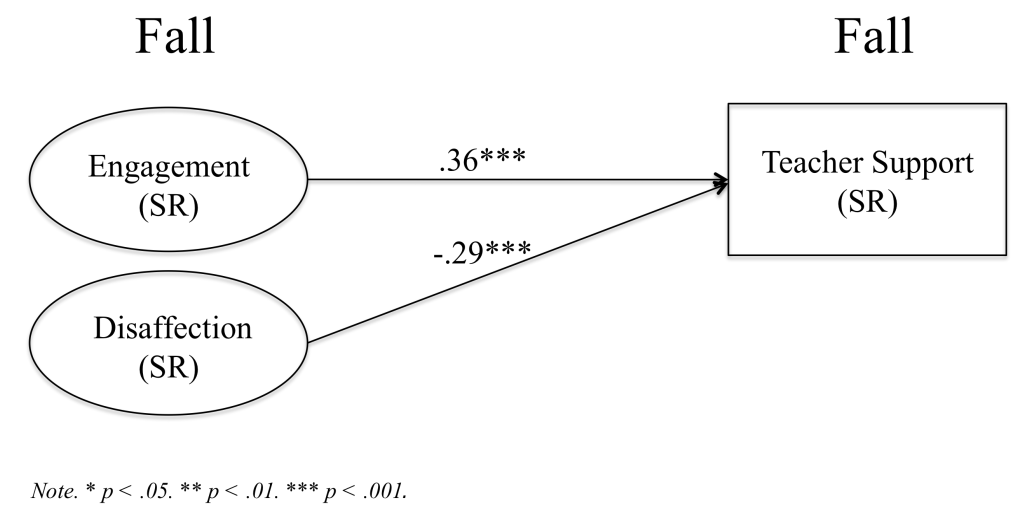

Figure 5.17. Relationship Between Engagement, Disaffection, and Teacher Support in Spring.



Research Question 3b. Does each component of motivation (engagement and

disaffection) have an effect on changes in teacher support from fall to spring above and beyond the effect of the other component?

H3b1) Student engagement in fall will predict changes in teacher support from fall to spring, over and above disaffection.

H3b2) Student disaffection in fall will predict changes in teacher support from fall to spring, over and above engagement.

A linear multiple regression analysis was used to examine whether student engagement and student disaffection jointly and uniquely predicted changes in teacher 
support from fall to spring. Hypothesis $3 \mathrm{~b} 1$ was not supported; Student engagement did not significantly predict changes in teacher support over and above those predicted by student disaffection. However, Hypothesis $3 \mathrm{~b} 2$ was supported such that student disaffection predicted changes in teacher support above and beyond student engagement (see Figure 5.18).

Figure 5.18. Relationship Between Engagement, Disaffection, and Changes in Teacher Support.

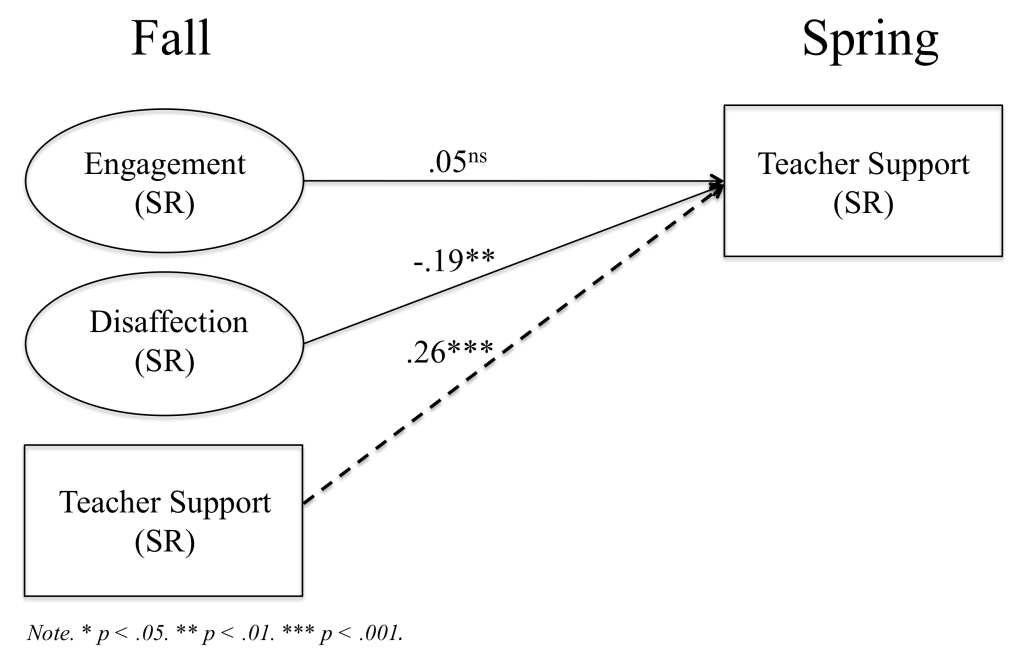

Research Question 4a. Do the effects of one component of motivation on teacher support depend on the level of the other component within each time point (fall and spring)?

H4a1) The relationship between engagement and teacher support will be stronger for students who are low in disaffection, suggesting low disaffection boosts the positive effects of engagement.

H4a2) The relationship between disaffection and teacher support in fall and in spring will be weaker for students who are high in engagement, suggesting high engagement buffers the negative effects of disaffection.

In order to address the question of whether there was a significant interaction 
between engagement and disaffection, teacher support in fall was regressed on student engagement and disaffection in the fall (both grand mean centered) and the interaction term (engagement*disaffection). The process was repeated in spring. The interaction between engagement and disaffection was significant in fall but not in spring. Hypothesis 4a1 was supported in fall such that the relationship between engagement and teacher support in fall and was stronger for students who were low in disaffection, suggesting low disaffection boosted the positive effects of engagement. Unfortunately, Hypothesis $4 \mathrm{a} 2$ in fall was not supported. Instead of the relationship between disaffection and teacher support being weaker for students reporting high engagement, these relations was actually stronger such that the slope for highly engaged students was steeper than for less engaged students (see Figure 5.19-5.22).

Figure 5.19. Interaction Between Engagement and Disaffection on Teacher Support in Fall.

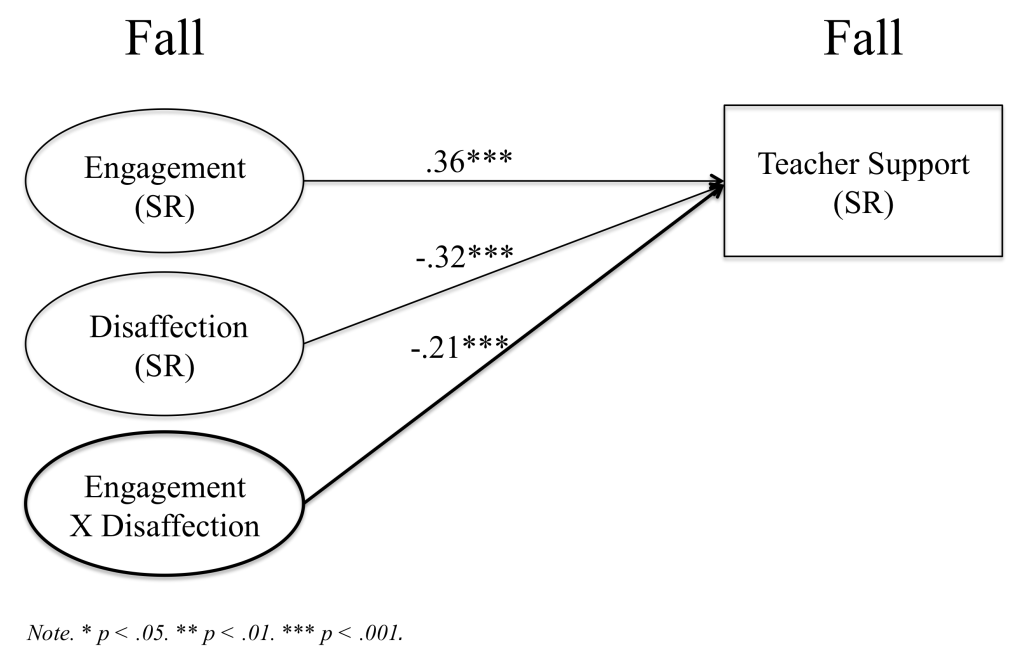


Figure 5.20. Disaffection Moderating the Relationship between Engagement (SR) and Teacher Support (SR) in the Fall.

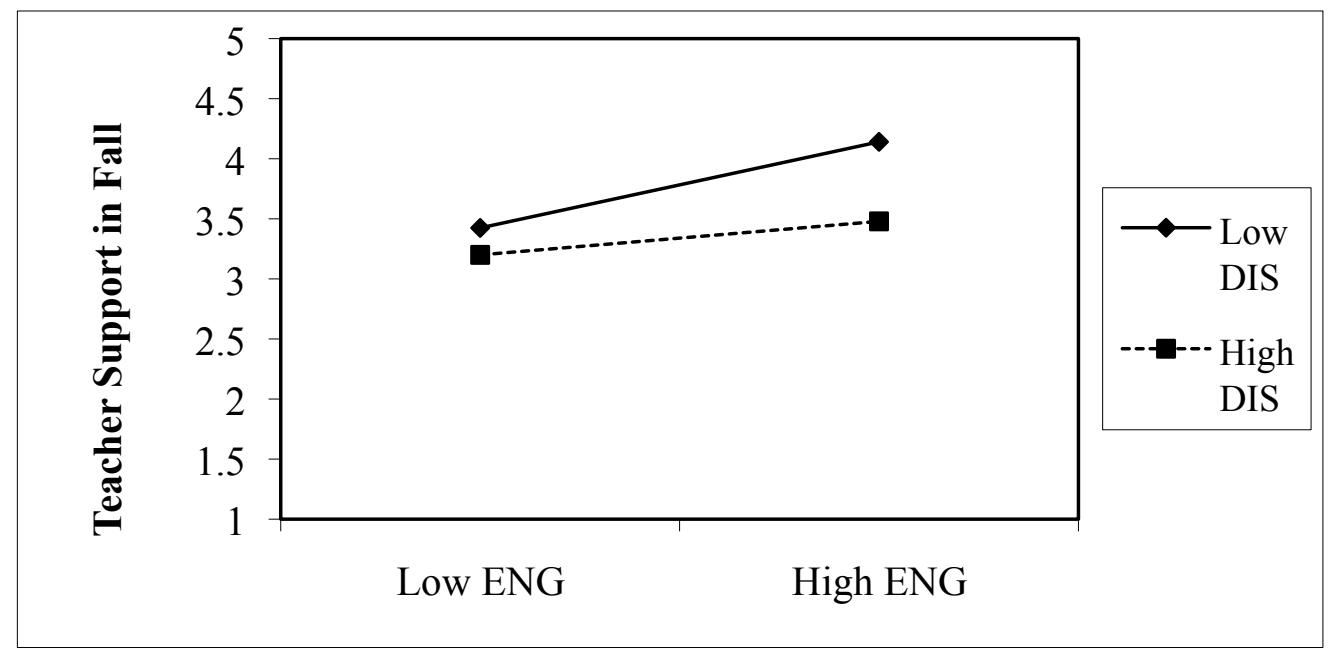

Figure 5.21. Engagement Moderating the Relationship between Disaffection (SR) and Teacher Support (SR) in the Fall.

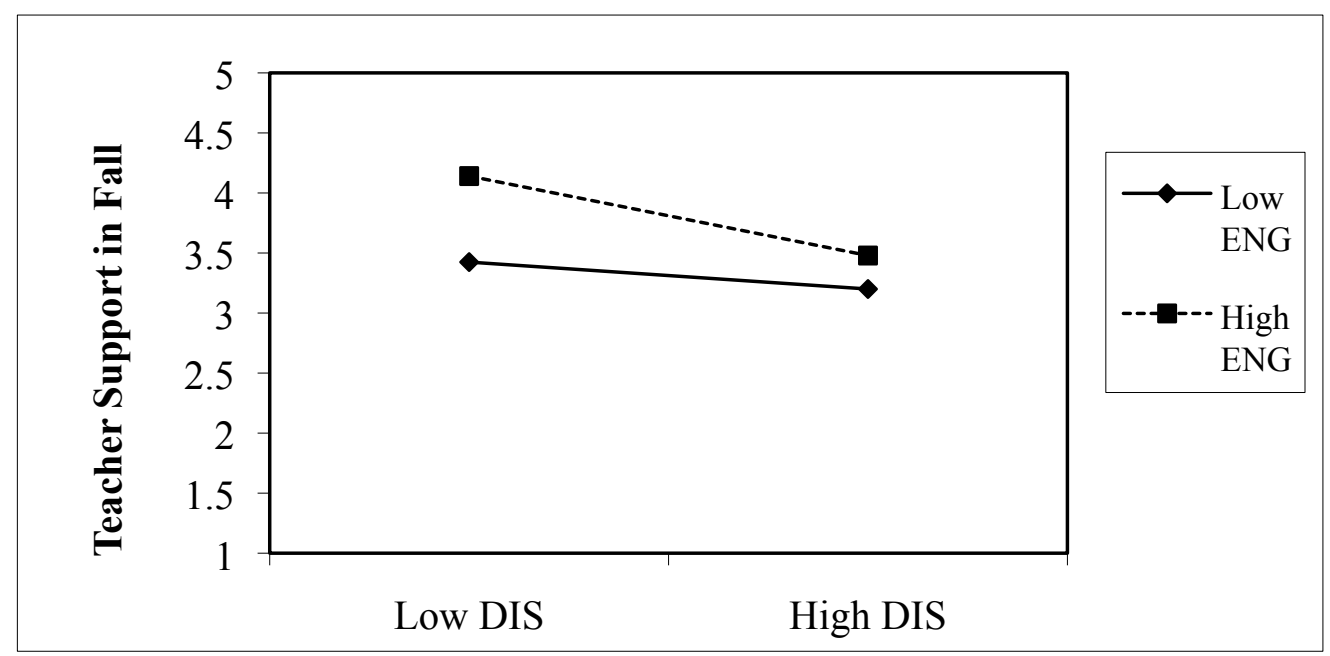


Figure 5.22. Interaction Between Engagement and Disaffection on Teacher Support in Spring.

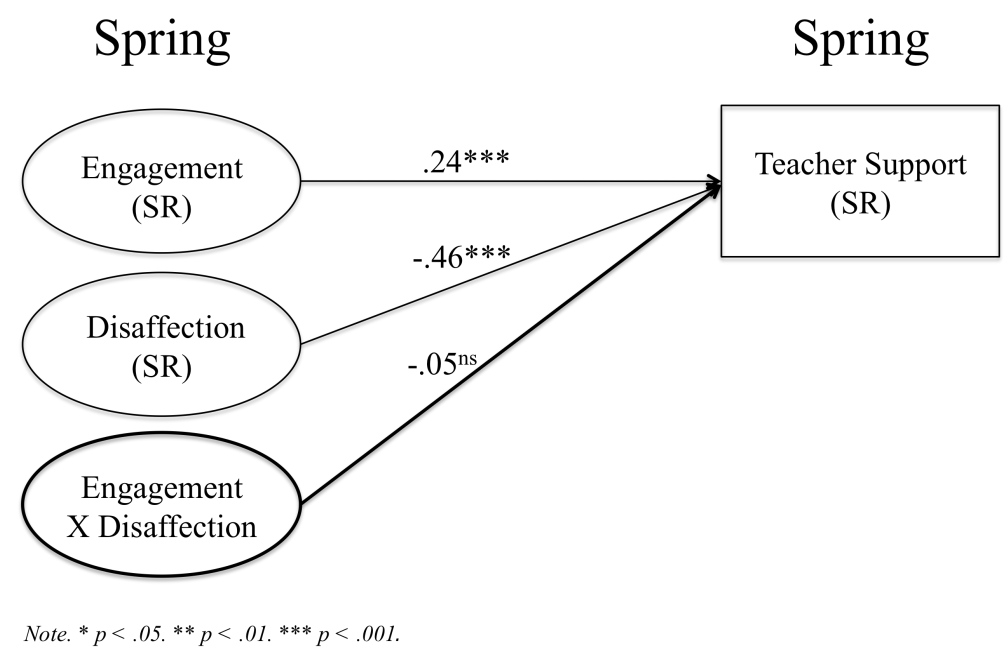

Research Question $4 \boldsymbol{b}$. Do the effects of one component of motivation on changes in teacher support from fall to spring depend on the level of the other component?

H4b1) The relationship between engagement and changes in teacher support will be stronger for students who are low in disaffection, suggesting low disaffection boosts the positive effects of engagement.

H4b2) The relationship between disaffection and changes in teacher support will be weaker for students who are high in engagement, suggesting high engagement buffers the negative effects of disaffection.

In order to address the question of whether there is a significant interaction between engagement and disaffection, teacher support in spring was regressed on student engagement and disaffection in the fall (both grand mean centered) and the interaction term (engagement*disaffection), controlling for teacher support in the fall (grand mean centered).

Hypothesis $4 \mathrm{a}$ and $4 \mathrm{~b}$ were not supported; the interaction between engagement and 
disaffection was not significant (See Figure 5.23.)

Figure 5.23. Interaction Between Engagement and Disaffection on Changes in Teacher Support from Fall to Spring.

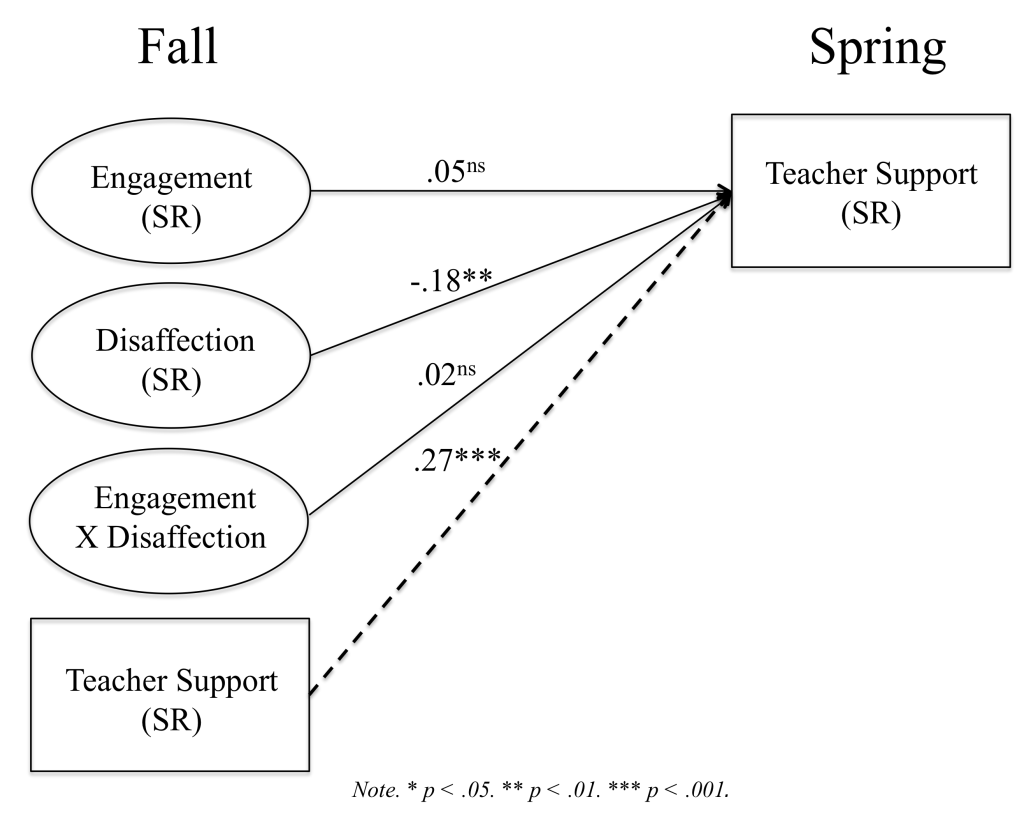

Research Question 5. Do these connections hold for student engagement and

disaffection as reported by teachers?

Research Question 5a. Do student engagement and disaffection (as reported by teachers)

predict changes in teacher support (as reported by students) from fall to spring,

controlling for teacher support in the fall?

H5a) Student engagement (TR) will predict increases in teacher support (SR)

from fall to spring.

H5b) Student disaffection (TR) will predict decreases in teacher support (SR)

from fall to spring.

RQ 5a-5d2 examine whether teachers' reports of students' motivation in the

classroom predict teachers' provision of support in the classroom as reported by students.

Hypothesis 5a was tested using linear multiple regression analyses. Specifically, teacher 
support in spring (student report) was regressed on student engagement in the fall

(teacher report), controlling for teacher support in the fall. As can be seen in Figure 5.24, this relationship was positive and significant $(ß=.15, \mathrm{t}(420)=3.20, p<.01)$, with engagement in fall accounting for $17 \%$ of the variance in the change in teacher support from fall to spring.

Figure 5.24. Relationship Between Student Engagement (TR) and Teacher Support (SR) Over Time.

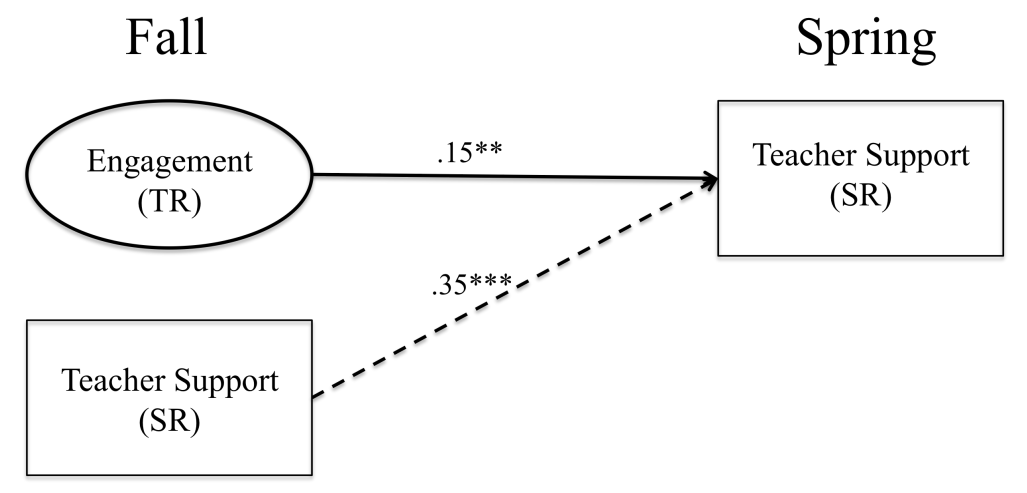

Note. ${ }^{*} p<.05 .{ }^{* *} p<.01 .{ }^{* * *} p<.001$.

To test hypothesis $5 \mathrm{~b}$, teacher support in spring (student report) was regressed on student disaffection (teacher report) in the fall, controlling for teacher support in the fall. This relationship was negative and significant $(ß=-.15, t(420)=-3.36, p<.01)$, with disaffection in fall accounting for $17 \%$ of the variance in the change in teacher support from fall to spring (see Figure 5.25.) 
Figure 5.25. Relationship Between Student Disaffection (TR) and Teacher Support (SR) Over Time.

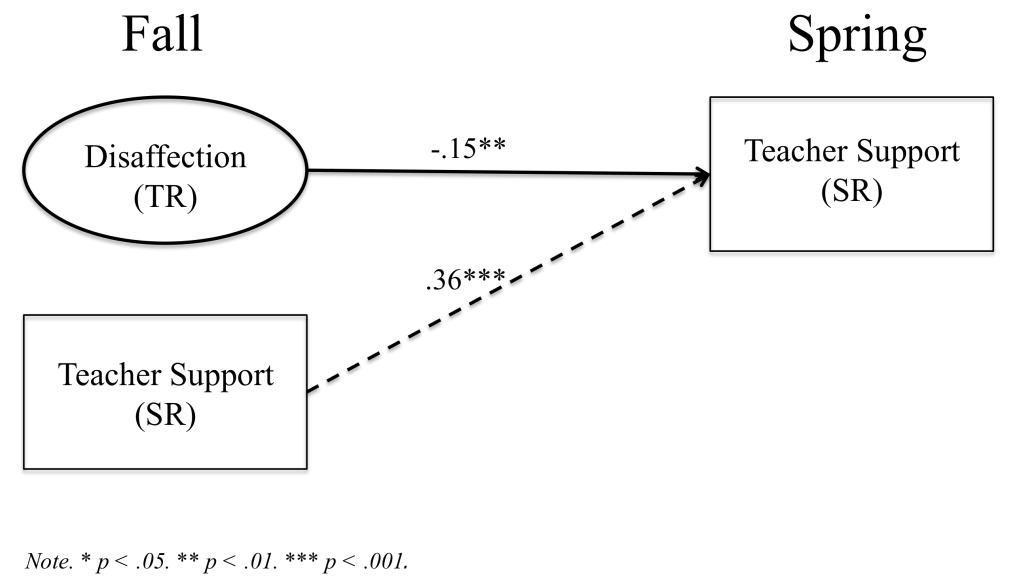

Research Question 5b1a. Are there gender differences in the relationships between student engagement and disaffection (TR) and teacher support (SR) within each time point?

Gender. Independent-measures t-tests were used to examine whether levels of teacher-reported student engagement and disaffection (TR) differed significantly for boys and girls. Results indicated teachers reported girls were significantly more engaged and significantly less disaffected in fall and in spring compared to boys. The results can be found in Table 5.5

Table 5.5

Mean Level Differences by Gender (Student Engagement and Student Disaffection)

\begin{tabular}{|c|c|c|c|c|c|c|}
\hline & \multicolumn{2}{|c|}{ Fall } & & \multicolumn{2}{|c|}{ Spring } & \multirow[b]{2}{*}{$t$} \\
\hline & $\begin{array}{c}\text { Girls } \\
M \\
(S D)\end{array}$ & $\begin{array}{c}\text { Boys } \\
M \\
(S D)\end{array}$ & $t$ & $\begin{array}{c}\text { Girls } \\
M \\
(S D)\end{array}$ & $\begin{array}{c}\text { Boys } \\
M \\
(\mathrm{SD})\end{array}$ & \\
\hline Student Engagement (Teacher-Report) & $\begin{array}{l}3.97 \\
(.80)\end{array}$ & $\begin{array}{l}3.70 \\
(.82)\end{array}$ & $-3.47 * *$ & $\begin{array}{l}3.81 \\
(.58)\end{array}$ & $\begin{array}{l}3.57 \\
(.80)\end{array}$ & $-3.52 * * *$ \\
\hline Student Disaffection (Teacher-Report) & $\begin{array}{l}1.54 \\
(.62)\end{array}$ & $\begin{array}{l}1.77 \\
(.65)\end{array}$ & $3.62 * * *$ & $\begin{array}{l}1.91 \\
(.61)\end{array}$ & $\begin{array}{l}2.25 \\
(.91)\end{array}$ & $4.47 * * *$ \\
\hline
\end{tabular}

Note. $N=423 .{ }^{*} p<.05 .{ }^{* *} p<.01 . * * * p<.001$.

Additionally, linear multiple regression analyses were conducted to test whether engagement and disaffection were more important predictors of teacher support for boys 
than for girls. Teacher-reports of engagement and disaffection and gender were grand mean centered. For each time point, teacher support (SR) was regressed on student engagement (TR), gender, and the interaction between student engagement and gender (created by calculating the cross-product of centered engagement and gender). Similarly, for each time point, teacher support (SR) was regressed on student disaffection (TR), gender, and the interaction between student disaffection and gender (created by calculating the cross-product of centered disaffection and gender).

No significant interaction effects were found at either time point for disaffection; however, there was a significant interaction between gender and teacher-reports of engagement in the fall, although not in the spring (see Figures 5.20-5.24.) The significant partial regression slope for the interaction between engagement in fall and student gender was negative (the gender variable is a marker for girls as the variable was dummy coded girls $=1$, boys $=0$ ). The significant interaction indicates that the positive relationship between engagement and teacher support was stronger for boys $(r=.32, p<.001)$, than for girls $(r=.10, p>.05)$ in the fall (see Figures $5.26-5.30)$. These results suggest that teacher support was more important for boys than for girls in fall. 
Figure 5.26. Interaction Between Engagement (TR) and Gender on Teacher Support (SR) in Fall.

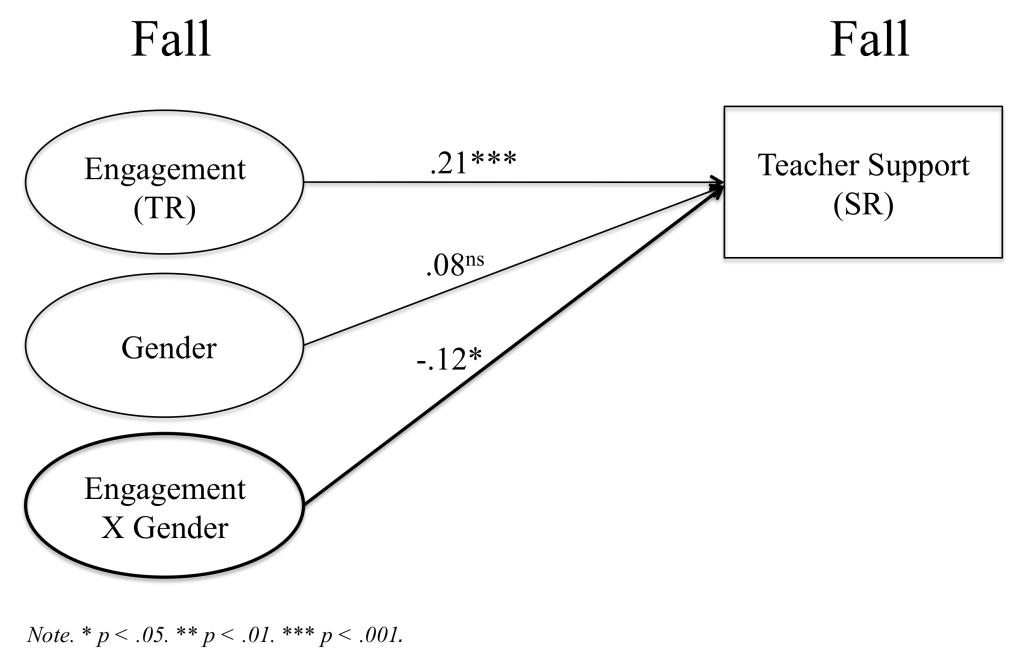

Figure 5.27. Gender Moderation of the Relationship between Engagement (TR) and Teacher Support in the Fall.




Figure 5.28. Interaction Between Engagement (TR) and Gender on Teacher Support (SR) in Spring.

\section{Spring}



Note. ${ }^{*} p<.05 . * * p<.01 . * * * p<.001$

Figure 5.29. Interaction Between Disaffection (TR) and Gender on Teacher Support (SR) in Fall.

Fall

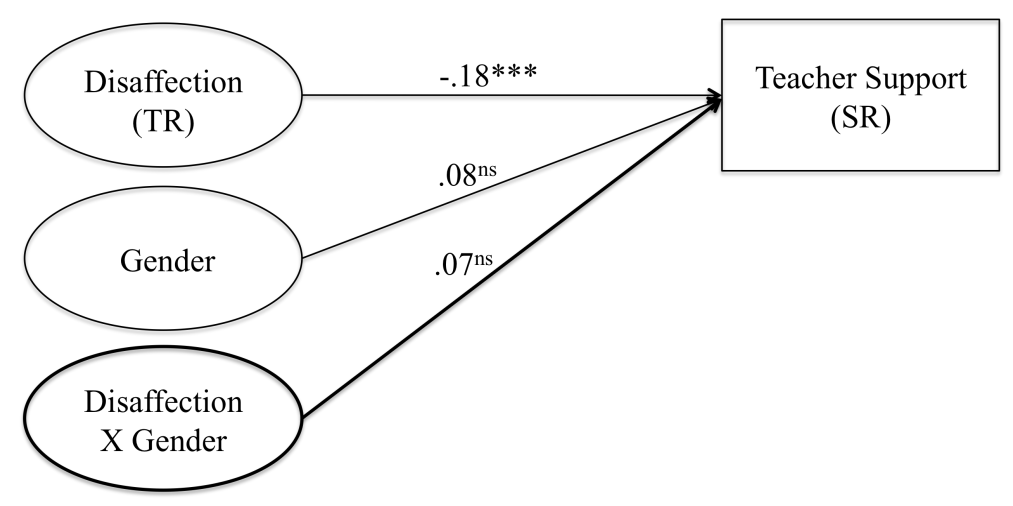

Note. $* p<.05 . * * p<.01 . * * * p<.001$. 
Figure 5.30. Interaction Between Disaffection (TR) and Gender on Teacher Support (SR) in Spring.

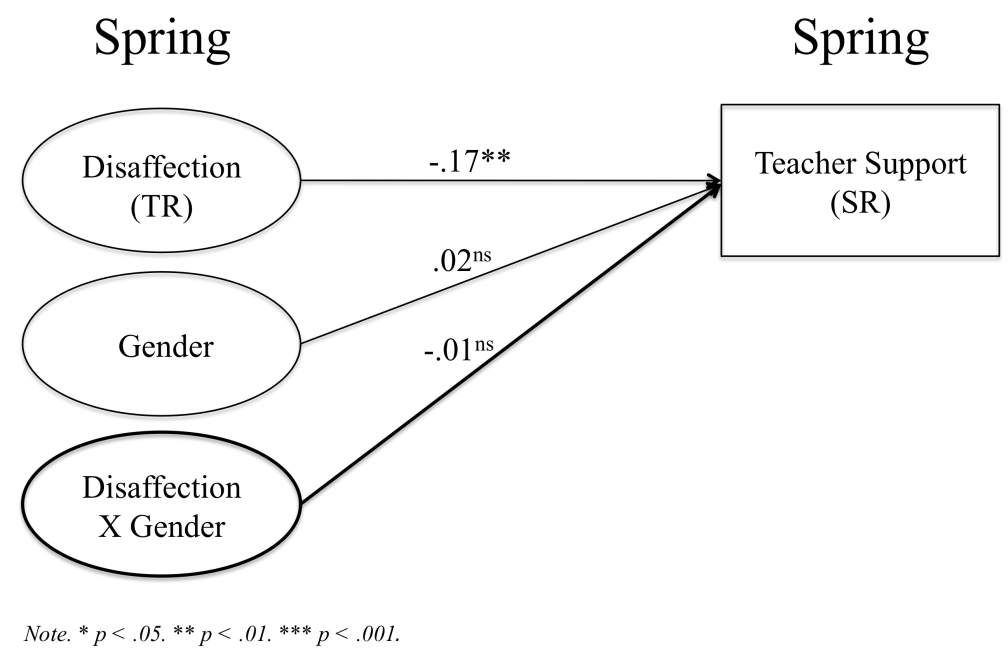

Research Question $5 \mathbf{b} 1 \mathbf{b}$. Are there gender differences in the relationships between student engagement and disaffection (TR) and changes in teacher support (SR) from fall to spring?

In addition to examining possible gender moderations within each time point, linear multiple regression analyses were conducted across time points in order to test for gender interaction effects on changes in teacher support. Teacher support (SR) in spring was regressed on student engagement (TR) in fall, gender, and the interaction between student engagement in fall and gender, controlling for teacher support in the fall. The process was repeated with student disaffection. No significant gender interaction effects were found for teacher-reported engagement or disaffection and changes in teacher support (see Figures 5.25 and 5.26). 
Figure 5.31. Interaction Between Engagement and Gender on Changes in Teacher Support.

Fall

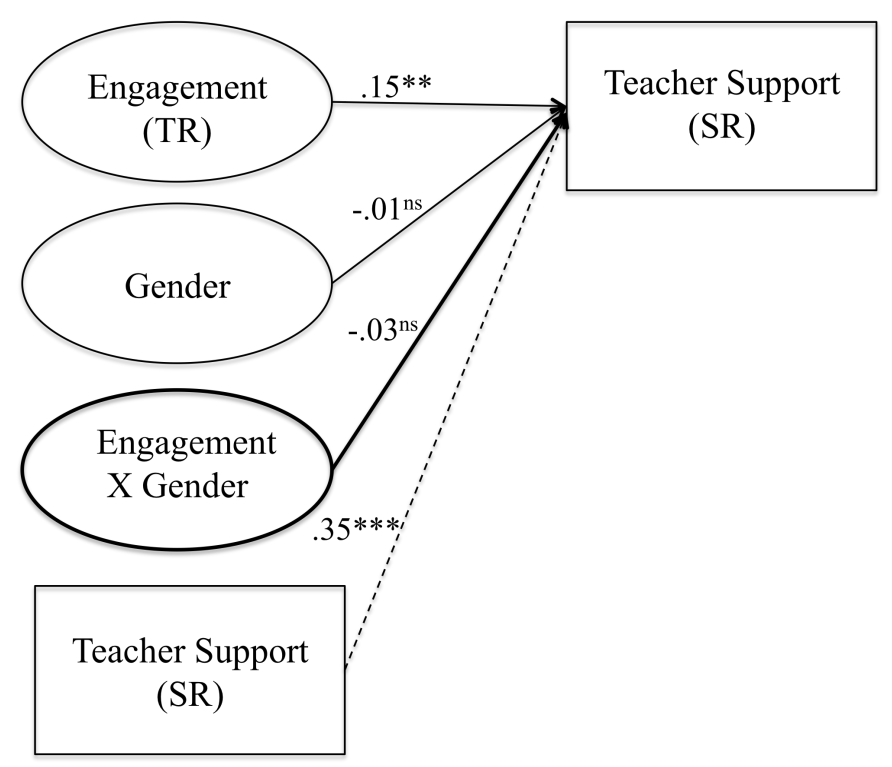

Figure 5.32. Interaction Between Disaffection and Gender on Changes in Teacher Support.

Fall



Spring
Research Question $5 \mathbf{b} 2 \boldsymbol{a}$. Are there grade differences in the relationship between student engagement and disaffection (TR) and teacher support (SR) within each time point? 
Grade-Level. Mean level differences in teacher-reports of engagement and disaffection, as a function of grade-level, were examined using analysis of variance (ANOVA). Results can be found in Table 5.6. Only teacher reports of disaffection in spring significantly differed by grade level. Post hoc Tukey tests were conducted to determine that disaffection in the spring was significantly higher for $8^{\text {th }}$ than for $7^{\text {th }}$ graders.

Table 5.6.

Summary of Descriptive Statistics for each Construct by Grade Level in Fall and Spring

\begin{tabular}{ccccccccc} 
& \multicolumn{9}{c}{ Fall } & \multicolumn{5}{c}{ Spring } \\
\cline { 2 - 9 } Scale & $6^{\text {th }}$ & $7^{\text {th }}$ & $8^{\text {th }}$ & & $6^{\text {th }}$ & $7^{\text {th }}$ & $8^{\text {th }}$ & \\
& $M$ & $M$ & $M$ & $F$ & $M$ & $M$ & $M$ & F \\
& $(\mathrm{SD})$ & $(\mathrm{SD})$ & $(\mathrm{SD})$ & & $(\mathrm{SD})$ & $(\mathrm{SD})$ & $(\mathrm{SD})$ & \\
\hline
\end{tabular}

\begin{tabular}{|c|c|c|c|c|c|c|c|c|}
\hline $\begin{array}{l}\text { Student Engagement } \\
\text { (Teacher-Report) }\end{array}$ & $\begin{array}{l}3.77 \\
(.97)\end{array}$ & $\begin{array}{l}3.90 \\
(.69)\end{array}$ & $\begin{array}{l}3.86 \\
(.60)\end{array}$ & $.89^{\mathrm{ns}}$ & $\begin{array}{l}3.67 \\
(.60)\end{array}$ & $\begin{array}{l}3.79 \\
(.67)\end{array}$ & $\begin{array}{l}3.64 \\
(.83)\end{array}$ & $1.77^{\mathrm{ns}}$ \\
\hline $\begin{array}{l}\text { Student Disaffection } \\
\text { (Teacher-Report) }\end{array}$ & $\begin{array}{l}1.62 \\
(.73)\end{array}$ & $\begin{array}{l}1.64 \\
(.56)\end{array}$ & $\begin{array}{l}1.69 \\
(.62)\end{array}$ & $.52^{\mathrm{ns}}$ & $\begin{array}{l}2.13^{\mathrm{ab}} \\
(.59)\end{array}$ & $\begin{array}{l}1.93^{\mathrm{a}} \\
(.70)\end{array}$ & $\begin{array}{l}2.16^{\mathrm{b}} \\
(.98)\end{array}$ & $3.54 *$ \\
\hline
\end{tabular}

Note. $N=423 .{ }^{*} p<.05 .{ }^{* *} p<.01 .{ }^{* * *} p<.001$. Grade $6=137$, Grade $7=142$, grade $8=144$. Means levels within a row that have the same superscripts are not significantly different from one another.

Linear multiple regression analyses were used to further examine the association between student grade level and the constructs of interest within each time point to determine whether student engagement and disaffection were more important predictors of teacher support for younger students than for older students. For each time point, teacher support (SR) was regressed on student engagement (TR), grade level, and the interaction between student engagement (TR) and grade level (created by calculating the cross-product of centered engagement and centered grade level). The process was repeated with student disaffection (TR). Results suggested there were significant interactions in fall between grade level and engagement and between grade level and disaffection (see Figures 5.33 - 5.36). 
Figure 5.33. Interaction Between Engagement (TR) and Grade on Teacher Support (SR) in Fall.



Note. $* p<.05 . * * p<.01 .{ }^{* * *} p<.001$.

Figure 5.34. Interaction Between Engagement (TR) and Grade on Teacher Support (SR) in Spring.

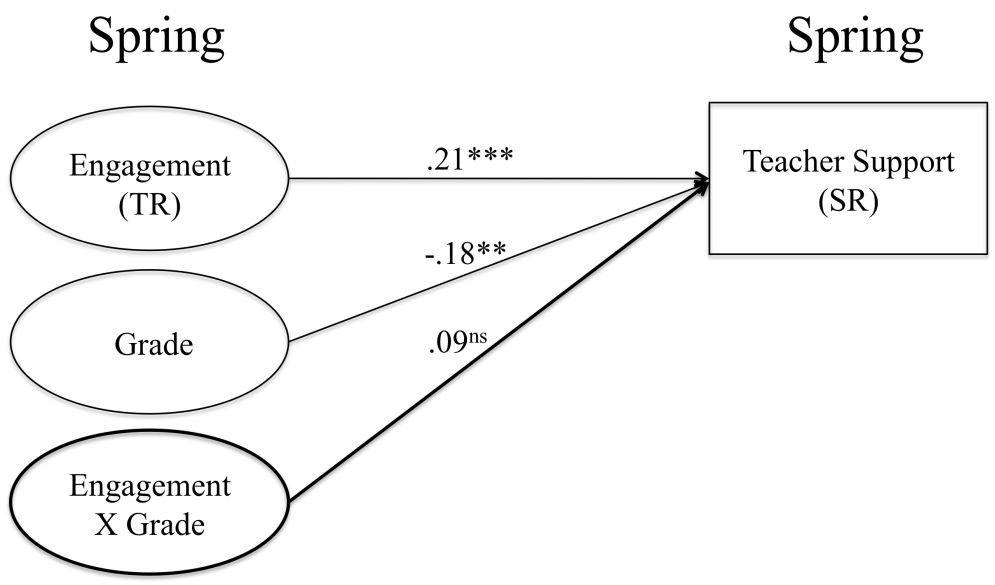

Note. $* p<.05 . * * p<.01 . * * * p<.001$. 
Figure 5.35. Interaction Between Disaffection (TR) and Grade on Teacher Support (SR) in Fall.



Figure 5.36. Interaction Between Disaffection (TR) and Grade on Teacher Support (SR) in Spring.

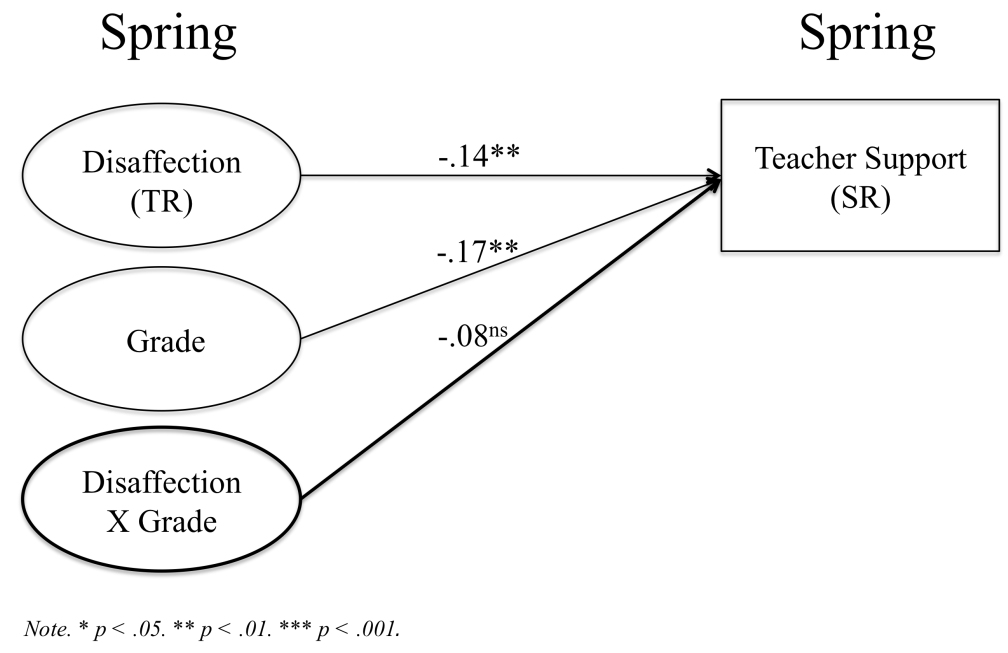

In order to better understand the significant grade interaction terms in fall for engagement and disaffection, follow up regression analyses were conducted. By dummy coding grade and using first $6^{\text {th }}$ graders and then $7^{\text {th }}$ graders as the reference category, multiple linear regressions were used to identify the grades between which the significant interactions resided.

Results indicated that a stronger positive connection was found between student 
engagement $(\mathrm{TR})$ and teacher support in fall for $8^{\text {th }}$ graders $(r=.35, p<.001)$ than for $6^{\text {th }}$ graders $(r=.10, p>.05)$. Similarly, there was a stronger positive association between student engagement (TR) and teacher support in fall for $7 \mathrm{th}^{\text {th }}$ graders $(r=.31, p<.001)$ than for $6^{\text {th }}$ graders $(r=.10, p>.05)$. Finally, a stronger negative connection was found between student disaffection (TR) and teacher support for $8^{\text {th }}$ graders $(r=-.28, p<.01)$ than for $6^{\text {th }}$ graders $(r=-.06, p>.05)$ (see Figures 5.37- 5.41).

Figure 5.37. Interaction Between Engagement (TR) and Grade on Teacher Support (SR) in Fall

\section{Fall}

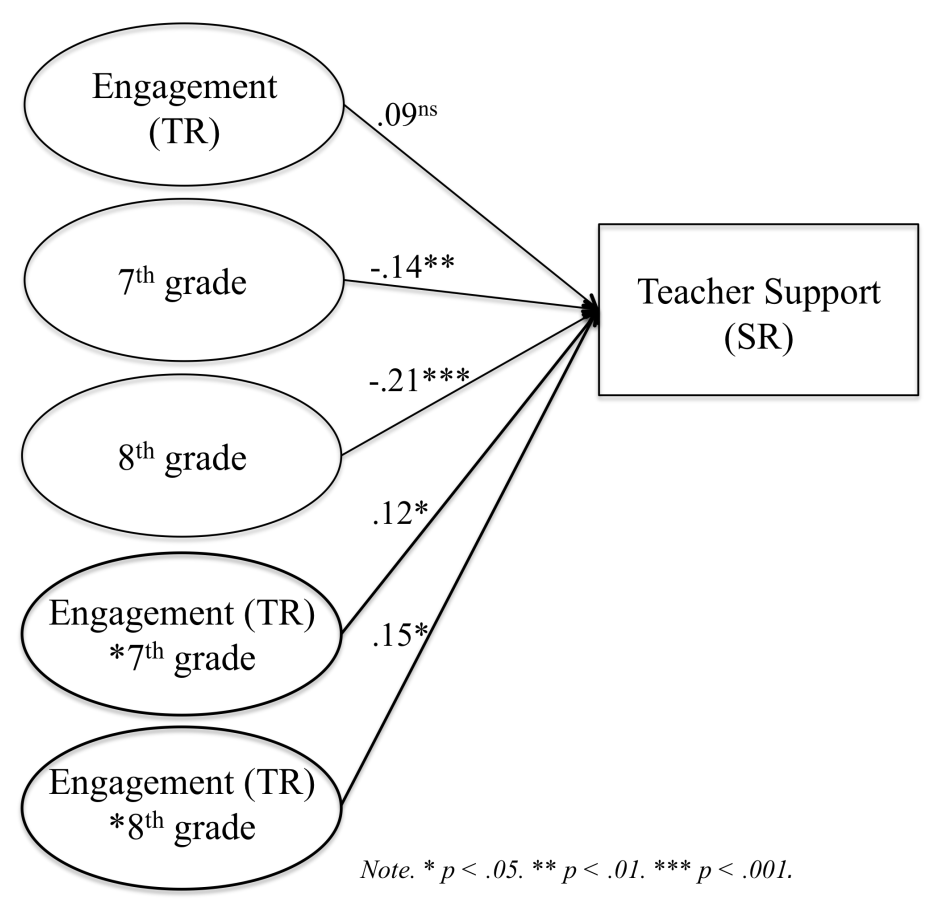


Figure 5.38 Relationship Between Engagement (TR) and Teacher Support for $6^{\text {th }}$ and $7^{\text {th }}$ Graders in Fall.

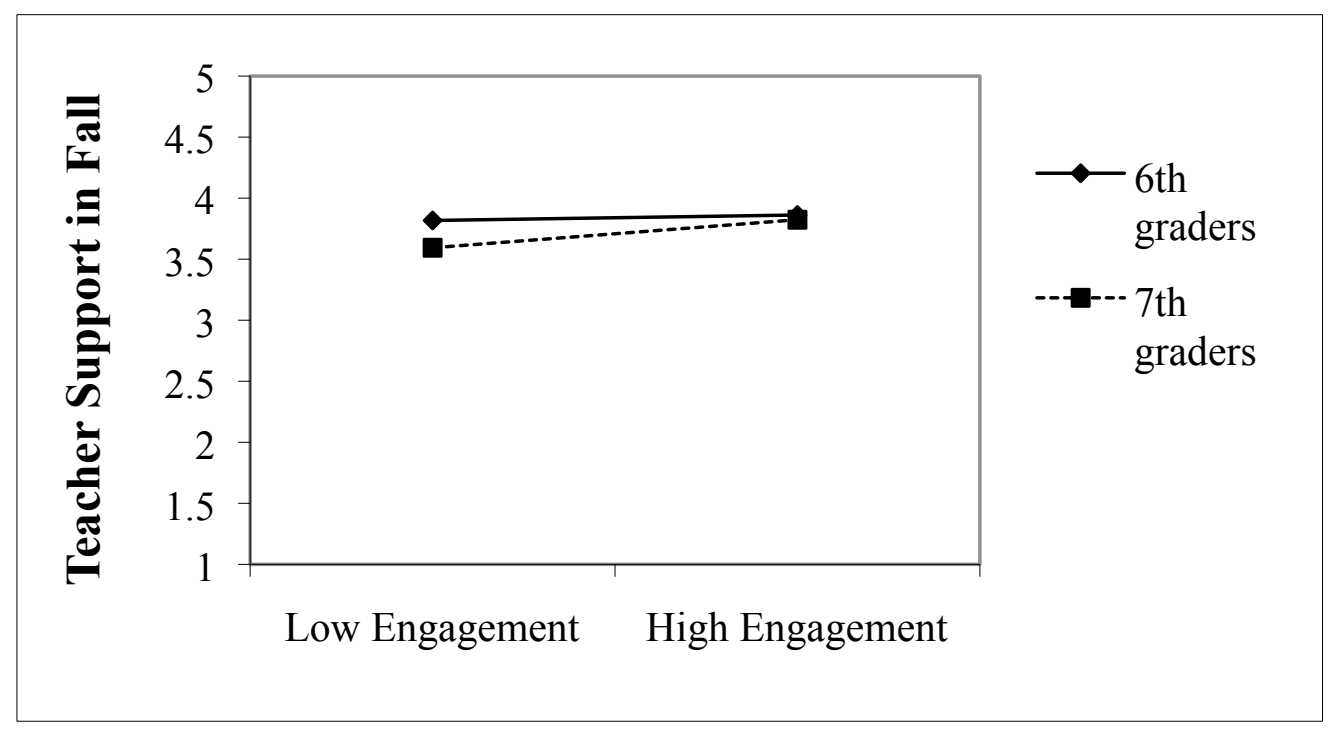

Figure 5.39. Relationship Between Engagement (TR) and Teacher Support for $6^{\text {th }}$ and $8^{\text {th }}$ Graders in Fall.

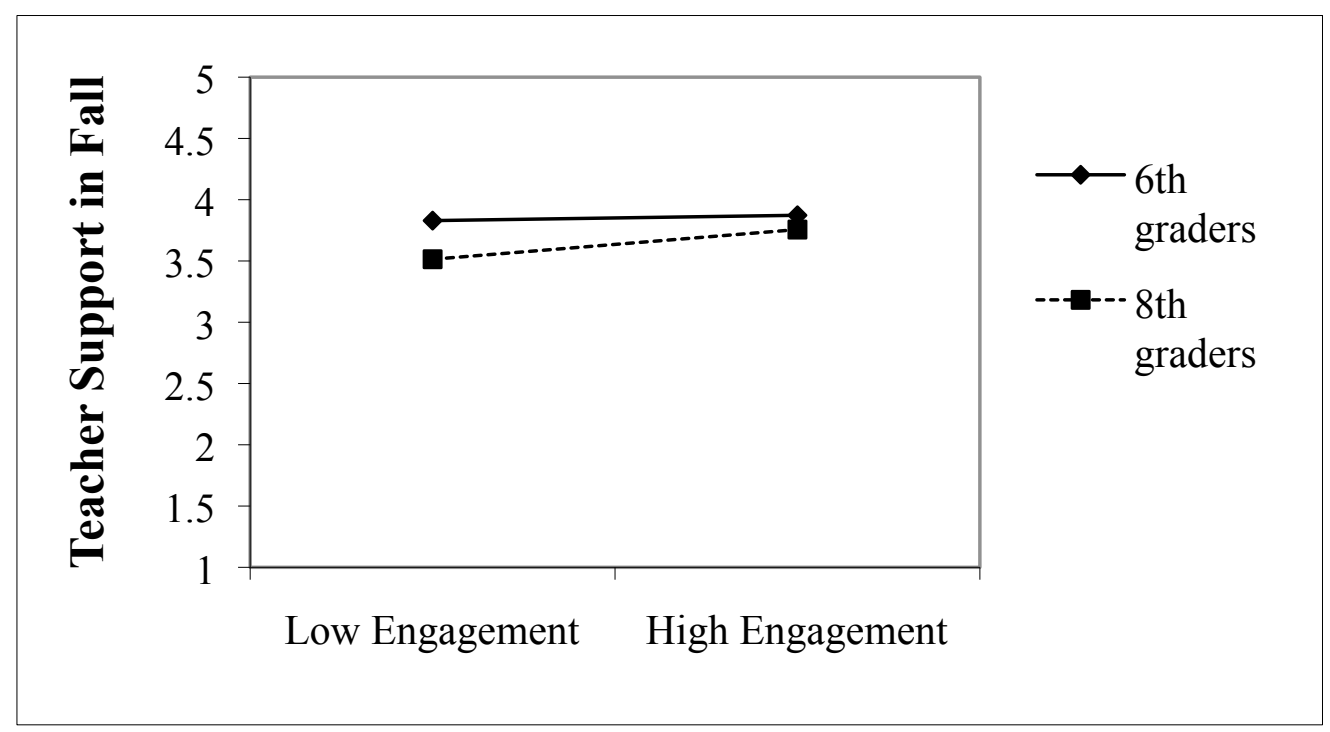


Figure 5.40 Interaction Between Disaffection (TR) and Grade on Teacher Support (SR) in Fall.



Figure 5.41 Relationship Between Disaffection (TR) and Teacher Support for $6^{\text {th }}$ and $8^{\text {th }}$ Graders in Fall.

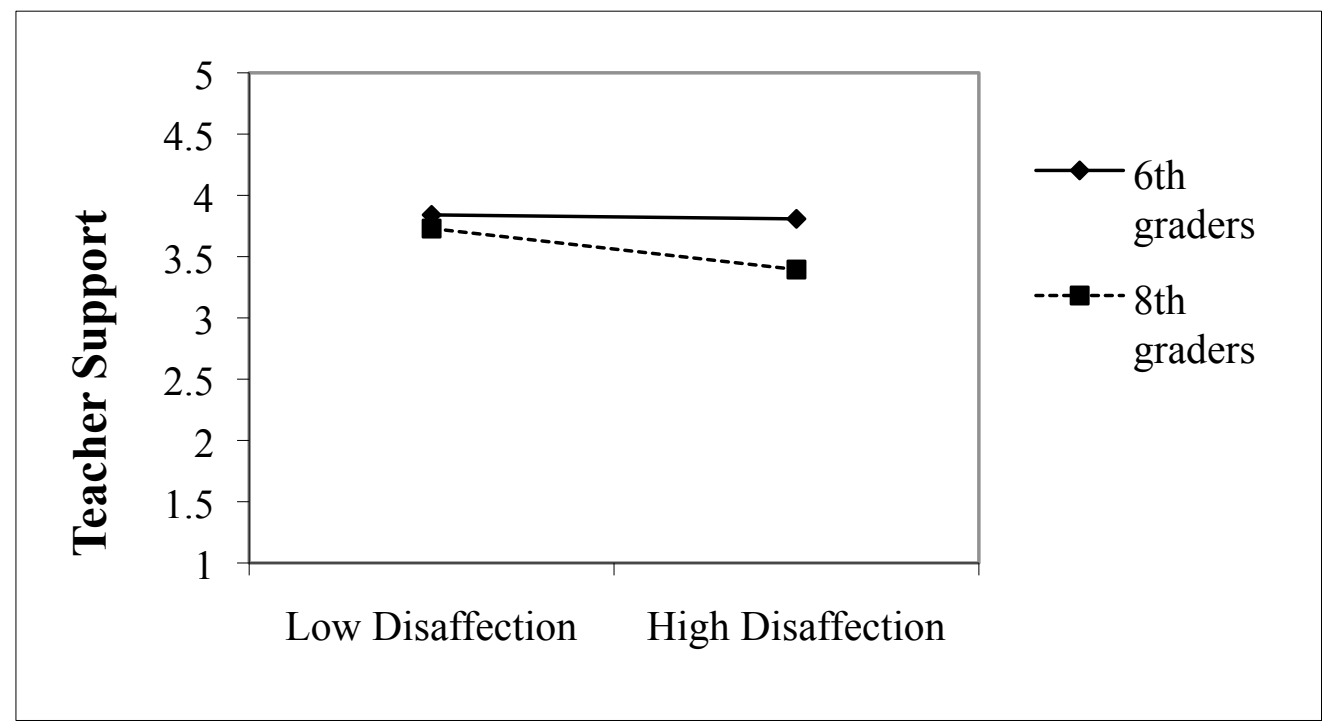

Research Question $\mathbf{5 b} \mathbf{b}$. Are there grade differences in the relationships between student engagement and disaffection (TR) and changes in teacher support (SR) from fall to spring? 
Finally, these gender interaction effects were examined across time in order to assess the potential impact of teacher-reported engagement and disaffection on changes in teacher support over the school year. Student grade-level was a significant moderator of the relationship between changes in teacher support and both engagement and disaffection (see Figures 5.42 and 5.43).

Figure 5.42. Interaction Between Engagement (TR) and Grade on Changes in Teacher Support (SR).

Fall

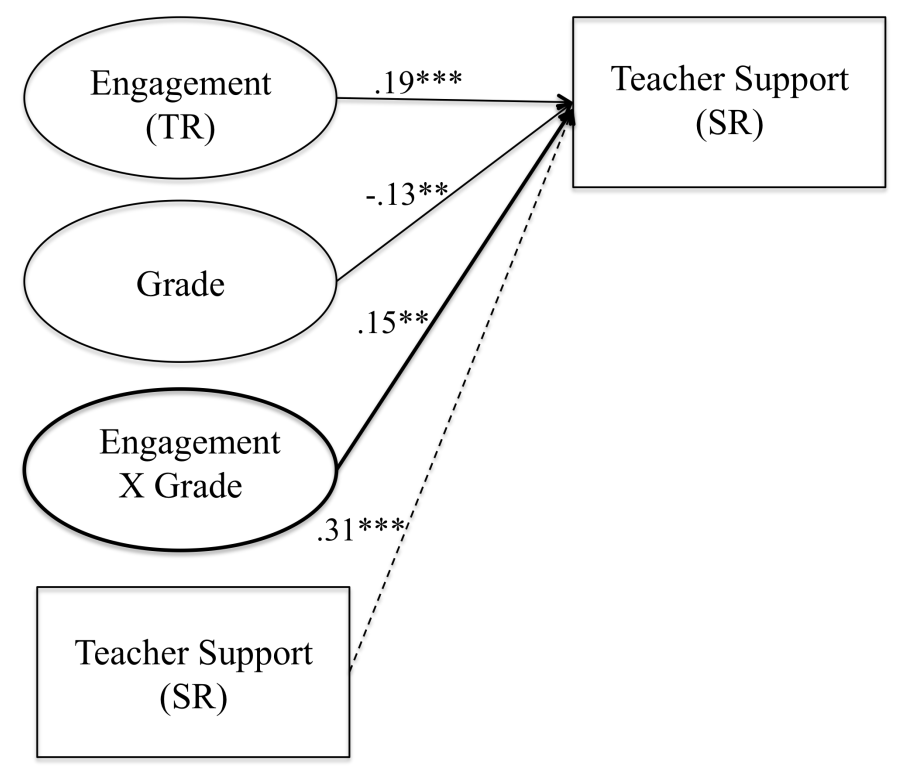

Spring

r Support 
Figure 5.43. Interaction Between Disaffection (TR) and Grade on Changes in Teacher Support (SR).

Fall

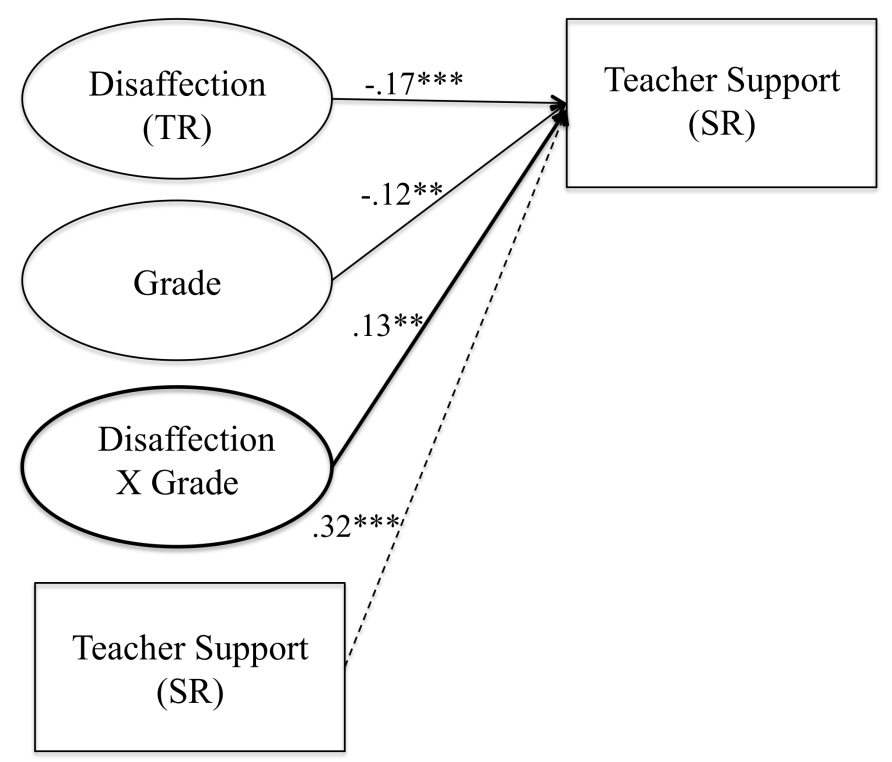

In order to better understand the significant grade interaction terms for engagement and disaffection on changes in teacher support, follow up regression analyses were conducted. By dummy coding grade and using first $6^{\text {th }}$ graders and then $7^{\text {th }}$ graders as the reference category, multiple linear regressions were used to identify the grades between which the significant interactions resided. Results indicated that a stronger positive connection was found between student engagement (TR) and teacher support (SR) for $8^{\text {th }}$ graders $(r=.46, p<.001)$ compared to both $7^{\text {th }}$ graders $(r=.21, p<.05)$ and $6^{\text {th }}$ graders $(r=.11, p>.05)$. Similarly, a stronger negative connection was found between student disaffection (TR) and teacher support (SR) for $8^{\text {th }}$ graders $(r=-.41, p<$ $.001)$ than for both and $7^{\text {th }} \operatorname{graders}(r=-.22, p<.01)$ and $6^{\text {th }}$ graders $(r=-.05, p>.05)$. These results suggest that engagement and disaffection were more important predictors of changes in teacher support for $8^{\text {th }}$ graders than for either $6^{\text {th }}$ or $7^{\text {th }}$ graders (Figures 5.44$5.51)$. 
Figure 5.44. Interaction Between Engagement (TR) and Grade (compared to $6^{\text {th }}$ grade) on Changes in Teacher Support (SR).

\section{Fall}

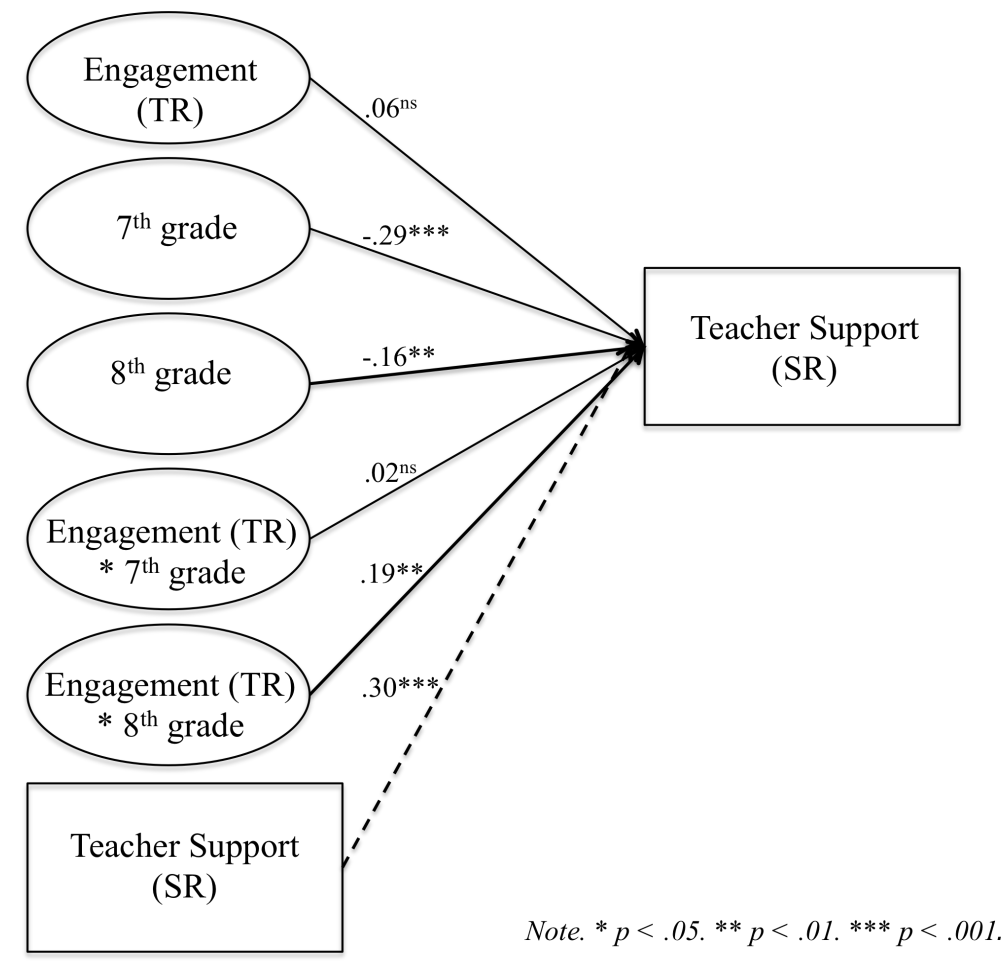

Figure 5.45. Relationship Between Engagement (TR) and Changes in Teacher Support (SR) for $6^{\text {th }}$ and $8^{\text {th }}$ graders.

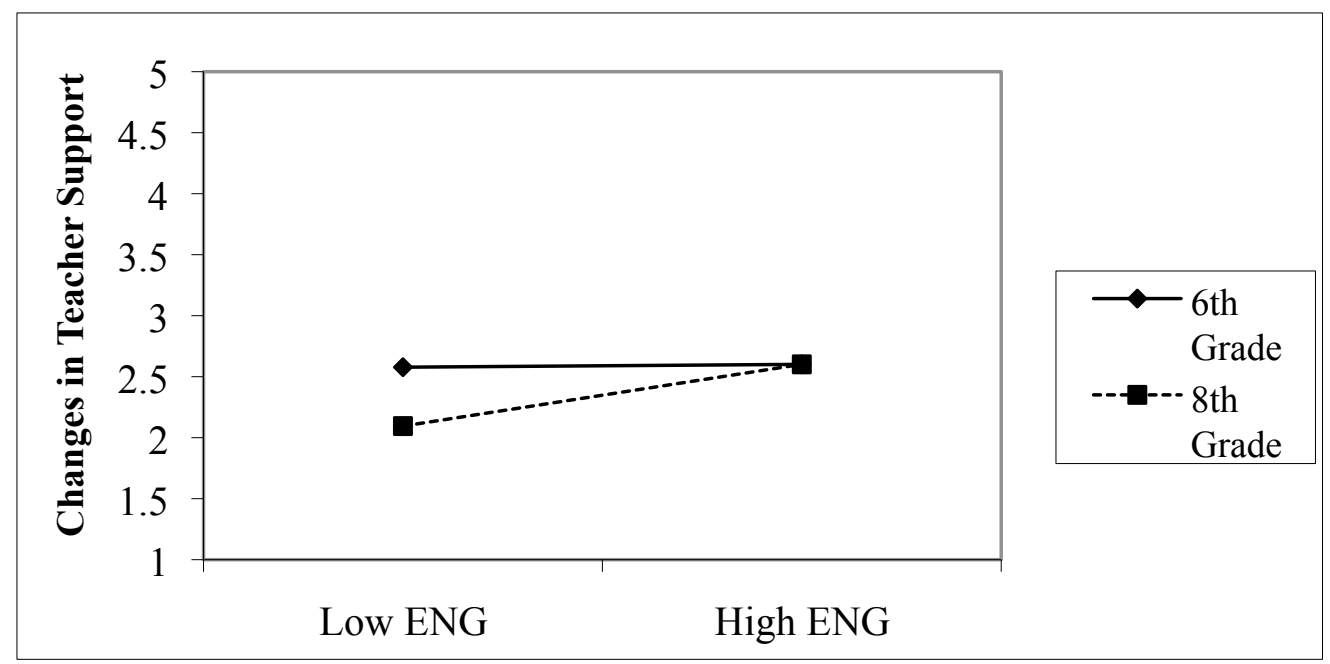


Figure 5.46. Interaction Between Engagement (TR) and Grade (compared to $7^{\text {th }}$ grade) on Changes in Teacher Support (SR).



Figure 5.47. Relationship Between Engagement (TR) and Changes in Teacher Support (SR) for $7^{\text {th }}$ and $8^{\text {th }}$ graders.

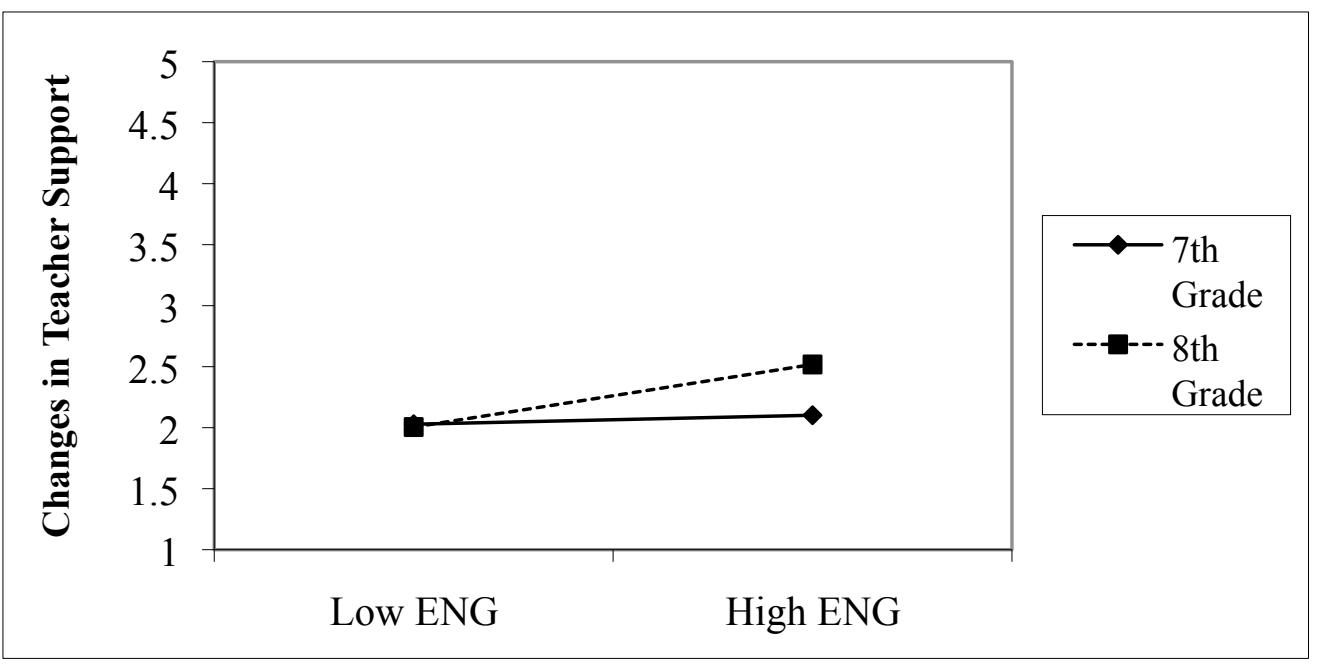


Figure 5.48. Interaction Between Disaffection (TR) and Grade (compared to $6^{\text {th }}$ grade) on Changes in Teacher Support (SR).

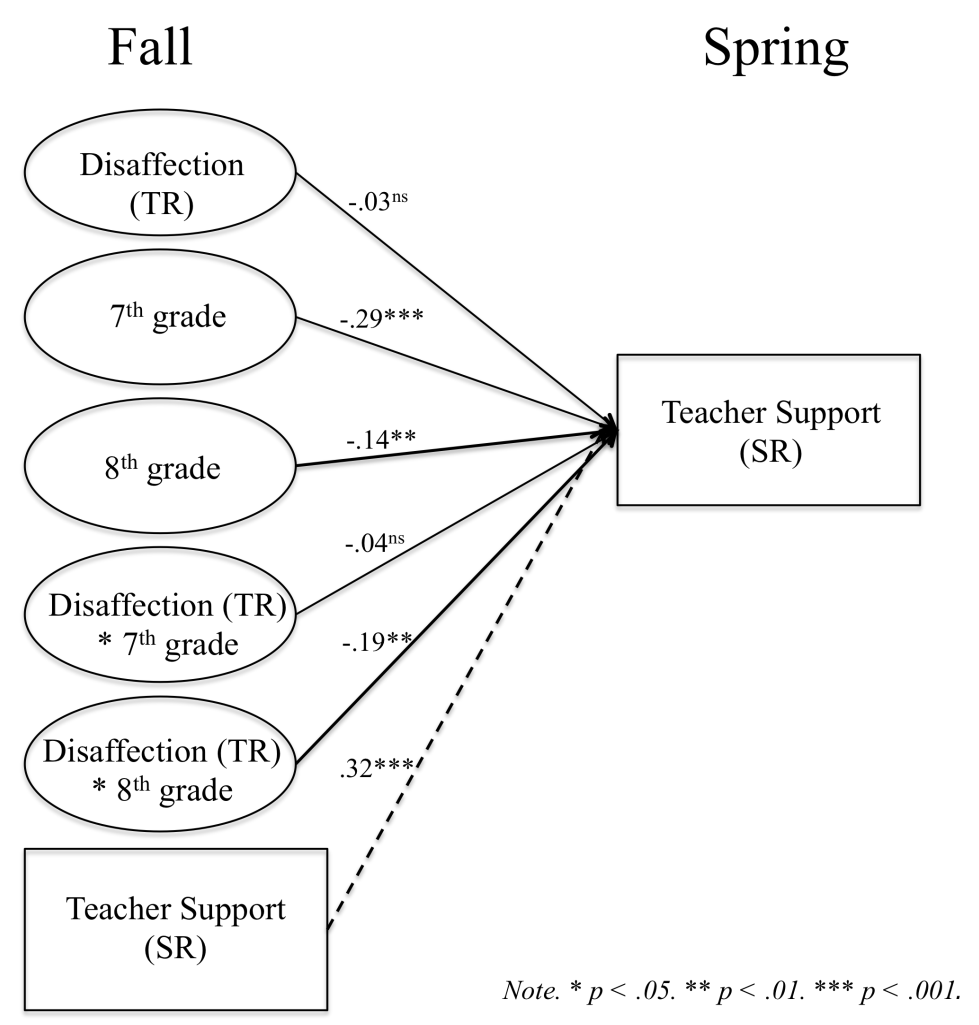

Figure 5.49. Relationship Between Engagement (TR) and Changes in Teacher Support for $6^{\text {th }}$ and $8^{\text {th }}$ graders.




Figure 5.50. Interaction Between Engagement (TR) and Grade (compared to $7^{\text {th }}$ grade) on Changes in Teacher Support (SR).

Fall



Figure 5.51. Relationship Between Disaffection (TR) and Changes in Teacher Support (SR) for $6^{\text {th }}$ and $8^{\text {th }}$ graders.

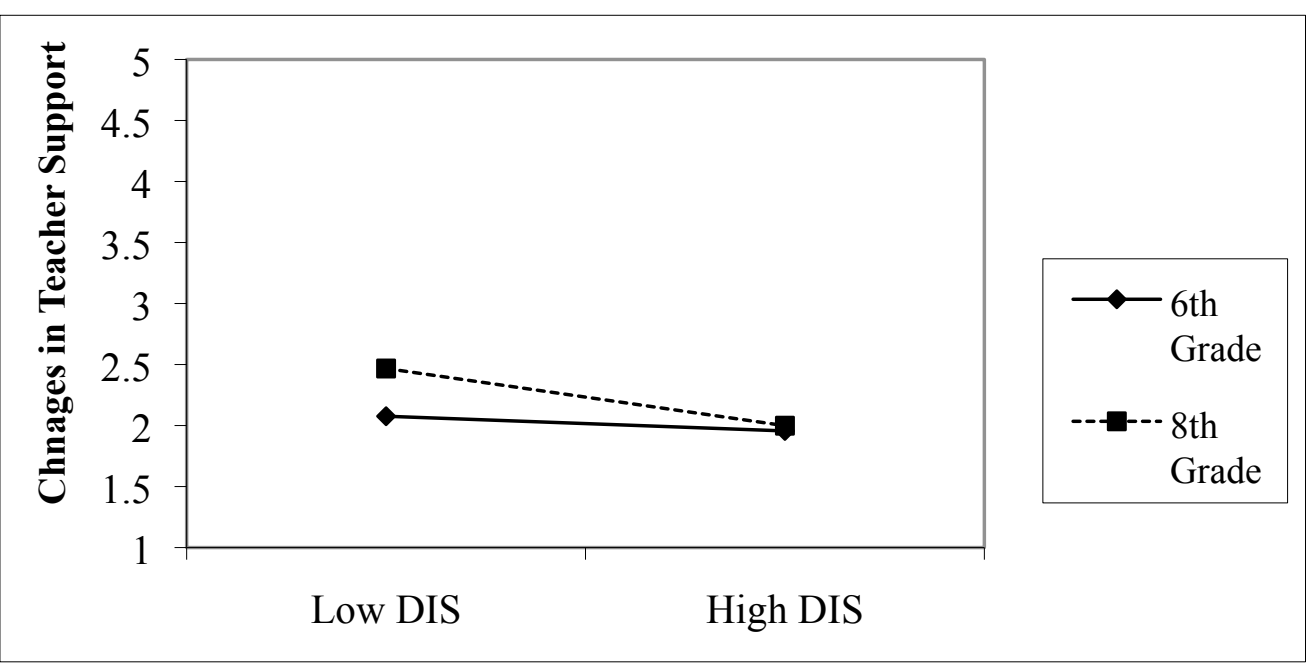


Research Question 5c1. Does each component of motivation (engagement and disaffection) as reported by teachers, have an effect on teacher support (SR) above and beyond the effect of the other component?

H5c1a) Student engagement (TR) will predict teacher support (SR), over and above disaffection within each time point (fall and spring).

H5c1b) Student disaffection (TR) will predict teacher support (SR), over and above engagement within each time point (fall and spring).

Linear multiple regression analyses were used to examine whether student engagement and student disaffection (TR) jointly and uniquely predicted teacher support (SR) within time points. Hypotheses $5 \mathrm{c} 1 \mathrm{a}$ was supported but hypothesis $5 \mathrm{c} 1 \mathrm{~b}$ was not. Engagement predicted teacher support above and beyond disaffection in fall and in spring. Disaffection did not exhibit unique effects over and above engagement (see Figures 5.52 and 5.53).

Figure 5.52 Relationship between Engagement, Disaffection, and Teacher Support in Fall.


Note. ${ }^{*} p<.05 . * * p<.01 .{ }^{* * *} p<.001$. 
Figure 5.53 Relationship between Engagement, Disaffection, and Teacher Support in Spring.

\section{Spring}

Spring

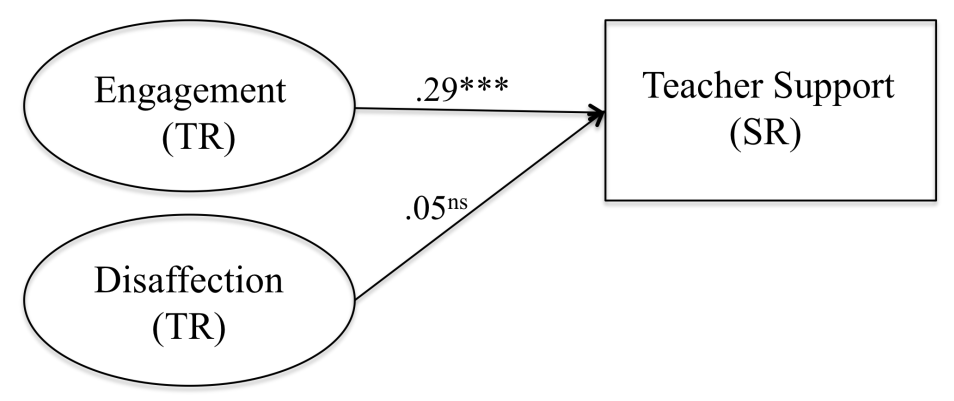

Note. $* p<.05 . * * p<.01 . * * * p<.001$.

Research Question 5c2. Does each component of motivation (engagement and

disaffection) as reported by teachers, have an effect on changes in teacher support (SR)

above and beyond the effect of the other component?

H5c2a) Student engagement (TR) in fall will predict changes in teacher support (SR) from fall to spring, over and above disaffection.

H5c2b) Student disaffection (TR) in fall will predict changes in teacher support (SR) from fall to spring, over and above engagement.

A linear multiple regression analysis was used to examine whether student engagement and student disaffection, as reported by teachers, jointly and uniquely predicted changes in teacher support, as reported by students. Hypotheses 5c1a and hypothesis $5 \mathrm{c} 1 \mathrm{~b}$ were not supported. Neither component of motivation predicted changes in teacher support over and above other, perhaps because the two components of motivation were too highly correlated $(r=-.76)$ to demonstrate unique effects (see Figure 5.54). 
Figure 5.54. Relationship Between Engagement, Disaffection, and Teacher Support Over Time.



Note. ${ }^{*} p<.05 . * * p<.01 . * * * p<.001$.

Research Question 5d1. Do the effects of one component of motivation (TR) on teacher support (SR) depend on the level of the other component within each time point (fall and spring)?

H5d1a) The relationship between engagement (TR) and teacher support (SR) (in fall and in spring) will be stronger for students who are low in disaffection, suggesting low disaffection boost the positive effects of engagement.

H5d1b) The relationship between disaffection (TR) and teacher support (SR) (in fall and in spring) will be weaker for students who are high in engagement, suggesting high engagement buffers the negative effects of disaffection. In order to address the question of whether there is a significant interaction between engagement and disaffection, teacher support (SR) in fall was regressed on student engagement and disaffection (TR) in the fall (both grand mean centered) and the interaction term (engagement*disaffection). The process was repeated with the constructs in spring. In fall, Hypothesis 5d1a was supported, but Hypothesis 5d1b was not 
supported. In fall, the relationship between engagement (TR) and teacher support (SR) was stronger for students who were low in disaffection, suggesting low disaffection boosted the positive effects of engagement. However, instead of the relationship between disaffection and teachers support being weaker for students perceived as highly engaged, these relations was actually stronger such that the slope for highly engaged students was steeper than for less engaged students. Neither hypothesis was supported for spring; no significant interaction effects were found for engagement and disaffection (TR) in spring.

Figure 5.55. Interaction Between Engagement (TR) and Disaffection (TR) on Teacher Support (SR) in Fall.

Fall



\section{Fall} Support 
Figure 5.56 Disaffection Moderating the Relationship between Engagement and Teacher Support in Fall.



Figure 5.57 Engagement Moderating the Relationship between Disaffection and Teacher Support in Fall.

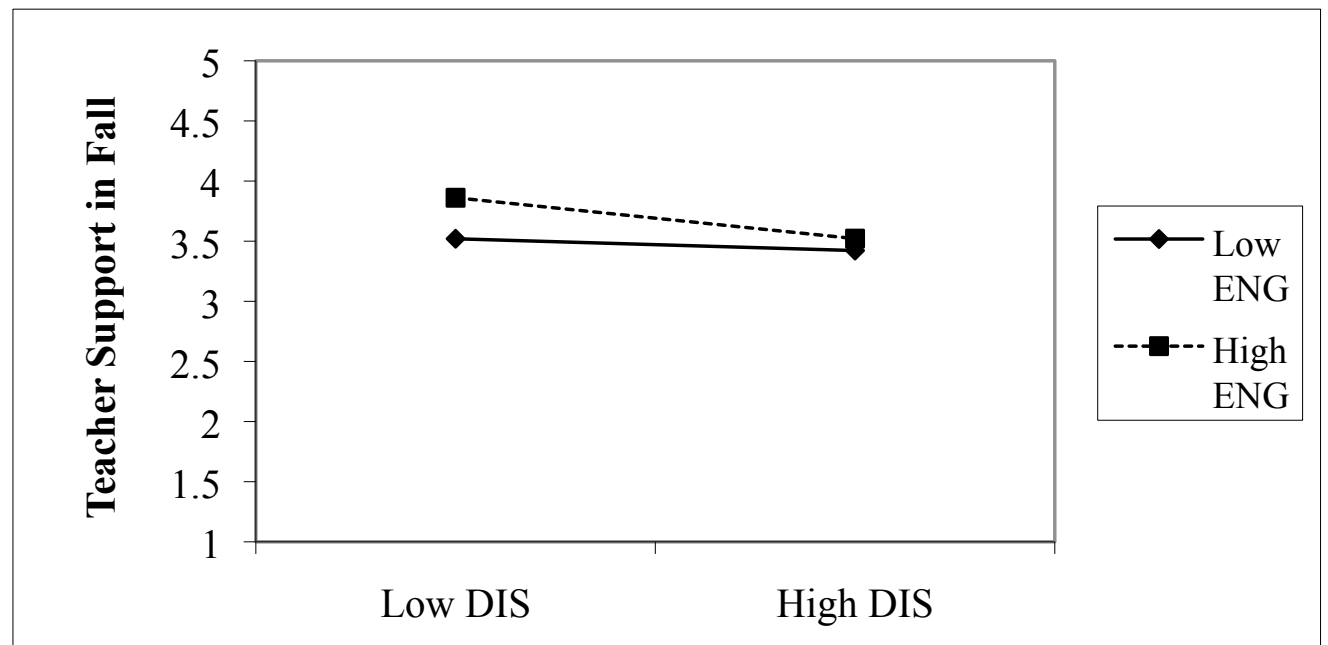

Research Question 5d2. Do the effects of one component of motivation (TR) on changes in teacher support (SR) from fall to spring depend on the level of the other component? H5d2a) The relationship between engagement (TR) and changes in teacher support (SR) will be stronger for students who are low in disaffection, suggesting low disaffection boosts the positive effects of engagement. 
H5d2b) The relationship between disaffection (TR) and changes in teacher support (SR) will be weaker for students who are high in engagement, suggesting high engagement buffers the negative effects of disaffection.

In order to address the question of whether there is a significant interaction between engagement and disaffection, teacher support (SR) in spring was regressed on student engagement and disaffection (TR) in the fall (both grand mean centered) and the interaction term (engagement*disaffection), controlling for teacher support in the fall (grand mean centered).

Hypothesis 5d1 was supported (see Figure 5.58). The relationship between engagement and changes in teacher support depended on the level of disaffection, such that for students whom teachers' perceived as less disaffected, the relationship between engagement and teacher support was positive while for students who were perceived as having high disaffection, the relationship between engagement and teacher support was slightly negative (see Figure 5.59). Engaged students with low disaffection gained more teacher support from fall to spring than did engaged students with high disaffection. Unfortunately, Hypothesis $5 \mathrm{~d} 2$ was not supported. Instead of the relationship between disaffection and teachers support being weaker for students perceived as highly engaged, these relations was actually stronger such that the slope for highly engaged students was steeper than for less engaged students (see Figure 5.60). Disaffected students with high engagement lost more teacher support form fall to spring than did disaffected students with low engagement. 
Figure 5.58. Interaction Between Engagement and Disaffection on Changes in Teacher Support from Fall to Spring.

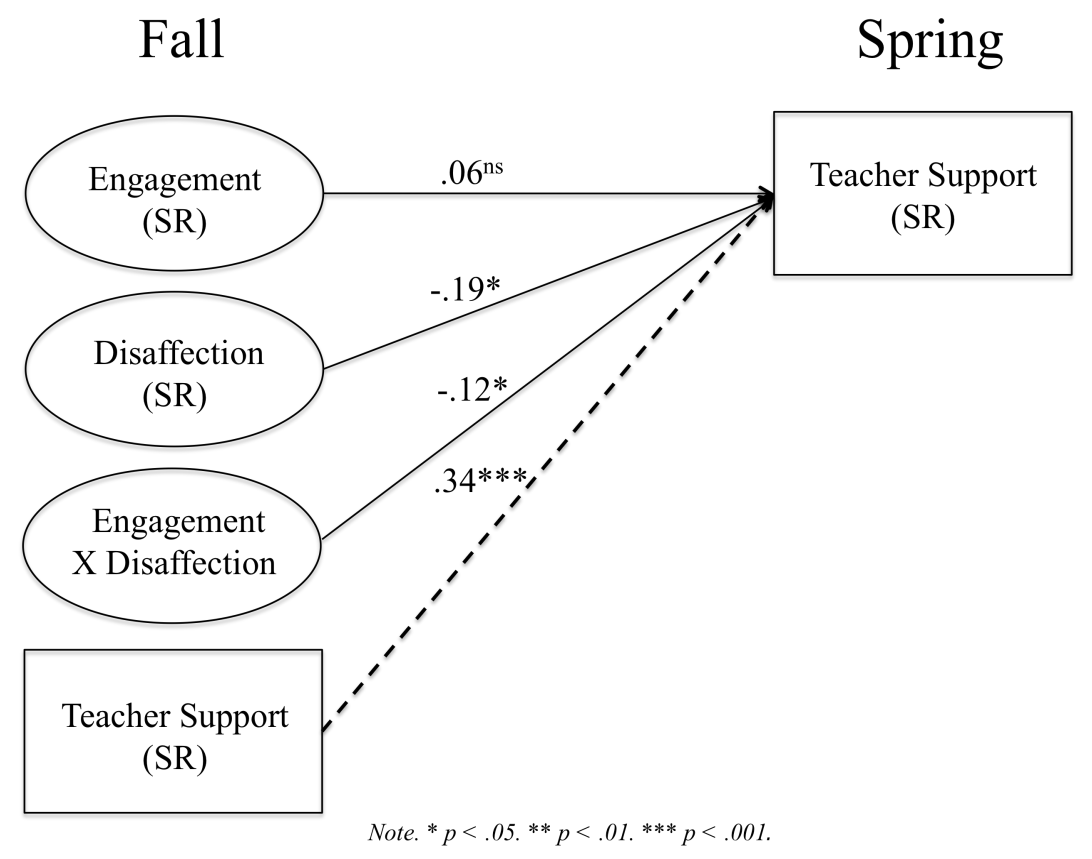

Figure 5.59. Relationship Between Engagement and Changes in Teacher Support from Fall to Spring.

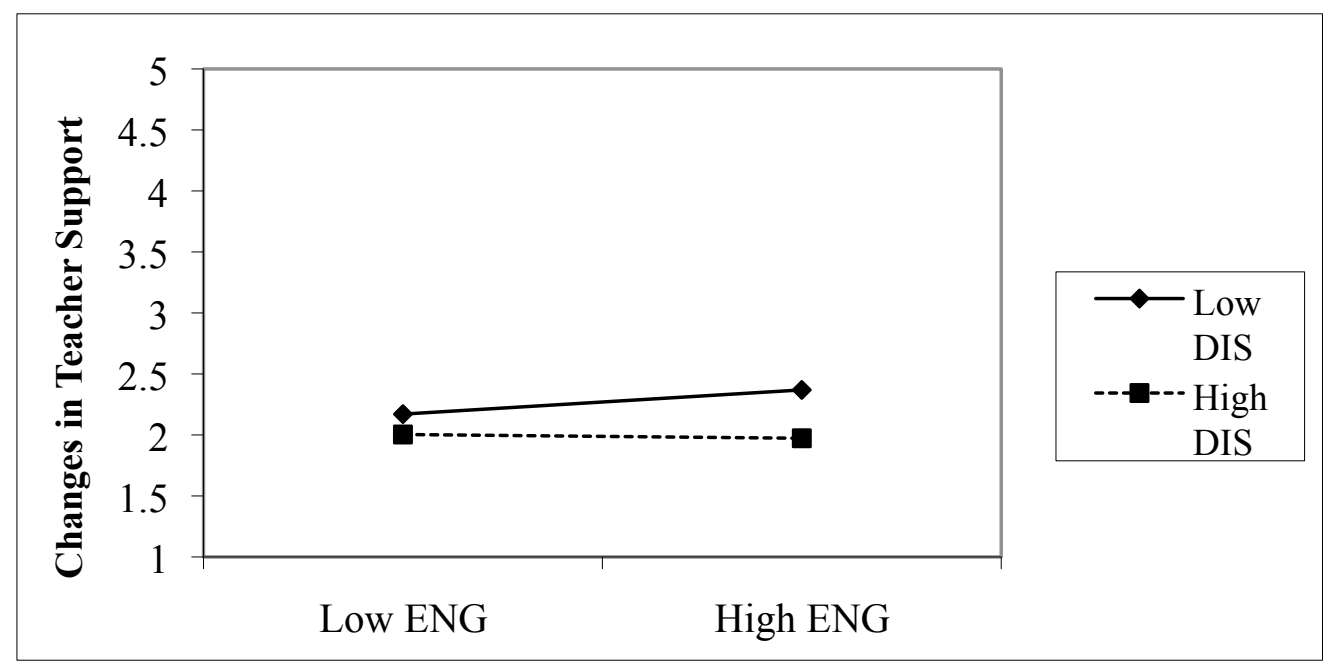


Figure 5.60. Relationship Between Disaffection and Changes in Teacher Support from Fall to Spring.






\section{Chapter 6}

\section{Discussion}

In this study, a conceptualization of engagement and disaffection as

distinguishable components of student motivation was used to examine the individual and combined utility of student engagement and disaffection as predictors of changes in teacher support across the school year. Unlike the majority of studies that have investigated these constructs and viewed them solely from the perspective of teachers' impacts on students, this study utilized a motivational framework rooted in Deci and Ryan's (1985) self-determination theory to examine the feedback or reciprocal effects of students' motivation on changes in teacher's provision of warmth, structure, and autonomy support over time. The results of this study are consistent with the presence of feedback effects of student motivation on teachers' provision of support. These reciprocal effects were examined across the academic school year, in a racially and ethnically diverse sample utilizing both student- and teacher-reports in order to gain a deeper understanding of the ways in which multiple components of student motivation may shape teacher support.

\section{Summary of Findings}

A summary of study results can be found in Table 6.1. Following a review of the descriptive findings, the results for each research question are summarized below. In terms of descriptive statistics, the constructs of interest displayed the expected patterns found in previous research despite the fact that this urban sample was racially and ethnically diverse. Satisfactory internal consistencies were found for all the measures used in this study. Somewhat surprisingly considering the number of risk factors 


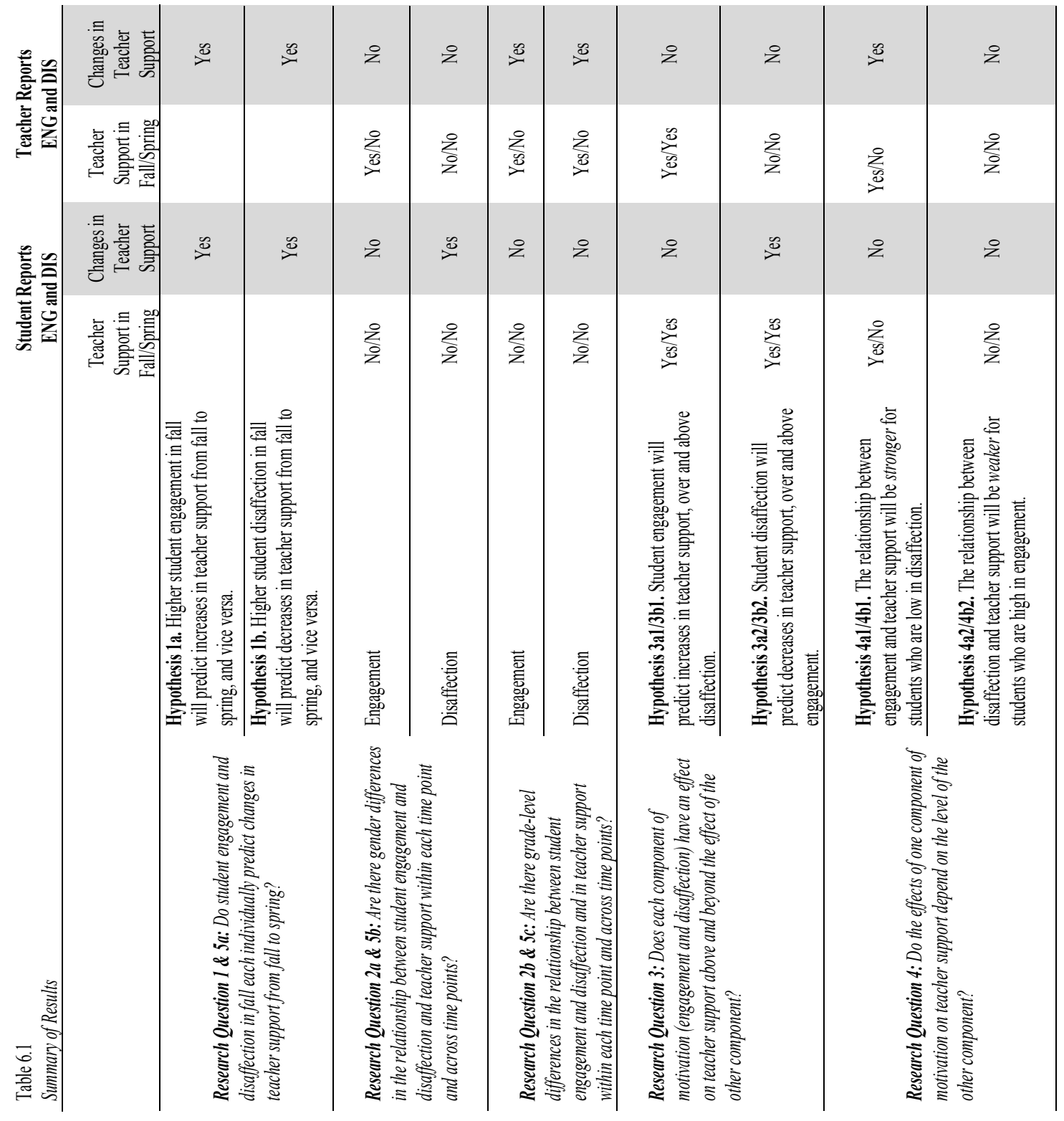


experienced by participants in this sample, both reporters perceived students as having high levels of engagement and low levels of disaffection at both time points. At the same time, however, for both student- and teacher-reports, engagement, declined significantly across the school year while disaffection increased significantly, as is typical for middle school students. Teacher support also declined significantly from fall to spring. As expected, according to both reporters, engagement and disaffection were highly negatively correlated, especially for teacher reports. Consistent with previous research, the correlations between teacher support and the two components of motivation were strong and in the expected directions (positive for engagement, negative for disaffection) for both reporters at both time points. Finally, cross-time stabilities for the constructs of interest were moderately strong. These strong stabilities may have made it more difficult to predict changes over time.

Reciprocal effects. As hypothesized, findings indicated that both components of student motivation predicted the way teachers treated their students over the course of the school year. Specifically, engagement and disaffection as reported both by students and by teachers individually predicted changes in teacher support over the school year, with engagement predicting increases in teacher motivational support from fall to spring, and disaffection predicting decreases in teacher support. These findings indicated that engaged students were more likely to gain teacher motivational support across the school year whereas disaffected students were more likely to lose teacher support. The only other study that documented such reciprocal effects had a sample composed almost exclusively of Caucasian students from working/middle class backgrounds, making this replication with a more diverse sample especially meaningful. Taken together, these 
findings, which were replicated across reporters, suggest that, over time, a student's motivational state may impact how her teachers treat her in the classroom.

Differences by gender. Mean-level gender differences in the constructs of interest were consistent with previous research that suggests girls tend to be more motivated than boys in school (Furrer, Skinner, \& Kindermann, 2008). In fall, girls reported being significantly more engaged and receiving significantly more teacher support than did boys. Boys reported significantly more disaffection at both time points than did girls. Similarly, teachers reported that girls were significantly more engaged and significantly less disaffected in fall and in spring compared to boys.

However, despite these differences in mean-level, there were few gender differences in the strength of the reciprocal effects of student motivation on teacher support. Only student-reported disaffection and teacher-reported engagement in the fall demonstrated any gender differences in their effects on teacher's provision of support. Specifically, the significant interaction between student-reported disaffection and student gender in predicting changes in teacher support indicated that, although disaffected students of both genders lost teacher support over the school year, disaffected boys lost significantly more teacher support than did disaffected girls. However, no other gender interactions were found for student-reports-- neither disaffection within time point (in fall or spring) nor for engagement either within or across time. Similarly, for teacher-reports, only one gender interaction was significant: The relationship between teacher-reported engagement and teacher support in the fall was moderated by gender such that, although engagement was a significant correlate of teacher support in fall for students of both genders, this association was stronger for boys than for girls. However, no other gender 
interactions were found for teacher-reported engagement or disaffection either within or across time. In sum, of the 12 tests for gender differences in the links between student motivation and teacher support, only two were found, and both cases demonstrated significant gender effects of the same form, such that engagement and disaffection demonstrated significant reciprocal effects for both genders; however, the effects were significantly stronger for boys.

Differences by grade-level. Across reporters, differences in mean levels of engagement and disaffection as a function of grade were consistent with previous research suggesting that engagement decreases and disaffection increases as students progress through middle school (Wigfield et al, 2006). Specifically, mean levels of student-reported engagement were significantly higher for $6^{\text {th }}$ than for $7^{\text {th }}$ or for $8^{\text {th }}$ graders in fall and spring; in addition, mean levels of disaffection was significantly lower for $6^{\text {th }}$ than for $7^{\text {th }}$ or for $8^{\text {th }}$ graders in the spring. For teacher reports, only mean levels of disaffection in spring significantly differed by grade level such that disaffection was higher for $8^{\text {th }}$ than for $7^{\text {th }}$ graders. As expected, in both fall and spring, $6^{\text {th }}$ graders reported significantly higher mean levels of teacher support than did $8^{\text {th }}$ graders. Seventh graders also reported significantly higher mean levels of teacher support than did $8^{\text {th }}$ graders, but only in spring. Taken together, examination of mean-level differences suggested that student motivation and teacher support decline as students progress through middle school.

In terms of grade differences in the connections between student motivation and teacher support, in general, significant reciprocal effects of student motivation on teacher support within and across time were found for students of all grades for both student- and 
teacher reports; however there were some grade-level differences in the strength of those associations. Although no grade-level differences in the effects of student motivation on teacher support were found for engagement or disaffection as reported by students, a consistent pattern of grade-level differences emerged from teacher-reports of both aspects of student motivation in fall and from fall to spring. In fall, the relationship between engagement and teacher support was significantly stronger for $7^{\text {th }}$ and $8^{\text {th }}$ graders compared to $6^{\text {th }}$ graders, suggesting that engagement may be more important in shaping teacher support for older students. Also in fall, disaffection was a more important predictor of teacher support for $8^{\text {th }}$ graders than for $6^{\text {th }}$ graders, suggesting that, like engagement, disaffection may be more important in shaping teacher support for older students. Finally, grade differences were found in the extent to which both engagement and disaffection predicted changes in teacher support. Student engagement was a stronger predictor of changes in teacher support for $8^{\text {th }}$ graders compared to either $6^{\text {th }}$ or $7^{\text {th }}$ graders. Similarly, student disaffection was a stronger predictor of decreases in teacher support for $8^{\text {th }}$ graders than for either $6^{\text {th }}$ or $7^{\text {th }}$ graders. Taken together, these results indicate that engagement and disaffection are more important predictors of teacher support in fall and in changes in teacher support over the school year for older students ( $8^{\text {th }}$ graders) than for younger students $\left(6^{\text {th }}\right.$ or $7^{\text {th }}$ graders $)$.

Engagement versus disaffection. Analyses of the unique and interaction effects of the two components of motivation produced conflicting evidence about the utility of separating engagement from disaffection. Assessing the unique effects of engagement and disaffection suggested partial support for their combined predictive utility, though less support was found for teacher-reports than student reports. 
For student- reports, each component of motivation (engagement and disaffection) made a unique contribution to teacher support above and beyond the effect of the other component; these unique effects were replicated within each time point (in fall and in spring). Across time, student-reported disaffection demonstrated unique effects on changes in teacher support but student-reported engagement did not. Given that unmotivated students are among the top stressors reported by teachers (Chang 2009), it appears likely that disaffection could exert a more powerful influence on teachers' behavior than would engagement, since problems with motivation are more salient to teachers.

For teacher-reports, however, less justification was found for separating engagement and disaffection into individual variables. In both fall and spring, engagement contributed uniquely to teacher motivational support; however, disaffection did not make a significant unique contribution to teacher support above and beyond engagement. Neither component of motivation predicted changes in teacher support above and beyond the other component. Due to the high correlation between teacherreported engagement and disaffection, it seemed that these variables were too closely related to show unique effects.

Finally, partial support was found for the separation of engagement and disaffection based on some significant interaction effects between the two constructs in fall and across time. Specifically, as predicted, the relationship between student- and teacher-reported engagement and teacher support was stronger for students who were low in disaffection, suggesting low disaffection boosted the positive effects of engagement; At the same time, and contrary to expectations, instead of the relationship 
between disaffection and teacher support being weaker for students perceived as highly engaged, these relations were actually stronger such that the slope for highly engaged students was steeper than for less engaged students. This pattern of effects was replicated across reporters but it was found only in fall. These same effects were also found for teacher-reports of student motivation as predictors of changes in teacher support. Specifically, students' engagement was a stronger predictor of gains in teacher support for students who were low in disaffection compared to students who were highly disaffected. Unfortunately, however, disaffection was a stronger predictor of losses in teacher support for highly engaged students than for their equally disaffected but less engaged peers.

Multiple reporters. Although there were some differences in results between the student- and teacher-reported measures of engagement and disaffection, the overall picture that emerged was similar across reporters. Teachers' seemed to underestimate mean levels of disaffection in fall compared to student reports, but by spring, student- and teacher-reported mean levels of disaffection were very similar. Teacher-reported measures of engagement and disaffection had higher reliabilities and stronger intercorrelations than did student-reports. However, consistent with a positive within reporter bias, teacher support, which is a student-report measure, more strongly correlated with students' reports of their engagement and disaffection than to teachers' reports.

Measures from both reporters showed significant main effects in predicting changes in teacher support but significant unique effects were found only for student reports of disaffection. Conversely, significant interaction effects between the two components of motivation in predicting changes in teacher support were found for 
teacher-reports but not for student reports. Finally, multiple significant grade interactions were found for teacher-reported engagement and disaffection but not for student reports of those constructs.

\section{Strengths and Limitations}

Relying on the motivational framework provided by Deci and Ryan's (1985) selfdetermination theory, this study presented a conceptualization of student engagement and disaffection as antecedents to, instead of consequences of, teacher's provision of support over the course of the academic year. However, as with all research, this study includes both strengths and limitations. Specific issues will be discussed in regard to the sample, measurement, and design of the current study.

Sample. Unlike Skinner and Belmont's (1993) previous study of reciprocal effects, which relied on a sample composed of working/middle class Caucasian students, the current study garnered enhanced generalizability by assessing low SES students from a variety of ethnic and racial backgrounds. While diverse, the present study's sample was limited by its slight underrepresentation of African American students (only $9 \%$ of the student body is African American). Also, because student participation is voluntary, a selection bias may have been present such that highly disaffected or unmotivated students likely opted out of completing the survey at higher rates than other students. Finally, a school that allows researchers to conduct a five-year longitudinal study with its students can be assumed to be high functioning and thus may not be a good example of the average school serving underprivileged students.

Measurement. A significant strength of this study is the inclusion of both student- and teacher-reports of student engagement and disaffection. Examining these 
multiple perspectives and finding that (with one notable exception) the constructs of interest behaved similarly across reporters increases our confidence in this study's conceptualization of student motivation. Having multiple reports also helps reduce the effects of common-method bias and affords us the opportunity to compare and contrast the student/participant perspective of these constructs with the adult/observer perspective.

At the same time, however, this study would have benefited from the addition of more items assessing teacher motivational support as well as the addition of teacherreports of their provision of motivational support in the classroom. Including more teacher support items would have made it possible to separate that construct into its three subcomponents (warmth, autonomy support, and structure) and thus gain a more detailed understanding of the specific teacher behaviors that are predicted by student engagement and disaffection. The current study was also limited by its focus on only student-reports of teacher support, which consequently prevented us from examining how teachers perceive themselves to be affected by their students. However, a case can be made that a student's perception of teacher support would be more important in terms of impacting motivation than a teacher's intention concerning support, as people can be affected by their perceptions of events more than the objective experience of an event. While also having teacher-reports of teacher support would undoubtedly add to this study, by capturing the students' experience of teacher support we have hopefully captured the active ingredient through which teachers' impact students.

Finally, considering that all of the target constructs are observable, the study would have been strengthened by the inclusion of observational measures. These could have been an effective way of reducing common-method bias. The addition of 
observational data could have further bolstered evidence of construct validity and perhaps elucidated the specific student actions that trigger provision or withdrawal of teacher support.

Design. Another strength of this study is the design, which included two time points. This enabled prediction of changes in teacher support from fall to spring. While two data points per year is certainly an improvement over the more common one point design, the development of teacher-student interactions does not necessarily conform to a bi-yearly schedule. Two measurement points per year are likely not sufficient to capture the episodic and incremental developments that student-teacher relationships undergo daily. Denser time-ordered measurement points, coupled with observational data, would be more likely to capture the reciprocal interactions that foster the overall changes in teacher support from fall to spring.

\section{Implications and Future Studies}

This study addressed a gap in the literature by adding to our understanding of classroom dynamics, specifically those relating to student motivation, teachers' provision of support and, ultimately, educational outcomes. This study highlights the importance of investigating how students can impact their teachers and suggests that findings from correlational research that have been interpreted as documenting that teacher support affects student engagement should be viewed as potentially bidirectional. This study also makes an important contribution in that it examined the effects of engagement and disaffection separately in order to learn how teachers may react to these two sets of student actions independently, jointly, and in interaction with each other. This study also speaks to the importance of considering information about the effects of teacher-student 
interactions from both teachers' and students' perspectives, and whether relationship dynamics differ as a function of students' gender and grade-level.

Reciprocal effects. The current study has important implications for future research. This is one of the few studies that has directly examined the feedback side of motivational dynamics in the classroom by viewing students as active agents capable of having an impact on teachers' behavior over time. By utilizing a two-time point design that made directional interpretations possible, this study was able to investigate how student motivation at the beginning of the school year predicts (and may influence) changes in teacher's provision of support over the course of the school year. Evidence for the presence of these reciprocal or feedback effects was strong and was replicated across reporters (student- and teacher-reports) for both components of motivation (engagement and disaffection). This replication of Skinner and Belmont's (1993) early study of reciprocal effects is made more meaningful because of the dissimilarity of the two samples, suggesting increased generalizability of these results across school contexts and historical periods.

The significant effects of engagement and disaffection taken individually as predictors of changes in teacher support suggest that the findings from correlational research that have been interpreted as documenting how teacher support affects student engagement should be viewed as potentially bidirectional. If further studies across reporters, grade levels, and populations continue to find evidence for the existence of feedback effects, it follows that previous one-time point correlational studies should be reconsidered from the alternative direction suggesting the possibility that student motivation could also be affecting teacher support. The powerful influence of teacher 
support in shaping changes in students' motivation is well documented; however, the current study suggests that students, through the support they elicit from their teachers, may be influencing their own later motivation and future achievement (Fredricks et al, 2004). Continuing to view the association between teacher support and student motivation as unidirectional may hinder our understanding of these effects and limit our ability to craft effective interventions to increase student engagement and decrease student disaffection in school.

The results of the current study suggesting feedback effects, taken together with the lag-time evidence of feedforward effects of teacher support on student motivation, suggest that the association between student engagement and disaffection and teacher support may not only be bi-directional but may also constitute a self-perpetuating feedback loop. Future research could use longitudinal designs that incorporate more time points to further explore the preliminary findings that indicate highly engaged students receive more subsequent teacher support, which in turn increases their engagement. Unfortunately, the converse may represent an even more powerful feedback loop; teachers' withdrawal of support from disaffected students could increase those students' levels of disaffection, which causes teachers to withdraw further or become coercive, bringing with it a greater likelihood of underachievement and eventual drop out (Skinner \& Belmont, 1993). The notion that the students who would benefit the most from increases in teacher support (those who show high disaffection and low engagement) are the least likely to receive it, carries weighty implications for the direction of future interventions. Future research could also investigate characteristics of teachers who do not follow the typical pattern, namely, who do not respond to disaffection with reduced 
support. What is it about certain teachers that may allow them to meet students' disaffection with more support instead of less?

At-risk students. By studying students at high risk for academic failure, we increased our confidence that the results of this study are applicable and relevant to vulnerable student populations. Approximately $21 \%$ of the students in this study were English language learners, and the sample included a high proportion of students who spoke other languages at home including Spanish, Russian, Ukrainian, and Vietnamese. With almost $85 \%$ of the school population qualifying for free or reduced priced lunch, this sample represented students from low SES families. Taken together, these demographic characteristics represent powerful risk factors that typically predict low engagement, academic underachievement, and the probability of high school drop out (Wingfield et al 2006). If such students are more likely to be disaffected, they may also disproportionately experience the withdrawal of teacher support as part of the detrimental feedback loops suggested in this study. Finding support for the presence of reciprocal effects in this at-risk sample, which until now had only been found in a predominantly Caucasian working/middle-class sample, also increases our confidence in the possible pervasiveness of these effects across contexts.

Engagement versus disaffection. A primary goal of this study was to examine the effects of student engagement and disaffection separately. Often viewed as opposite ends of the same continuum, these distinguishable but related constructs were examined individually in order to explore how they act separately and jointly, and how they interact with each other. As expected, in this study, engagement and disaffection were strongly negatively correlated for student reports and especially for teacher reports. One 
explanation for the strength of association in teacher-reports is that teachers must rely on their observations to infer students' emotional states; hence, their understanding of these constructs could have been based more on students' behavior as they were unable to directly access students' feeling states, such as anxiety, boredom, or enjoyment, that help differentiate these constructs from each other. Teacher-reports of engagement and disaffection are based on global assessments of students' motivation while students' reports of these constructs are based on their direct experiences of these multiple, complex and ever-changing states. Student may also mask their negative emotions in the classroom thus denying their teachers access to the full spectrum of their motivationrelated emotions. Perhaps this idea of unintentional over-simplification, in which teachers assume that students who are engaged can't be disaffected (and vice versa), contributes to the stronger correlations between teacher-reports of the two components of motivation.

As hypothesized, for both student-and teacher-reports, engagement and disaffection each individually predicted changes in teacher support. For student reports, disaffection emerged as a somewhat stronger predictor than did engagement; although for teacher reports, the two components appeared to have approximately equal effects on changes in teacher support. Moreover, when both engagement and disaffection were evaluated in the same model within time points, student-reports of engagement and disaffection each contributed unique variance to teacher support; although for teacher-reports, only engagement demonstrated predictive utility above and beyond disaffection. Perhaps because teacher-reports of disaffection at both time points had much lower reliabilities than engagement, the effects of disaffection were attenuated and so did not demonstrate unique effects within time. 
It was more difficult to document these unique effects in predicting change over time. One possible explanation is that our target outcomes became smaller because of the stability of teacher support, which may explain why for student-reports, both components demonstrated unique effects within time but only disaffection demonstrated unique effects over time. Another explanation for this finding is that, looking back at the main effects, disaffection exerted a somewhat stronger influence on changes in teacher support than did engagement for student-reports. Contrary to expectations, no unique effects were found for teacher-reports of engagement or disaffection over time. One explanation for this finding is the high overlap between teacher-reported engagement and disaffection, as reflected in the high correlation between them. However, if multicollinearity were the major cause of this lack of significant unique effects of disaffection in fall or spring, it would not explain why unique effects were found for engagement in fall and in spring. Perhaps teacher-reported engagement demonstrated unique effects within each time point because engagement is such a precious and salient resource for teachers. Hence, it may be important to distinguish engagement from disaffection, if student feelings of disaffection seem to be more powerful predictors whereas teacher-reports suggest the salience of engagement to teachers.

Finally, of most interest to the question of whether engagement and disaffection should be treated as separate constructs are the results of the analyses examining the interactions between engagement and disaffection as predictors of teacher support within and across time. For both student and teacher reports, there were significant interaction effects for fall but not for spring. One explanation for these results is that in fall teachers were still getting to know their students and were more likely to pay close attention to 
students' behavior and adjust their own behavior accordingly. However, by spring, perhaps teachers had calibrated to students and created, at least in their own minds, individual motivation profiles for each student. Thus, they would be less likely to adjust their behavior towards students based on engagement and disaffection but rather would react to students based on their continued assumptions of how motivated a student is normally. Teacher's mental models of student motivation may be a stable system where student are labeled as either motivated or unmotivated and treated accordingly.

In addition to the significant engagement and disaffection interaction effects in fall, this interaction was also significant across time but for teacher reports only. One possible explanation for the more complex patterns seen in teacher-reports is that the factor that is most important in shaping changes in teachers' behaviors is not how students are actually feeling or how hard they think they are trying (as captured by student-reports) but how teachers perceive students to be feeling and acting (as captured by teacher-reports). If teachers weight how engaged students are in deciding how to respond to their disaffection, this subtle calculus may show up only in teachers' perceptions of these motivational states.

The interpretation of the significant interactions between engagement and disaffection was the same for within time point (fall), across time points (fall to spring) as well as across reporters. In each of these analyses, the relationship between engagement and (changes in) teacher support was stronger for students who were low in disaffection compared to student who were highly disaffected. As predicted, low levels of disaffection boosted the positive effects of engagement on (changes in) teacher support.

On the other hand, the relationship between disaffection and teacher 
support/changes in teacher support did not show the expected pattern in the interactions. Instead of the relationship between disaffection and teacher support being weaker for students perceived as highly engaged, these relations were actually stronger such that the negative slope between disaffection and teacher support for highly engaged students was steeper than for less engaged students. Instead of high engagement buffering the effects of disaffection, results suggested that teachers reacted to disaffection by withdrawing their support more strongly when students were highly engaged than they did when reacting to disaffection from less engaged students. Perhaps because teachers believe that students who are high in both engagement and disaffection have the potential to be highly engaged, they unintentionally express their disappointment that such students are not meeting their motivational potential by withdrawing motivational support.

On the other hand, perhaps teachers are attempting to be compensatory and not punitive in their provision of support. Teachers may be withdrawing less from their most vulnerable students (who are low in engagement and high in disaffection) and withdrawing more from their more motivated students (who are high in engagement and high in disaffection) because they are trying not to hurt the students who are already struggling the most. Teachers are could be withdrawing less from the students who need teacher support the most. Future studies could investigate this unexpected interaction effect in several ways. First, researchers could interview teachers about students who appear to be high on both constructs in order to understand how teachers feel about this possible student profile. It would also be important for future studies to include teacherreports of teacher support in order to see if these patterns hold across reporters.

Second, these types of questions highlight a need for future studies to utilize 
person-centered analyses to better understand how these multifaceted, changing student motivational states can interact with each other to predict changes in teachers' behavior over time. Considering that engagement and disaffection are highly negatively correlated, future person-centered studies can ask whether there are students who appear to be high or low on both components of motivation and investigate what these students look like in the classroom. Person-centered analyses could also assist in investigating whether students are perhaps masking disaffection and examine how well teachers can identify students who are attempting to hide aspects of their motivational states in the classroom.

Third, future studies could help us make sense of these interaction effects by separating engagement and disaffection into their emotional and behavioral components. The current study did not have enough items to separate each component of motivation into its emotional and behavioral aspects; however, doing so may elucidate the specific dimensions of motivation that are creating these interaction effects. Disaffection encompasses a particularly broad range of emotions from anxiety, to boredom, to frustration, which, when combined with aspect of engagement, may each create very different motivational profiles. Within a group of students who show high disaffection, there may be multiple different disaffection profiles; namely one disaffected student may be high on anxiety and "going through the motions" which could make them more attractive to teachers than a disaffected student who is high on frustration and disruptive classroom behavior. Because disaffection can be imbued with these different emotional overtones, it may be that some of these kinds of disaffection are more common in combination with high engagement; for example, anxious disaffection may be more commonly paired with high engagement than is frustrated disaffection. What kinds of 
disaffection and engagement do these students show in the classroom and do their kinds of motivation differ from students showing traditional (high on one component, low on the other) profiles of motivation? These potentially different profiles that may exist within each construct of motivation may represent an important key to understanding and interpreting how engagement and disaffection jointly interact. In sum, despite important distinctions between the two forms of student motivation as evidenced by the presence of some unique effects and interaction effects within fall and across time, more research must be done in order to better understand the benefits and consequences of treating the components of motivation separately.

Student- vs. teacher-reports. A key goal of this study was to compare students' subjective reports of their motivation with teachers' perceptions of students' motivation in the classroom. Examination of mean levels of the target constructs displayed the same overall patterns across reporters; namely mean levels of both components of motivation were similar although teachers did appear to underestimate disaffection in fall; however, by spring, student- and teacher-reports of both constructs were very similar. Perhaps teachers began the year with an overly optimistic view of student's lack of disaffection, but as the school year progressed and teachers became more familiar with their students (or their students were more comfortable expressing their disaffection), teachers recalibrated their perceptions to be more consistent with student-reports. The other notable measurement difference between student and teacher reports concerned the internal consistency reliability of the study constructs over time. Reliabilities were approximately equal except for teacher reports of engagement, which were much higher than the Cronbach's alpha for any of the other measures. Perhaps the combination of 
student engagement being a coveted and salient motivational state to teachers as well as the assumption that teachers are more consistent reporters could partially explain the elevated reliability for teacher-reported engagement.

As predictors of changes in teacher support, student- and teacher reported motivation revealed similar patterns of results and the overall picture that emerged was similar across reporters. Specifically, support for the individual reciprocal effects of student engagement and disaffection were found across reporters. All of the gender effects and engagement*disaffection interaction effects took the same form and reflected the same interpretations across reporters. However, a few key differences emerged across student- and teacher-reports. Teacher-reported engagement and disaffection, as a predictor of teacher support, indicated a consistent pattern of grade-level effects in the fall and over time; in contrast, no grade-level effects of any kind were found for student reports. One explanation for the finding of grade differences is that, as students become more disaffected as they progress through middle school, their teachers react more strongly to students' increasing disaffection. Similarly, because engaged students become harder to find as students get older, teachers may react more strongly to older students who do exhibit engagement.

Perhaps there is an important possible third variable to consider when interpreting the results of analyses using teacher-reports of student engagement and disaffection. Considering that teachers are responsible for assigning grades to students, teachers' may be biased by student's academic achievement when rating students on their engagement and disaffection in the classroom. The same biases may be impacting students' reports of teacher support as well. Namely, it is possible that students with higher grades reported 
experiencing more motivational support from their teachers because they were succeeding academically and their teachers were supporting them because of their success and not their motivation. Future studies could examine if engagement still has significant feedback effects on changes in teacher support in analyses that control for achievement, as well as investigating possible interaction effects between the components of motivation and achievement. Future studies could also use observational measures to gain a perspective on these relationships, since observers would be blind to students' prior academic successes or challenges in the classroom.

Finally, the use of multi-reporter data has implications for how the associations between these constructs actually play out in the classroom. Having both student and teacher reports does more than double the number of perspectives, it may also speak to the sequential nature of the ways in which the two parties actively influence each other. One may suggest that there is a different "expectation" at each step in these possible motivational feedback loops. Specifically, in terms of teachers impacting student motivation, student-reports of teacher support may theoretically be more important to understanding students' later motivation than teacher reports because it's the students' perception of teacher support that would inform a change in their motivation, not the teachers' intentions. Similarly, teachers' perceptions of student motivation may be better at explaining teacher's subsequent provision of motivational support because teachers are likely to be reacting to their perceptions of students motivation, not the students' internal understanding of their motivation or even students objective displays of engagement and disaffection in the classroom. Taken together, this presents the idea that for each step in the process, first one party exhibits a behavior and then the other party interprets this 
action from their own perspective before reacting to it. Investigating more thoroughly this idea of the sequential nature of these constructs and the importance of translating an experience into a specific perspective represents another avenue for future research to explore (Skinner \& Belmont, 1993).

Differences by gender and grade-level. Across reporters, findings indicated reciprocal effects of student motivation on teacher support were present for students of all grades and genders; however, there were some differences in the strength of these associations - they were more pronounced for boys and for older students. Engagement in fall (as reported by teachers) and disaffection over time (as reported by students) were more important in shaping teacher support for boys than for girls. Considering that, according to research on teachers' differential treatment, boys receive more teacher attention and interactions than do girls (Sadker, Sadker, \& Klein, 1991), perhaps these findings simply reflect a consistent pattern of teacher behavior that is focused more on boys. If teachers normally direct more attention and effort towards boys, an engaged and enthusiastic boy may be rewarded with further increased teacher support. Similarly, if teachers are paying more attention to boys and boys' motivational states are more salient to teachers, then they may be more reactive to boys' disaffection in the classroom. Another explanation for why disaffection was a stronger predictor of decreases in teacher support for boys is that previous studies suggest that boys generally do more poorly in school and, as was found in this sample, boys are generally less motivated in school than girls (Sadker, Sadker, \& Klein, 1991). Perhaps teachers, anticipating low motivation from boys, were influenced by these expectations to consequently be more reactive to boys' disaffection. Boys may also be losing more teacher support across the school year 
because boys are generally not performing as well academically and this may influence teachers' perceptions of boys' motivation in the classroom.

The other interesting finding concerning differences in the strength of associations between student motivation and teacher support suggested that for teacher-reports, engagement and disaffection had a stronger effect on teacher support for $8^{\text {th }}$ graders than for younger students (both in fall and across time). One explanation for why motivation would be a more important predictor of changes in teacher support for older students is that teachers were aware of the looming transition of their students to high school and this may have raised the stakes and possibly influenced teachers to be more strategic with their provision of support. Teachers may have focused their support on preparing engaged $8^{\text {th }}$ graders for high school and withdrew their support from disaffected $8^{\text {th }}$ graders who they did not think would benefit from extra support. However, these interaction effects were not found in spring suggesting that if this were true, teachers abandoned this process by spring. As these grade differences were not replicated for student-reports, it may be important for future studies to continue to examine these gradelevel effects from the student's perspective.

\section{Implications for Intervention and Policy}

Taken together, the evidence for the influence of students' motivation on teachers' classroom behavior highlights the urgency of intervening in student-teacher interaction patterns in order to support students' academic success. The ability of teacher support to positively influence students' engagement and subsequent achievement in school is well established; however, the possibility that students, through the motivation they express in class, are also capable of impacting how much support they receive from their teachers 
suggests the existence of amplifying feedback loops in which the motivationally rich get richer and the poor get poorer. By helping teachers learn to support their disaffected students as much as they support their engaged students, classroom interventions could ensure that the most vulnerable students don't receive the least motivational support.

In order to help improve teachers' practices with the students who are most in need of support, it will be important to find out why disaffection is so stressful to teachers. Does student disaffection threaten teachers' self-system processes by thwarting their need for competence, in which case interventions should be aimed at helping teachers' needfulfillment? Perhaps an important first step to intervening in classroom motivational dynamics would be to talk openly with teachers about how normal and understandable it is to react to disaffection negatively (Furrer, Skinner, \& Pitzer, in press). By normalizing this reasonable but taboo teacher reaction, perhaps researchers can engage in an open dialogue with teachers in order to gain better first-person knowledge about the factors influencing teachers' tendency to withdraw support from disaffected students. It may also be beneficial to remind teachers of the power they have to alter students' motivation by providing students with warmth, structure, and autonomy support. Informing teachers that withdrawing from disaffected students will most likely lead to those students becoming more disaffected may also be part of an intervention program that emphasizes the value of improving classroom practices for the benefit of teachers. Finally, interventions stemming from self-determination theory aimed at helping teachers improve their teaching style in all three aspects of motivational support have demonstrated positive impacts on students needs-fulfillment and engagement in the classroom (Tessier, Sarrazin, \& Ntoumanis, 2010). 
Beyond traditional intervention approaches, mindfulness-based interventions may be a promising tool for helping teachers view student disaffection as beneficial information about a student's needs instead of as a stressful challenge, an indication of a student's inalterable limitations, or a personal insult to their teaching. Mindfulness can be used as a tool to help practitioners become more aware of their thoughts, actions and emotions but without judgment, which could help teachers become aware of their behaviors towards less motivated students without instilling in them a sense of blame or guilt. Mindfulness has been shown to help decrease emotional reactivity and improve emotional regulation, which may assist teachers in curbing their initial reaction of withdrawing support from unmotivated students and instead help teachers react in ways that promote the engagement of discouraged students (Roeser, 2013). Mindfulness may assist teachers in reframing challenging students as opportunities for professional growth by reminding teachers how fundamental they are to improving students' motivation (Skinner \& Beers, in press).

Finally, it will be critical to explore individual factors that may explain differences among teachers in their provision of warmth, structure and autonomy support. What personal qualities or resources allow some teachers to provide optimal levels of support to all students even though most teachers follow a general trend of withdrawing support from students struggling with motivation in school? Teachers who are able to provide their students with high, consistent levels of support or who respond to student disaffection with increased support could be valuable in informing key outcomes for future interventions. Investigating the underlying mechanisms behind some teachers' ability to provide increasing support to disaffected students is vital step in changing 
teacher behavior patterns to reflect a compensatory rather than deprivation model of support.

\section{Conclusion}

This study, by utilizing a two time-point design, a diverse at-risk student population, and measures from both student and teacher perspectives, attempted to make a contribution to the sparse but potentially important research literature examining how student's motivation can shape their experiences with teachers in the classroom. This study demonstrated that student engagement and disaffection may influence changes in the quality of support students receive from their teachers over the school year. This support for the existence of reciprocal effects of students on teachers was found across student- and teacher-reports and appeared consistent across gender and grade-level, although in some cases it was somewhat more pronounced for boys and $8^{\text {th }}$ graders.

Overall, this study found some support for the importance of examining the effects of engagement and disaffection separately, based on unique effects in which studentreports of disaffection and teacher-reports of engagement seemed to be more salient as well as on a few interactions suggesting that the effects of engagement may depend on students' levels of disaffection and vice versa. Such patterns demonstrated the need for further investigation of the structure of each component of student motivation, with special attention to the emotional components of disaffection. Furthermore, the presence of reciprocal effects of student motivation on teachers' provision of support over time has particularly pertinent implications for future studies; namely, the vast majority of the studies examining these constructs, which have looked at single time point correlations between teacher support and student motivation and have been interpreted as 
unidirectional, my be reevaluated as bidirectional given the current study's findings. The current study suggests that students, as well as teachers, may be influencing motivational dynamics in the classroom. Taken together, the results of the present study suggest that students may be shaping their teachers' provision of motivational support and thus may be influencing their subsequent engagement and achievement in school. 
References

Anderman, E. M., \& Maehr, M. L. (1994). Motivation and schooling in middle grades. Review of Educational Research, 64(2), 287-309.

Anderson, K. E., Lytton, H., \& Romney, D. M. (1986). Mothers' interactions with normal and conduct-disordered boys: Who affects whom? Developmental Psychology, 22(5), 604-609.

Altermatt, E. R., Jovanovic, J., \& Perry, M. (1998). Bias or responsivity? Sex and achievement-level effects on teachers' classroom questioning practices. Journal of Educational Psychology,90(3), 516-527.

Babad, E. (1993). Teachers' differential behavior. Educational Psychology Review, 5(4), 347-376.

Baker, J. A. (1999). Teacher-student interaction in urban at-risk classrooms: Differential behavior, relationship quality, and student satisfaction with school. The Elementary School Journal, 100(1), 57-70.

Bell, R. Q. (1968). A reinterpretation of the direction of effects in studies of socialization. Psychological Review; 75(2), 81.

Bell, R. Q. (1977) "Socialization findings reexamined." Child effects on adults (1977): $53-84$

Brunk, M. A., \& Henggeler, S. W. (1984). Child influences on adult controls: An experiment investigation. Developmental Psychology, 20(6), 1074-1081.

Carr, M., \& Kurtz-Costes, B. E. (2011). Is being smart everything? The influence of studentachievement on teachers' perceptions. British Journal of Educational Psychology, 64(2),263-276. 
Castell C., A. (1988) Teacher - Student interactions and race in integrated classrooms. The Journal of Educational Research, 92(6), 115-120

Chang M.-L. (2009) An appraisal perspective of teacher burnout: Examining the emotional work of teachers. Educational Psychology Review 21(3), 193-218

Deci, E. L., \& Ryan, R. M. (1985). Intrinsic motivation and self-determination in human behavior. Springer.

Finn, J. D. (1989). Withdrawing from school. Review of Educational Research, 59(2), 117-142.

Fredricks, J. A., Blumenfeld, P. C., \& Paris, A. H. (2004, January). School engagement: Potential of the concept, state of the evidence. Review of Educational Research, 74(1), 59-109.

Furrer, C. Skinner, E. A. \& Kindermann, T. (2003, April). How the motivationally "rich" get "richer": Reciprocal effects of student engagement in the classroom on changes in teacher support over the school year. Poster session presented at the biennial conference of the Society for Research in Child Development.

Furrer, C. J., Skinner, E. A., \& Pitzer, J. R. (in press). The influence of teacher and peer relationships on students' classroom engagement and everyday resilience. In D. J. Shernoff \& J. Bempechat (Eds.), National Society for the Study of Education Yearbook: Engaging Youth in Schools: Empirically-based Models to Guide Future Innovations.

Gottfried, A. E., Fleming, J. F., \& Gottfried, A. W. (2001). Continuity of academic intrinsic motivation from childhood through late adolescence: A longitudinal study. Journal of Educational Psychology, 93(1), 3-13. 
Greenwood, C. R. (1999). Reflections on a research career: Perspective on 35 years of research at the Juniper Gardens Children's Project. Exceptional Children, 66, 722.

Grant, L., \& Rothenberg, J. (1986). The social enhancement of ability differences: Teacher-student interactions in first-and second-grade reading groups. The Elementary School Journal, 87(1), 29-49.

Guthrie, J. T., \& Davis, M. H. (2003). Motivating struggling readers in middle school through an engagement model of classroom practice. Reading \& Writing Quarterly, 19(1), 59-85. Routledge.

Houts, R. M., Caspi, A., Pianta, R. M., Arseneault, L., \& Moffitt, T. E. (2010). The challenging pupil in the classroom: The effect of the child on the teacher. Psychological Science, 21, 1802-1810.

Irvine, J. J. (1985). Teacher communication patterns as related to the race and sex of the student. The Journal of Educational Research, 338-345

Janosz, M., Archambault, I., Morizot, J. and Pagani, L. S. (2008), School engagement trajectories and their differential predictive relations to dropout. Journal of Social Issues, 64: 21-40.

Jelsma, B. M. (1982). Adult control behaviors: The interaction between orientation toward control in women and activity level of children. Unpublished doctoral dissertation, University of Rochester.

Jimerson, S. R., Campos, E., \& Greif, J. L. (2003). Toward an understanding of definitions and measures of school engagement and related terms. The California School Psychologist, 8, 7-27. 
Johnson, S., Cooper, C., Cartwright, S., Donald, I., Taylor, P., \& Millet, C. (2005). The experience of work-related stress across occupations. Journal of managerial psychology, 20(2), 178-187.

Kindermann, T. A. (1993). Natural peer groups as contexts for individual development: The case of children's motivation in school. Developmental psychology, 29(6), 970

Klem, A. M., \& Connell, J. P. (2004). Relationships matter: Linking teacher support to student engagement and achievement. Journal of School Health, 74(7), 262-273.

Ladd, G. W., Birch, S. H., \& Buhs, E. S. (1999). Children's social and scholastic lives in kindergarten: Related spheres of influence? Child Development, 70(6), 13731400.

Marks, H. M. (2000). Student engagement in instructional activity: Patterns in the elementary, middle, and high school years. American Educational Research Journal, 37(1), 153-184.

Martin, A. J., \& Dowson, M. (2009). Interpersonal relationships, motivation, engagement, and achievement: Yields for theory, current issues, and educational practice. Review of Educational Research, 79(1), 327-365.

Morrison, G. M., Robertson, L., Laurie, B. and Kelly, J. (2002), Protective factors related to antisocial behavior trajectories. Journal of Clinical Psychology, 58: 277-290.

Newberry, M., \& Davis, H. A. (2008). The role of elementary teachers' conceptions of closeness to students on their differential behaviour in the classroom. Teaching and Teacher Education, 24(8), 1965-1985.

Pelletier, L. G., Séguin-Lévesque, C., \& Legault, L. (2002). Pressure from above and 
pressure from below as determinants of teachers' motivation and teaching behaviors. Journal of Educational Psychology, 94(1), 186

Pelletier, L. G., \& Vallerand, R. J. (1996). Supervisors' beliefs and subordinates' intrinsic motivation: A behavioral confirmation analysis. Journal of Personality and Social Psychology, 71(2), 331

Roeser, R. W. (2013). Mindfulness and human development: A commentary on the special issue. Research in Human Development, 10(3), 273-283.

Roeser, R. W., Skinner, E., Beers, J., \& Jennings, P. A. (2012). Mindfulness Training and Teachers' Professional Development: An emerging area of research and practice. Child Development perspectives, 6(2), 167-173.

Ryan. M., \& Deci, E. L. (2000). Self-determination theory and the facilitation of intrinsic motivation, social development, and well-being. American Psychologist, 55, 6878.

Sadker, M., Sadker, D., \& Klein, S. (1991). The issue of gender in elementary and secondary education. Review of research in education, 17, 269-334.

Skinner, E., \& Beers, J. (in press). Mindfulness and teachers' coping in the classroom: A developmental model of teacher stress, coping, and everyday resilience. In K. Chonert-Reichl \& R. Roeser (Eds.), Mindfulness and teachers' coping in the classroom: A developmental model of teacher stress, coping, and everyday resilience: Handbook on mindfulness in education: Emerging theory, research, and programs. Berlin: Springer Verlag 
Simpson, A. W., \& Erickson, M. T. (1983). Teachers' verbal and nonverbal communication patterns as a function of teacher race, student gender, and student race. American Educational Research Journal, 20(2), 183-198.

Skinner, E. (2012, May 8). Motivation in education: The teacher's role in the developmental dynamics of engagement, coping, and motivational resilience. Presentation presented at School of Education, Portland State University.

Skinner, E. A., \& Belmont, M. J. (1993). Motivation in the classroom: Reciprocal effects of teacher behavior and student engagement across the school year. Journal of Educational Psychology, 85(4), 571-581.

Skinner, E., Furrer, C., Marchand, G., \& Kindermann, T. (2008). Engagement and disaffection in the classroom: Part of a larger motivational dynamic? Journal of Educational Psychology, 100(4), 765-781.

Skinner, E. A., Kindermann, T. A., Connell, J. P., \& Wellborn, J. G. (2009). Engagement as an organizational construct in the dynamics of motivational development. In K. Wentzel \& A. Wigfield (Eds.), Handbook of motivation in school (pp. 223-245). Malwah, NJ: Erlbaum.

Skinner, E., Kinderman, T., \& Furrer, C. (2009). A motivational perspective on engagement and disaffection: Conceptualization and assessment of children's behavioral and emotional participation in academic activities in the classroom. Educational and Psychological Measurement, 69(3), 493-525.

Skinner, E. A., Wellborn, J. G., \& Connell, J. P. (1990). What is takes to do well in school and whether I've got it: The role of perceived control in children's engagement and school achievement Journal of Educational Psychology, 82, 22- 
32.

Tabachnick, B. G., \& Fidell, L. S. (2007). Using multivariate statistics (5th ed.). Boston: Pearson Allyn and Bacon.

Tessier, D., Sarrazin, P., \& Ntoumanis, N. (2010). The effect of an intervention to improve newly qualified teachers' interpersonal style, students' motivation and psychological need satisfaction in sport-based physical education. Contemporary Educational Psychology, 35(4), 242-253.

Tucker, C. M., Zayco, R. A., Herman, K. C., Reinke, W. M., Trujillo, M., Carraway, K., ... \& Ivery, P. D. (2002). Teacher and child variables as predictors of academic engagement among low-income African American children. Psychology in the Schools, 39(4), 477-488.

Ullah, H., \& Wilson, M. A. (2007). Students' academic success and its association to student involvement with learning and relationships with faculty and peers. College Student Journal, 41(4).

Wigfield, A., Eccles, J. S., Roeser, R. W., \& Schiefele, U. (2006). Development of academic motivation. In child and adolescent development: An advanced course (pp. 406-434). John Wiley \& Sons.

Wong, M. G. (1980). Model students? Teachers' perceptions and expectations of their Asian and White students. Sociology of education, 236-246. 
Appendix A. Literature Review Article Tables

\begin{tabular}{|c|c|c|c|c|c|}
\hline Study & Measurement & Sample & IV & DV & Outcome \\
\hline $\begin{array}{l}\text { Skinner } \\
\text { and } \\
\text { Belmont } \\
(1993)\end{array}$ & $\begin{array}{l}\text { Students and teachers } \\
\text { completed } \\
\text { questionnaires at two } \\
\text { time-points (October \& } \\
\text { April) assessing student } \\
\text { engagement and } \\
\text { teacher support }\end{array}$ & $\begin{array}{l}\mathrm{N}=144 \\
3^{\text {rd }}-5^{\text {th }} \\
\text { grade }\end{array}$ & $\begin{array}{l}\text { Student } \\
\text { engagement }\end{array}$ & $\begin{array}{l}\text { Teacher } \\
\text { support } \\
\text { (involvement, } \\
\text { structure, and } \\
\text { autonomy) }\end{array}$ & $\begin{array}{l}\text { Highly engaged } \\
\text { students received } \\
\text { more support } \\
\text { from their } \\
\text { teachers from fall } \\
\text { to spring, while } \\
\text { highly disaffected } \\
\text { students lost } \\
\text { teacher support } \\
\text { over the school } \\
\text { year. }\end{array}$ \\
\hline $\begin{array}{l}\text { Baker } \\
(1999)\end{array}$ & $\begin{array}{l}\text { Systematic observations } \\
\text { coded for positive and } \\
\text { negative student- } \\
\text { teacher interactions; } \\
15 \text {-minute student } \\
\text { interviews "assessing } \\
\text { their satisfaction with } \\
\text { school and the stresses } \\
\text { and supports available } \\
\text { to them at school". } \\
\text { Student-report } \\
\text { measures of quality of } \\
\text { teacher-student } \\
\text { relationships }\end{array}$ & $\begin{array}{l}\mathrm{N}=61 \\
3^{\text {rd }}-5^{\text {th }} \\
\text { grade } \\
100 \% \text { of } \\
\text { students \& } \\
\text { teachers } \\
\text { were } \\
\text { African } \\
\text { American }\end{array}$ & $\begin{array}{l}\text { Satisfaction } \\
\text { vs. } \\
\text { dissatisfacti } \\
\text { on with } \\
\text { school }\end{array}$ & $\begin{array}{l}\text { Quality of } \\
\text { student- } \\
\text { teacher } \\
\text { interactions } \\
\text { (observations) } \\
\text {, Quality of } \\
\text { student- } \\
\text { teacher } \\
\text { relationship } \\
\text { (survey), \& } \\
\text { Students' } \\
\text { experiences at } \\
\text { school and } \\
\text { with teacher } \\
\text { (interview). }\end{array}$ & $\begin{array}{l}\text { Students who like } \\
\text { school receive } \\
\text { more teacher } \\
\text { support, have } \\
\text { better } \\
\text { relationships with } \\
\text { their teachers, and } \\
\text { overall have } \\
\text { different patterns } \\
\text { of behavioral } \\
\text { interactions with } \\
\text { theirs teacher than } \\
\text { do kids who don't } \\
\text { like school }\end{array}$ \\
\hline $\begin{array}{l}\text { Furrer, } \\
\text { C., } \\
\text { Skinner, } \\
\text { E., \& } \\
\text { Kinder- } \\
\text { mann, T. } \\
\text { (2009, } \\
\text { April). }\end{array}$ & $\begin{array}{l}\text { Students and teachers } \\
\text { completed } \\
\text { questionnaires at two } \\
\text { time-points (October \& } \\
\text { April) assessing student } \\
\text { engagement } \text { and } \\
\text { teacher motivational } \\
\text { support. }\end{array}$ & $\begin{array}{l}\mathrm{N}=805 \\
4^{\text {th }}-7^{\text {th }} \\
\text { grade }\end{array}$ & $\begin{array}{l}\text { Student } \\
\text { engagement } \\
\text { (behavioral } \\
\text { engagement, } \\
\text { emotional } \\
\text { engagement, } \\
\text { behavioral } \\
\text { disaffection, } \\
\text { and } \\
\text { emotional } \\
\text { disaffection) }\end{array}$ & $\begin{array}{l}\text { Teacher } \\
\text { motivational } \\
\text { support } \\
\text { (involvement } \\
\text { vs. neglect, } \\
\text { structure vs. } \\
\text { chaos and } \\
\text { autonomy } \\
\text { support vs. } \\
\text { coercion). }\end{array}$ & $\begin{array}{l}\text { Student } \\
\text { behavioral and } \\
\text { emotional } \\
\text { disaffection in } \\
\text { spring predicted } \\
\text { decreases in } \\
\text { teacher support in } \\
\text { fall for both } \\
\text { student and } \\
\text { teacher reports } \\
\text { while student } \\
\text { emotional and } \\
\text { behavioral } \\
\text { engagement in } \\
\text { spring was } \\
\text { associated with } \\
\text { increases in } \\
\text { teacher support in } \\
\text { fall, though only } \\
\text { for teacher reports } \\
\text { of student } \\
\text { engagement. }\end{array}$ \\
\hline
\end{tabular}


Appendix A. $\quad$ Literature Review Article Tables

\begin{tabular}{|c|c|c|c|c|c|}
\hline Study & Measurement & Sample & IV & DV & Outcome \\
\hline $\begin{array}{l}\text { Houts, Caspi, } \\
\text { Pianta, } \\
\text { Arseneault, } \\
\& \text { Moffitt } \\
(2010)\end{array}$ & $\begin{array}{l}\text { At age 5, } \\
\text { children's } \\
\text { challenging } \\
\text { behavior was } \\
\text { assessed by } \\
\text { mother reports, } \\
\text { teacher reports, } \\
\text { and observer } \\
\text { ratings. At age } \\
\text { 12, children's } \\
\text { teachers } \\
\text { completed } \\
\text { survey reports } \\
\text { of the amount } \\
\text { of effort } \\
\text { required to } \\
\text { instruct } \\
\text { individual } \\
\text { students. }\end{array}$ & $\begin{array}{l}\mathrm{N}=1,102 \\
\text { pairs of } \\
\text { twins }\end{array}$ & $\begin{array}{l}\text { Children's } \\
\text { challenging } \\
\text { behavior was } \\
\text { assessed by } \\
\text { a). mother and } \\
\text { teacher reports } \\
\text { of } 18 \text { symptoms } \\
\text { of } \\
\text { hyperactivity- } \\
\text { impulsivity and } \\
\text { inattention and } \\
\text { b). observer } \\
\text { ratings of } \\
\text { children's } \\
\text { irritability/negat } \\
\text { ive affect and } \\
\text { impulsivity/dist } \\
\text { ractibility } \\
\text { during a home } \\
\text { visit. }\end{array}$ & $\begin{array}{l}\text { Teacher's effort } \\
\text { expenditure } \\
\text { (Ex. "How } \\
\text { frequently must } \\
\text { you give this } \\
\text { child extra } \\
\text { encouragement } \\
\text { to get him/her to } \\
\text { take part? How } \\
\text { frequently must } \\
\text { you act to curb } \\
\text { disruptive } \\
\text { behavior by this } \\
\text { child?"). }\end{array}$ & $\begin{array}{l}\text { Students' } \\
\text { challenging } \\
\text { behavior at } \\
\text { age } 5 \\
\text { predicted } \\
\text { required } \\
\text { teacher effort } \\
\text { for students at } \\
\text { age } 12 \text {. }\end{array}$ \\
\hline
\end{tabular}


Appendix A.

Literature Review Article Tables

\begin{tabular}{|c|c|c|c|c|c|}
\hline Study & Measurement & Sample & IV & $\mathrm{DV}$ & Outcome \\
\hline $\begin{array}{c}\text { New- } \\
\text { berry \& } \\
\text { Davis } \\
(2008)\end{array}$ & $\begin{array}{l}\text { Qualitative: } \\
\text { Researchers } \\
\text { coded the } \\
\text { transcripts of } \\
\text { in-depth, } \\
\text { structured } \\
\text { interviews } \\
\text { with } 3 \\
\text { teachers to 1). } \\
\text { Rate their } \\
\text { feelings of } \\
\text { closeness to } \\
\text { each of their } \\
\text { students 2). } \\
\text { Describe each } \\
\text { teacher- } \\
\text { student } \\
\text { relationships } \\
\text { 3). Indentify } \\
\text { patterns of } \\
\text { interpersonal } \\
\text { closeness and } \\
\text { distance 4). } \\
\text { Talk about } \\
\text { their } \\
\text { understanding } \\
\text { of what it } \\
\text { means to be } \\
\text { close to } \\
\text { students. }\end{array}$ & $\begin{array}{l}\mathrm{N}=3 \\
\text { Elementary } \\
\text { school } \\
\text { teachers }\end{array}$ & $\begin{array}{l}\text { The grounded } \\
\text { model } \\
\text { specified } 3 \\
\text { student } \\
\text { factors } \\
\text { (personality, } \\
\text { challenges, } \\
\text { push for } \\
\text { relationships) }\end{array}$ & $\begin{array}{l}\text { The } 3 \text { student } \\
\text { factors were } \\
\text { related to } 5 \\
\text { different } \\
\text { teacher } \\
\text { interaction- } \\
\text { approach } \\
\text { orientations } \\
\text { towards } \\
\text { students } \\
\text { (from most } \\
\text { emotionally } \\
\text { open } \\
\text { orientation to } \\
\text { most } \\
\text { emotionally } \\
\text { closed } \\
\text { orientation; } \\
\text { feeling } \\
\text { affinity, being } \\
\text { reflective, } \\
\text { implementing } \\
\text { strategies, } \\
\text { treating } \\
\text { casually, and } \\
\text { acting } \\
\text { professional) }\end{array}$ & $\begin{array}{l}\text { Students who are } \\
\text { friendly and } \\
\text { bright, pose few } \\
\text { challenges, and } \\
\text { actively seek a } \\
\text { close relationship } \\
\text { with their } \\
\text { teachers' have } \\
\text { higher quality } \\
\text { relationships with } \\
\text { their teachers and } \\
\text { received more } \\
\text { emotionally } \\
\text { supportive } \\
\text { interaction- } \\
\text { approaches from } \\
\text { their teachers. } \\
\text { Conversely } \\
\text { students who are } \\
\text { more difficult to } \\
\text { get along with, } \\
\text { pose many } \\
\text { challenges to } \\
\text { teachers, and are } \\
\text { either } \\
\text { uninterested in } \\
\text { having a close } \\
\text { relationship or } \\
\text { require a great } \\
\text { amount of } \\
\text { teacher effort to } \\
\text { interact with, } \\
\text { appear to make } \\
\text { teachers feel } \\
\text { vulnerable and } \\
\text { subsequently are } \\
\text { more likely to be } \\
\text { marginalized by } \\
\text { their teacher } \\
\text { relationship. }\end{array}$ \\
\hline
\end{tabular}


Appendix A. Literature Review Article Tables

\begin{tabular}{|c|c|c|c|c|c|}
\hline Study & Measurement & Sample & IV & DV & Outcome \\
\hline $\begin{array}{l}\text { Ladd, } \\
\text { Birch, \& } \\
\text { Buhs } \\
(1999)\end{array}$ & $\begin{array}{l}\text { Observed students } \\
\text { classroom } \\
\text { behavior several } \\
\text { times per week } \\
\text { over } 10 \text { weeks } \\
\text { using point-time } \\
\text { and scan sampling } \\
\text { techniques on } \\
\text { students' } \\
\text { classroom } \\
\text { behaviors. } \\
\text { Observed } \\
\text { emotional tone of } \\
\text { teacher-child } \\
\text { interactions on 1- } \\
5 \text { scales, averaged } \\
\text { to create overall } \\
\text { emotion tone } \\
\text { score. }\end{array}$ & $\begin{array}{l}\text { Study } 1 \\
\mathrm{~N}=200 ; \\
\text { Kinder- } \\
\text { garteners } \\
\mathrm{N}=16 ; \\
\text { teachers } \\
\text { Study } 2 \\
\mathrm{~N}=199 ; \\
\text { Kinder- } \\
\text { garteners } \\
\mathrm{N}=17 \\
\text { teachers }\end{array}$ & $\begin{array}{l}\text { Prosocial } \\
\text { behavioral } \\
\text { styles vs. } \\
\text { Antisocial } \\
\text { behavioral } \\
\text { styles }\end{array}$ & $\begin{array}{l}\text { Teacher-child } \\
\text { relationship } \\
\text { quality, } \\
\text { teacher-child } \\
\text { conflict, and } \\
\text { teacher-child } \\
\text { closeness }\end{array}$ & $\begin{array}{l}\text { Study 1: } \\
\text { a) Antisocial } \\
\text { behavioral styles } \\
\text { were negatively } \\
\text { related to teacher- } \\
\text { child relationship } \\
\text { quality. } \\
\text { Study 2: } \\
\text { b) Antisocial } \\
\text { behavioral styles } \\
\text { were negatively } \\
\text { related to teacher- } \\
\text { child closeness and } \\
\text { significantly } \\
\text { predicted teacher- } \\
\text { child conflict. }\end{array}$ \\
\hline $\begin{array}{l}\text { Pelletier, } \\
\text { Seguin- } \\
\text { Levesque } \\
\& \\
\text { Legaull, } \\
(2002)\end{array}$ & $\begin{array}{l}\text { Participation in } \\
\text { the study involved } \\
\text { completing a } \\
\text { questionnaire } \\
\text { package at home } \\
\text { and returning it a } \\
\text { week later to the } \\
\text { school secretary. }\end{array}$ & $\begin{array}{l}\mathrm{N}=254 \\
\text { teachers } \\
\text { (89 men } \\
\text { and } 165 \\
\text { women) }\end{array}$ & $\begin{array}{l}\text { Teachers' } \\
\text { perceptions of } \\
\text { students' level } \\
\text { of motivation } \\
\text { toward school } \\
\text { ( } 4 \\
\text { subdimensions: } \\
\text { intrinsic } \\
\text { motivation, } \\
\text { extrinsic } \\
\text { motivation by } \\
\text { identified } \\
\text { regulation, } \\
\text { extrinsic } \\
\text { motivation by } \\
\text { introjected } \\
\text { regulation and } \\
\text { extrinsic } \\
\text { motivation by } \\
\text { external } \\
\text { regulation). }\end{array}$ & $\begin{array}{l}\text { Teacher's } \\
\text { autonomy } \\
\text { support vs } \\
\text { control } \\
\text { orientation. } \\
\text { (Scale is } \\
\text { composed of } \\
\text { eight } \\
\text { vignettes, } \\
\text { describing } \\
\text { typical } \\
\text { problems that } \\
\text { occur in } \\
\text { schools, and } \\
\text { teachers }\end{array}$ & $\begin{array}{l}\text { The more teachers } \\
\text { believed that their } \\
\text { students were being } \\
\text { self-determined } \\
\text { toward school, the } \\
\text { more teachers were } \\
\text { self-determined } \\
\text { toward their work. } \\
\text { The more teachers' } \\
\text { were self- } \\
\text { determined toward } \\
\text { their work, the more } \\
\text { they indicated being } \\
\text { autonomy } \\
\text { supportive. }\end{array}$ \\
\hline
\end{tabular}


Appendix A.

Literature Review Article Tables

\begin{tabular}{|c|c|c|c|c|c|}
\hline Study & Measurement & Sample & IV & $\mathrm{DV}$ & Outcome \\
\hline $\begin{array}{l}\text { Brunk \& } \\
\text { Henggeler } \\
(1984)\end{array}$ & $\begin{array}{l}\text { Experiment: Child } \\
\text { confederates displayed } \\
\text { either anxious- } \\
\text { withdrawn or conduct- } \\
\text { disorder behavior } \\
\text { towards } 32 \text { mothers in } \\
\text { order to determine } \\
\text { whether different child } \\
\text { behaviors elicited } \\
\text { differential use of } 7 \\
\text { main parent behaviors, } \\
\text { Discipline, Command, } \\
\text { Ignore, Indirect } \\
\text { Command, Reward, } \\
\text { Helping, Question. }\end{array}$ & 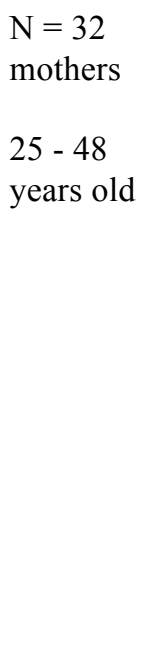 & $\begin{array}{l}\text { conduct- } \\
\text { disorder } \\
\text { condition } \\
\text { vs. } \\
\text { withdrawn } \\
\text {-anxious } \\
\text { condition }\end{array}$ & $\begin{array}{l}\text { Positive parental } \\
\text { behaviors } \\
\text { (reward/praise, } \\
\text { helping/providing } \\
\text { information, } \\
\text { indirect question/ } \\
\text { suggestion that } \\
\text { leaves option } \\
\text { open for child and } \\
\text { questions) } \\
\text { Vs. } \\
\text { Negative parental } \\
\text { behaviors } \\
\text { (discipline/punish } \\
\text { ment, command, } \\
\text { ignoring) }\end{array}$ & $\begin{array}{l}\text { Different } \\
\text { experimentally } \\
\text { manipulated child } \\
\text { behavior } \\
\text { conditions } \\
\text { (conduct disorder } \\
\text { vs. withdrawn) } \\
\text { elicited } \\
\text { differential } \\
\text { provision of } \\
\text { parental support. }\end{array}$ \\
\hline $\begin{array}{l}\text { Jelsma } \\
(1982)\end{array}$ & $\begin{array}{l}\text { Experiment: Mothers } \\
\text { were assigned to teach } \\
\text { child confederates } \\
\text { anagrams in a lab } \\
\text { setting for } 10 \text { minutes. } \\
\text { Children confederates } \\
\text { were trained to act } \\
\text { either highly } \\
\text { active/less responsive } \\
\text { or less active/more } \\
\text { responsive. Mother's } \\
\text { responses were } \\
\text { assessed. }\end{array}$ & 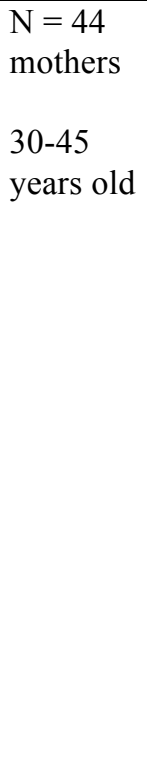 & $\begin{array}{l}\text { "difficult" } \\
\text { vs. "easy" } \\
\text { child- } \\
\text { confederat } \\
\text { e behavior }\end{array}$ & $\begin{array}{l}\text { Frequency and } \\
\text { quality of adult } \\
\text { responses.... } \\
\text { Quantitative } \\
\text { coding: based on } \\
3 \text { categories } \\
\text { 'controlling } \\
\text { statements', } \\
\text { 'informational } \\
\text { statements' } \\
\text { positive feedback' } \\
\text { Qualitative } \\
\text { coding: } 6 \\
\text { dimensions rated } \\
\text { on a } 7 \text { points scale } \\
\text { assessed affect. }\end{array}$ & $\begin{array}{l}\text { Children's } \\
\text { activity/responsiv } \\
\text { eness affected } \\
\text { adults' verbal } \\
\text { behavior, the } \\
\text { quality of adult- } \\
\text { child interactions, } \\
\text { and the adults' } \\
\text { orientation } \\
\text { towards control. } \\
\text { The mothers were } \\
\text { more controlling, } \\
\text { less supportive, } \\
\text { and enjoyed the } \\
\text { children less } \\
\text { when the children } \\
\text { were highly } \\
\text { active/less } \\
\text { responsive. }\end{array}$ \\
\hline $\begin{array}{l}\text { Anderson, } \\
\text { Lytton, \& } \\
\text { Romney } \\
(1986)\end{array}$ & $\begin{array}{l}\text { Mothers were } \\
\text { observed for three } 15 \\
\text { minute sessions with } \\
\text { a). their own child } b \text { ). } \\
\text { a child of the opposite } \\
\text { classification (CD vs. } \\
\text { normal) of their own, } \\
c \text { ). and a child of the } \\
\text { same classification of } \\
\text { their own to observe } \\
\text { the quality of mother's } \\
\text { interactions with CD } \\
\text { and 'normal boys'. }\end{array}$ & $\begin{array}{l}\mathrm{N}=32 \\
\text { mother- } \\
\text { child } \\
\text { dyads } \\
\text { (16 boys } \\
\text { with } \\
\text { conduct } \\
\text { disorders } \\
, 16 \\
\text { without })\end{array}$ & $\begin{array}{l}\text { Conduct } \\
\text { disordered } \\
\text { child vs. } \\
\text { 'normal' } \\
\text { child. }\end{array}$ & $\begin{array}{l}\text { Frequency of } \\
\text { mothers' positive, } \\
\text { negative, or } \\
\text { requesting } \\
\text { behaviors and the } \\
\text { child's } \\
\text { compliance with } \\
\text { mothers' requests. }\end{array}$ & $\begin{array}{l}\text { Mothers of both } \\
\text { groups made } \\
\text { significantly } \\
\text { more negative } \\
\text { responses to and } \\
\text { asked } \\
\text { significantly } \\
\text { more requests of, } \\
\text { and were more } \\
\text { coercive with the } \\
\text { CD boys than the } \\
\text { 'normal boys'. }\end{array}$ \\
\hline
\end{tabular}


Appendix A.

Literature Review Article Tables

\begin{tabular}{|c|c|c|c|c|c|}
\hline Study & Measurement & Sample & IV & DV & Outcome \\
\hline $\begin{array}{l}\text { Pelletier \& } \\
\text { Vallerand, } \\
\text { 1996) }\end{array}$ & $\begin{array}{l}\text { In lab, participant } \\
\text { was told that he } \\
\text { would serve as a } \\
\text { supervisor and that } \\
\text { he would be } \\
\text { teaching a } \\
\text { subordinate how to } \\
\text { solve a spatial } \\
\text { relations puzzle for } \\
\text { a period of } 20 \text { min. } \\
\text { Subordinates and } \\
\text { supervisors (survey } \\
\text { measures after } \\
\text { teaching exercise) } \\
\text { and judges } \\
\text { (watching from one- } \\
\text { way mirror) ratings } \\
\text { of the autonomy } \\
\text { supportiveness of } \\
\text { the supervisor's } \\
\text { behavior. }\end{array}$ & $\begin{array}{l}\text { 30 male } \\
\text { graduate } \\
\text { students } \\
\text { participated as } \\
\text { supervisors } \\
\sim 30 \text { male high } \\
\text { school } \\
\text { students } \\
\text { participated as } \\
\text { subordinates }\end{array}$ & $\begin{array}{l}\text { Subordinate } \\
\text { labeled as } \\
\text { intrinsically } \\
\text { vs. } \\
\text { extrinsically } \\
\text { motivated }\end{array}$ & $\begin{array}{l}\text { Superviso } \\
\text { rs' level } \\
\text { of } \\
\text { autonomy } \\
\text { supportive } \\
\text { vs } \\
\text { controllin } \\
\text { g } \\
\text { behaviors } \\
\text { towards } \\
\text { subordinat } \\
\text { es during } \\
\text { lesson. }\end{array}$ & $\begin{array}{l}\text { Supervisors } \\
\text { who had been } \\
\text { led to believe } \\
\text { that they were } \\
\text { interacting with } \\
\text { an intrinsically } \\
\text { motivated } \\
\text { subordinate } \\
\text { perceived } \\
\text { themselves, and } \\
\text { were perceived } \\
\text { by the } \\
\text { subordinates } \\
\text { AND the } \\
\text { judges, as } \\
\text { supporting } \\
\text { autonomy much } \\
\text { more than the } \\
\text { supervisors who } \\
\text { had been led to } \\
\text { believe that } \\
\text { they were } \\
\text { interacting with } \\
\text { an extrinsically } \\
\text { motivated. }\end{array}$ \\
\hline
\end{tabular}


Appendix B.

\section{Student Engagement (Student-Report):}

Behavioral Engagement:

- I try hard to do well in school.

- If I do badly on my homework, I will work harder next time.

\section{Emotional Engagement:}

- I look forward to coming to school.

- I enjoy learning new things in school.

- If something bad happens in school, I don't let it get me down.

\section{Student Disaffection (Student-Report):}

Behavioral Disaffection:

- In school, I don't work very hard.

- When a class is too much work, I just don't do it.

- When I get behind in my homework, I just give up.

\section{Emotional Disaffection:}

- I can't stand doing schoolwork.

- I really don't care about school.

- When we work on something in class, I feel bored.

- I don't care about getting good grades.

\section{Student Engagement (Teacher-Report):}

Behavioral Engagement:

- In science, this student works hard.

- In science, this student actively participates.

- In general, this student puts in a lot of effort.

- When faced with setbacks, this student bounces back.

- When faced with a setback, this student works harder.

Emotional Engagement:

- In science, this student seems interested.

- In general, this student likes school.

\section{Student Disaffection (Teacher-Report):}

Behavioral Disaffection:

- In my class, this student refuses to do anything.

- In my class, this student can be disruptive.

- In general, this student acts like school doesn't matter. 
Emotional Disaffection:

- In my class, this student does not really care.

- When faced with setbacks, this student gives up.

\section{Teacher Motivational Support (Student-Report):}

Warmth:

- My teachers really care about me.

- My teachers just don't understand me (-).

- I can't really count on my teachers (-).

Structure:

- People here know I can do good work.

- People here are always telling me what to do (-).

Autonomy support:

- My teachers explain why the things I learn I school are important.

- The rules at this school are so unfair (-). 